\title{
ROSÂNGELA FELIPE RODRIGUES
}

Caracterização morfológica da subplacenta em cutia (Dasyprocta leporina) 


\section{ROSÂNGELA FELIPE RODRIGUES}

\section{Caracterização morfológica da subplacenta em cutia (Dasyprocta leporina)} Tese apresentada ao Programa de Pós-
Graduação em Anatomia dos Animais
Domésticos e Silvestres da Faculdade de
Medicina Veterinária e Zootecnia da
Universidade de São Paulo para a obtenção do
título de Doutor em Ciências

Departamento:

Cirurgia

Área de concentração:

Anatomia dos Animais Domésticos e Silvestres

Orientador:

Profa. Dra. Maria Angelica Miglino 
Autorizo a reprodução parcial ou total desta obra, para fins acadêmicos, desde que citada a fonte.

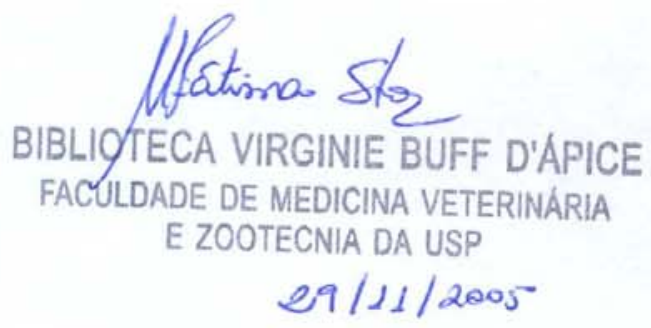

DADOS INTERNACIONAIS DE CATALOGAÇÃO-NA-PUBLICACุÃO

(Biblioteca da Faculdade de Medicina Veterinária e Zootecnia da Universidade de Sào Paulo)

T.1613

FMVZ
Rodrigues, Rosângela Felipe

Caracterização morfológica dả subplacenta em cutia (Dasyprocta leporina) / Rosângela Felipe Rodrigues. - São Paulo : R. F. Rodrigues. 2005.

$93 \mathrm{f}$. : il.

Tese (doutorado) - Universidade de São Paulo. Faculdade de Medicina Veterinária e Zootecnia. Departamento de Cirurgia, 2005.

Programa de Pós-graduação: Anatomia dos Animais Domésticos e Silvestres.

Área de concentração: Anatomia dos Animais Domésticos e Silvestres.

Orientador: Profa. Dra. Maria Angélica Miglino.

1. Dasyprocta leporina. 2. Subplacenta. 4. Morfologia. 5. Microvascularização. I. Titulo. 


\section{FOLHA DE AVALIAÇÃO}

Nome: RODRIGUES, Rosângela Felipe

Título: Caracterização morfológica da subplacenta em cutia (Dasyprocta leporina)

Tese apresentada ao Programa de Pós-Graduação em Anatomia dos Animais Domésticos e Silvestres da Faculdade de Medicina Veterinária e Zootecnia da Universidade de São Paulo para a obtenção do título de Doutor em Ciências

Data:

\section{Banca Examinadora}

$\operatorname{Prof}(a) \cdot \operatorname{Dr}(a)$ Instituição:

Assinatura: Julgamento:

Prof(a). Dr(a). Instituição:

Assinatura: Julgamento:

$\operatorname{Prof}(a) . \operatorname{Dr}(a)$. Instituição:

Assinatura: Julgamento:

$\operatorname{Prof}(a) . \operatorname{Dr}(a)$. Instituição:

Assinatura: Julgamento:

$\operatorname{Prof}(a) \cdot \operatorname{Dr}(a)$.

Assinatura:
Instituição: Julgamento: 
A candeia do corpo são os olhos; se os teus othos forem bons, todo o teu corpo terá luz. Se, porém, teus olhos forem maus, o teu corpo permanecerá em trevas. $S e$, portanto, a luz que há em ti são trevas, que grandes trevas serão! 


\section{DEDICATÓRIA}

A Deus, que me deu a vida, essência e liberdade.

O amor é a força mais abstrata, e também a mais potente, que há no mundo.

Gandhi

Às minhas filhas Eduarda e Beatriz, que amo e esteve presente em todos os momentos, para a confecção desta pesquisa.

Ao meu esposo, Alan que sempre acreditou em mim.

"Na vida há coisas simples e importantes... Simples como eu e importantes como você!" Te amo.

Aos meus pais Clarice Elisabete e Geraldo, às minhas irmãs Renata e Rosana, ao meu cunhado Leandro que acreditaram, incentivaram e me ajudaram para que este sonho se realizasse.

"Amo vocês". 


\section{AGRADECIMENTOS ESPECIAIS}

\section{Maria Angelica Miglino}

Rendo-me à dedicação, seriedade e aos ensinamentos desse ser que guiou meus passos, mostrando o caminho do conhecimento e da sabedoria para que eu conseguisse chegar ao mais alto pódio, sonhado por muitos e atingido por poucos.

Hoje dedico a minha conquista a sua eficiência e perseverança para que eu pudesse realizar este sonho...

Obrigada.

Aos eternos amigos

Wilson Machado de Souza e Nair Trevizan Machado de Souza, Rose Eli Azarias e família, Lina Moreira e família, Rosa Helena dos Santos Ferraz

O amor que há numa grande amizade é como a luz do dia, clareia o pensamento, anima o coração e enche a vida de alegria.

O valor que há numa grande amizade, é tão caloroso e brilhante como o sol de verão, a cada dia e a cada instante.

O grande amor que há numa grande amizade significa mais do que as palavras podem dizer porque uma grande amizade é um milagre que abençoa os dias que temos pra viver Um dos milagres da minha vida é simplesmente ter conhecido vocês! 


\section{AGRADECIMENTOS}

A CAPES - Coordenação de Aperfeiçoamento de Pessoal de Nível Superior, pelo auxílio financeiro para a realização deste projeto.

Ao Departamento de Anatomia, área de Anatomia dos Animais Domésticos e Silvestres da Faculdade de Medicina Veterinária e Zootecnia da Universidade de São Paulo - FMVZ-USP.

Aos professores do Departamento de Anatomia, área de Anatomia dos Animais Domésticos e Silvestres da Faculdade de Medicina Veterinária e Zootecnia - USP: Prof. Dr. Antônio Augusto Coppi Maciel Ribeiro, Profa. Dra. Arani Nanci Bonfim Mariana, Prof. Dr. Francisco Javier Hernandez Blazquez, Profa. Dra. Irvênia Luiza de Santis Prada, Prof. Dr. Ii-Sei Watanabe, Prof. Dr. José Roberto Kfoury Júnior, Prof. Dr. Marcos Antonio Orsi, Profa. Dra. Paula Papa e Prof. Dr. Pedro Primo Bombonato.

Aos amigos pós-graduandos do Curso de Anatomia dos Animais Domésticos e Silvestres da Faculdade de Medicina Veterinária e Zootecnia - USP.

Prof. Dr. Áureo Tatsumi Yamada, Departamento de histologia e embriologia do Instituto de Biologia - Unicamp, o meu muito obrigada por sua orientação.

"Se vi mais longe, foi porque me apoiei nos ombros de gigantes" Newton.

Marina Bonatelli obrigada pela ajuda e paciência.

"As pessoas entram em nossas vidas por acaso, mas não é por acaso que elas permanecem."

Aos amigos Moacir F. Oliveira e Tatiana Carlesso dos Santos pelos bons momentos juntos. 
Ao Prof. Dr. Gilson Helio Toniollo por nos auxiliar nas cirurgias aplicando sua experiência, Obrigada.

Aos técnicos: Ronaldo, Edinaldo (Índio), Diogo, Wanderley e à secretária Jaqueline e ao secretário Maicon, do Departamento de Anatomia, área de Anatomia dos Animais Domésticos e Silvestres da FMVZ-USP, pela amizade, carinho e companheirismo.

Agradeço aos médicos veterinários e funcionários do Hospital Veterinário "Dr. Halim Atique", do Curso de Medicina Veterinária do Centro Universitário de Rio Preto - São José do Rio Preto - SP, na figura de seu Diretor Prof.M.Sc. Halim Atique Netto. 


\section{RESUMO}

RODRIGUES, R.F. Caracterização morfológica da subplacenta em cutia (Dasyprocta leporina). [Morphologic characterization of the subplacenta in agouti (Dasyprocta laporina)]. 2005. 93f. Tese (Doutorado em Ciências) Faculdade de Medicina Veterinária e Zootecnia, Universidade de São Paulo, São Paulo, 2005.

A cutia Dasyprocta leporina é um roedor pertencente à sub-ordem histricomorfa, e é encontrada em todo território nacional. Os roedores da sub-ordem histricomorfa apresentam uma placenta dotada de uma estrutura peculiar, a subplacenta. Nesta pesquisa estudou-se em 9 (nove) placentas de cutias, nas três fases de gestação (inicial, média e final). Este estudo consistiu da análise morfológica placentária, pelas microscopias de luz e eletrônica, em conjunto com as técnicas de citoquímica, imunohistoquímica, e microvascularização. A subplacenta da cutia encontra-se localizada no ápice da placenta corioalantoidiana, separada desta por um tecido mesenquimal. Insere-se na parede uterina em íntimo contato com o tecido materno. Histologicamente a subplacenta consistiu de estruturas lamelares, cujos eixos são formados por tecido mesenquimal fetal. Sobre estes apoiam-se arranjos epiteliais de cito e sinciciotrofoblasto. $\mathrm{Na}$ região de interface da subplacenta e da decídua, foram encontradas populações de células trofoblásticas gigantes multinucleadas, citoqueratina positivas. A vimentina apresentou intensa reação positiva junto ao revestimento endotelial dos vasos do tipo arterial, e no interior do tecido mesenquimal do eixo central das lamelas da subplacenta. A reação de PCNA apresentou reatividade positiva no citotrofoblasto das lamelas da subplacenta, e em algumas células do sincício, principalmente no terço médio de gestação. A análise ultra-estrutural da subplacenta mostrou duas populações de células trofoblásticas distintas na parede das lamelas: o cito e o sinciciotrofoblasto. A vascularização da subplacenta analisada pela perfusão de látex colorido, e por Mercox, ao microscópio eletrônico de varredura, demonstrou a ausência de vasos de origem materna, e irrigação oriunda da artéria fetal. Esta após capilarização dirigia-se para os lóbulos da placenta principal, cuja disposição lembrava uma circulação do tipo portal.

Palavras-chave: Dasyprocta leporina. Subplacenta. Placenta. Morfologia. Microvascularização. 


\section{ABSTRACT}

RODRIGUES, R.F. Morphologic characterization of the subplacenta in agouti (Dasyprocta leporina). [Caracterização morfológica da subplacenta em cutia (Dasyprocta leporina)]. 2005. 93 f. Tese (Doutorado em Ciências) Faculdade de Medicina Veterinária e Zootecnia, Universidade de São Paulo, São Paulo, 2005.

The agouti Dasyprocta leporina is a rodent belongs to the suborder hystricomorph, and may be found in all national territory. The hystricomorph has one specific structure on the placenta, the subplacenta. In this research 9 (nine) placentae of agouti were studied, in three different gestation age (early, middle and late). The study consisted of placental morphologic analysis by light and electron microscopy, associated with cytochemical, immunohystochemistry and microvascularization techniques. The subplacenta of agouti is localized on the apical part of the chorioallantoic placenta, separated by a mesenchyme and inserted on the uterus wall. Histologically the subplacenta consisted of lamear structures where the axis was formed by mesenchyme. On this structure the epithelial formation of the cytotrophoblast and syncytiotrophoblast was found. In the region between suplacenta and decidua the multinucleate giant trophoblast cells were observed, cytokeratin immunostaining. The endothelial cells on the arterial vessels showed intense positive reaction to vimentin and also the mesenchyme from axis of the lamelae. The cytotrophoblast on the lamelae and some cells of the syncytiotrophoblast showed PCNA positive reaction, principally in middle part of gestation. The ultra-structure analysis of the subplacenta showed two cells populations on the lamelae: the cytotrophoblast and syncytiotrophoblast. The vascularization analyzed by scanning electron microscopy of the Mercox $^{\circledR}$ and by colored latex perfusion demonstrated only fetal vessels on the subplacenta originated from fetal artery. The fetal artery, after branched in a net of capillaries, run to lobules of the principal placental, and this behavior suggest a type of portal circulation.

Key words: Dasyprocta leporina. Subplacenta. Microvascularization. Morfology. Placenta 


\section{Lista das Figuras}

Figura 1 - Aspectos macroscópicos da placenta de cutia (Dasyprocta leporina). A) Corno uterino gravídico (Ug) dilatado pela placenta e feto inserido na face mesometrial $(\mathrm{Rm})$. B) Útero aberto expondo a conexão entre o útero $(U)$ e a placenta principal (PI). C-D) Corte sagital mediano de placenta após fixação em formol no terço médio e esquema representativo. Notar as duas regiões: placenta principal (PI) e subplacenta (S) em íntimo contato com a decídua (d). Atravessando a placenta principal encontra-se um vaso $(\rightarrow)$ proveniente do funículo umbilical (FU).

Figura 2 - Fotomicrografia da subplacenta da cutia em início A) e terço médio de gestação B). Notar o íntimo contato da decídua (d) com a subplacenta (S) resultando em áreas com tecido amorfo $(*)$. As lamelas (LM) desenvolvemse e modificam seu arranjo. Entre a placenta principal, $(\mathrm{PI})$ e a subplacenta (S) observa-se à zona transicional (Zt). Parafina, H.E.

Figura 3 - Fotomicrografia da subplacenta da cutia (Dasyprocta leporina). A) Zona transicional (Zt), no terço médio de gestação, notar a presença de um tecido mesenquimal fetal que separa as duas regiões e que penetra entre as lamelas (LM) da subplacenta (S) e a distinta histoarquitetura entre a placenta ( $\mathrm{Pl})$ e a subplacenta (S). B) Detalhe da zona transicional ( $\mathrm{Zt}$ ), observar o tecido mesenquimal fetal evidenciando a presença de vaso ( $v$ ) entre a placenta e subplacenta. C) Região em que o tecido endometrial comprometido $(*)$ apresenta vasos sanguíneos (V) destituído de revestimento endotelial e substituídas por células trofoblásticas $(\Rightarrow)$. Parafina, H.E.

Figura 4 - Fotomicrografia da subplacenta da cutia (Dasyprocta leporina). A) Organização lamelar da subplacenta, com o eixo constituído de tecido conjuntivo mesenquimal (M) de origem fetal e pequenos vasos (V). Neste eixo apóia-se um arranjo epitelial de células citotrofoblásticas (Ct) que continua com o sinciciotrofoblasto (St). B) Detalhe de uma lamela com o seu eixo mesenquimal (M) e capilares (V). Os citotrofoblastos apóiam-se no tecido mesenquimal em arranjo epitelial contínuo e mais externamente os sinciciotrofoblastos. Parafina, H.E. C-D) Reação PAS positiva no sinciciotrofoblasto (St) e negativa para o citotrofoblasto (Ct), sem tratamento C) e com D) amilase, mostrando ligeiramente redução de intensidade. Parafina, PAS.

Figura 5 - A) Fotomicrografia das células trofoblásticas gigantes (G) na subplacenta da cutia (Dasyprocta leporina) próximo a vasos sangüíneos materno (V) e a interposição de uma camada de tecido endometrial amorfo $(*)$ entre as células gigantes. B) tecido amorfo $(*)$ que entremeiam as células trofoblásticas gigantes (G) localizadas no perímetro da subplacenta (S) apresenta reação positiva ao PAS mesmo após tratamento enzimático pela amilase. C) reação imunoperoxidase para citoqueratina, reação positiva presente nas células trofoblásticas gigantes (G). D) massa sincicial (St) que apresenta fraca reação positiva ao Alcian Blue e negativa para 0 citotrofoblasto. Parafina, A) H.E.; B) PAS; C) Citoqueratina. 
Figura 6 - Fotomicrografias das reações de imunoperoxidase para citoqueratina e vimentina na subplacenta no terço médio de gestação. A) Detalhe da reação positiva para citoqueratina presente no citotrofoblasto (Ct) e no sincício trofoblasto (St). B) No mesênquima fetal (M) a reação é negativa para citoqueratina enquanto no citotrofoblasto (Ct) e no sincício trofoblasto (St) a reação é positiva. C) $\mathrm{Na}$ parede dos vasos sanguíneos maternos (V), encontrados no endométrio próximo a região da subplacenta, a reação é negativa para vimentina. Observar a reação positiva nos vasos presentes no mesênquima das lamelas da subplacenta. D) Notar a reação positiva para vimentina nos vasos fetais (Vf) encontrados no interior das lamelas da subplacenta.

Figura 7 - Fotomicrografia da subplacenta de cutia, no terço final de gestação, observar a reação positiva nos núcleos das células do citotrofoblasto (Ct) das lamelas da subplacenta. Notar a marcação positiva ao PCNA de algumas células dos sincícios (St).

Figura 8 - A) Lamela (LM) constituída por um eixo de tecido mesenquimal fetal (M) com a presença de vasos (V). Nele apóia-se o citotrofoblasto (Ct) e mais externamente o sinciciotrofoblasto (St). Corte semi-fino. Azul de Toluidina. Eletromicrografias, B) Observar 0 aspecto do tecido conjuntivo mesenquimal (M) encontrado no eixo de uma lamela e camadas de células citotrofoblásticas (Ct) alinhadas em arranjo epitelial. Notar a presença dos espaços intersticiais formados entre os prolongamentos citoplasmáticos formados entre as células trofoblásticas que aparentemente não apresentam qualquer conteúdo. C) As células citotrofoblásticas (Ct) unem-se com as sinciciais (St) através das junções celulares $(\rightarrow)$ e os espaços bem nítidos (*). O citotrofoblasto $(\mathrm{Ct})$ apresenta poucas mitocôndrias $(\mathrm{m})$ e retículo endoplasmático rugoso (re) incompleto, além de apresentar um único núcleo. D) Espaços dilatados formam-se entre as células do citotrofoblasto (Ct) através de seus prolongamentos citoplasmáticos. O sinciciotrofoblasto (St) pode ser distinguido do citotrofoblasto $(\mathrm{Ct})$ pela presença de grande quantidade de microvilos na sua superfície e faz união com citotrofoblasto através de desmossomos $(\Rightarrow)$.

Figura 9 - Eletromicrografias da subplacenta de cutia. A) Lamelas no sinciciotrofoblasto (St), sem nenhum conteúdo, a presença dos múltiplos núcleos e ausência de limite do citoplasma nas células sincicias. B) As células sinciciais ( $\mathrm{St}$ ) encontradas centralmente nas lamelas da subplacenta apresentam múltiplos núcleos $(\mathrm{N})$, contendo nucléolo evidente, além de áreas de extração $(\triangle)$ do citoplasma ao lado de grandes lacunas (I). C) Observar em detalhe o citoplasma do sinciciotrofoblasto (St), retículo endoplasmático rugoso (re), pequenos grânulos eletrodensos, núcleo (N) irregular e microvilos na superfície.

Figura 10 - Eletromicrografias da subplacenta de cutia. A-B) células trofoblásticas gigantes apresentando áreas de extração citoplasmática $(\triangle)$ grânulos eletrodensos $(\mathrm{g})$ e margens livres das células com microvilos $(\rightarrow)$, reticulo endoplasmático rugoso ( $\mathrm{r}$ ) e núcleos $(\mathrm{N})$ 
Figura 11- Fotografias da placenta de cutia após injeção por látex (A-B) e Mercox (CD). A) As artérias maternas (am) estão em vermelho, as veias maternas (vm) em amarelo enquanto que a artéria fetal esta em branco, além de identificarmos a placenta $(\mathrm{PI})$ no útero gravídico $(\mathrm{Ug})$ e o útero não prenhe (U). B) Em corte sagital mediano notar a vascularização da subplacenta $(\mathrm{Sp})$, no terço médio de gestação, irrigada pelas as artérias fetais $(\Rightarrow)$, que estão em branco, enquanto que as artérias maternas (am), em vermelho, situam na região decidual. C) As veias maternas (vm) estão coradas em azul, e formam um anel em torno da subplacenta denominado "anel venoso". Observar que a subplacenta não é vascularizada pelos vasos maternos (vm) e sim pela artéria fetal, em vermelho. D) A artéria fetal (af), corada em vermelho, irriga toda a placenta principal (PI) inclusive a subplacenta (S), observado na figura anterior.

Figura 12- Eletromicrografias de varredura de molde vascular da placenta de cutia. A) Vista geral da rede vascular da subplacenta com a presença de vasos centrais (Vc) oriundos da placenta principal, que se ramificam. B) Observar a artéria fetal com a impressão negativa dos núcleos das células endoteliais delgadas e dispostas longitudinalmente $(\Rightarrow$ ) na subplacenta (S). C) Notar a rede vascular (V) que se forma a partir de um vaso central (Vc) que se ramifica e observar vasos que apresentam na sua superfície luminal estrangulamentos $(\vec{a})$. D) Detalhe dos vasos com seus trajetos tortuosos e de estrangulamentos $(\rightarrow$ ) em suas superfícies. 


\section{SUMÁRIO}

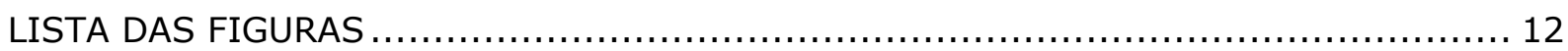

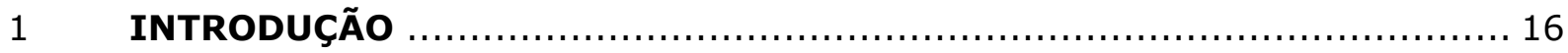

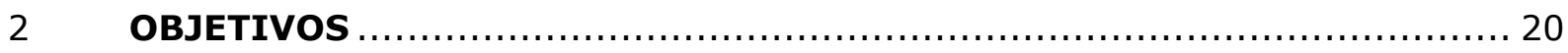

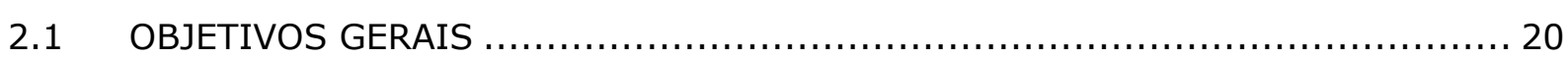

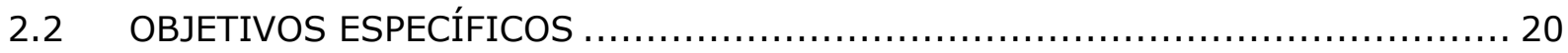

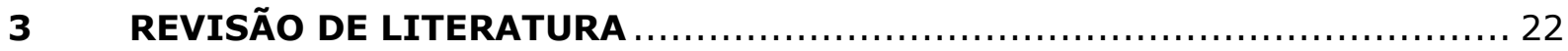

3.1 MORFOLOGIA DA SUBPLACENTA DOS ROEDORES HISTRICOMORFOS ............ 22

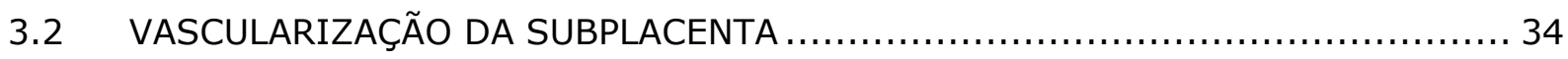

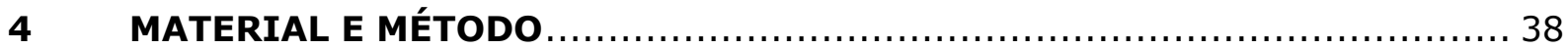

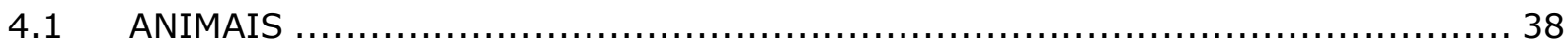

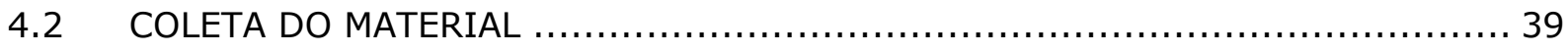

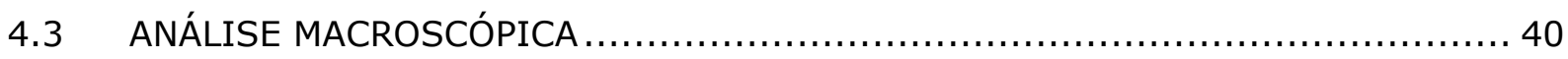

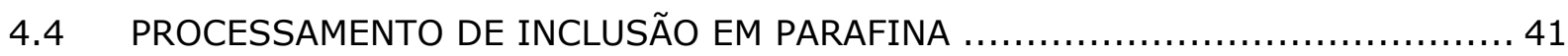

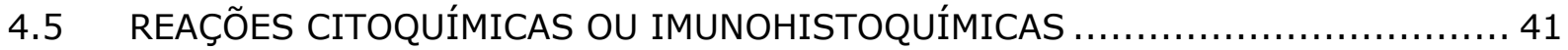

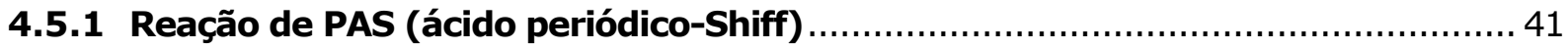

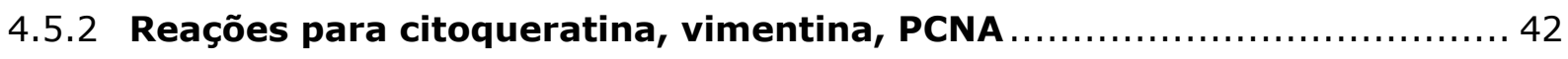

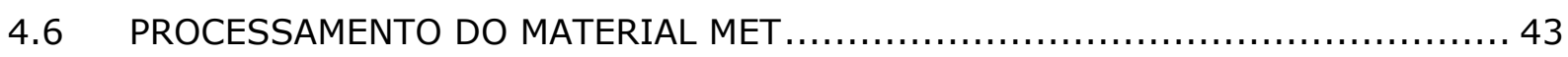

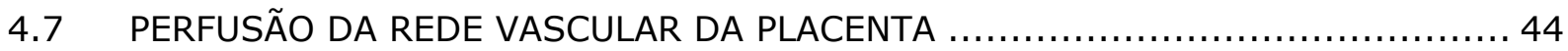

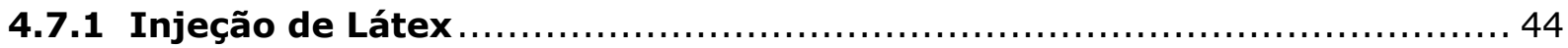

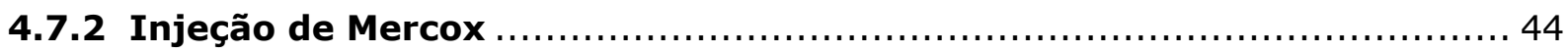

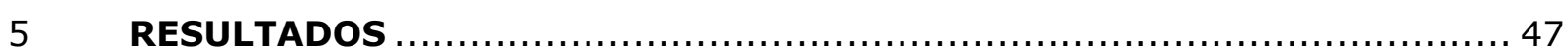

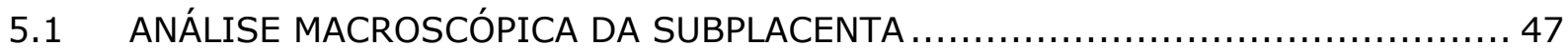

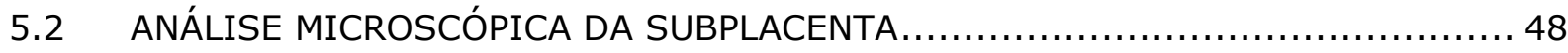

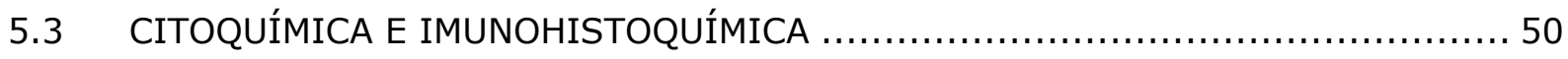

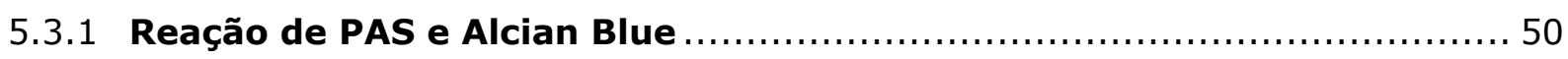

5.3.2 Reações para Citoqueratina, Vimentina e PCNA …............................................. 50

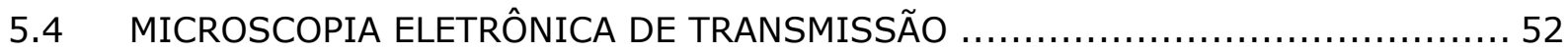

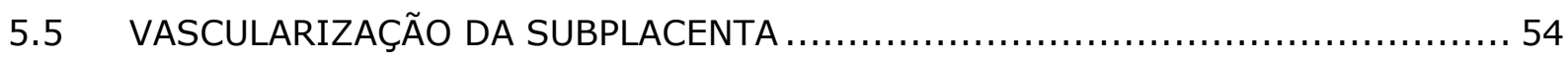

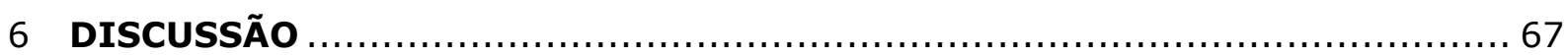

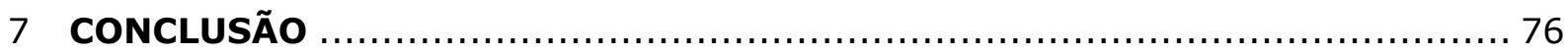

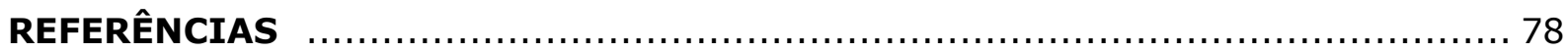

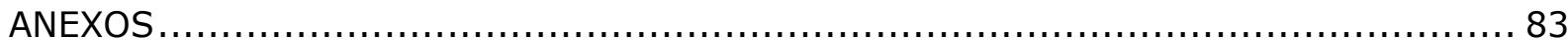




\section{INTRODUÇÃO}

A cutia é um roedor silvestre entrado no sul da América Central, e em todo o território da América do Sul, principalmente no Brasil. Roedor da família Dasyproctidae, na qual incluem-se onze espécies, a cutia é um mamífero distribuído praticamente em todo território nacional.

Particularmente a cutia vermelha (Dasyprocta leporina) habita os Estados do Norte, Nordeste e Sudeste. Nestas regiões, a população rural utiliza estes animais como fonte alternativa de proteína, principalmente na região Nordeste, local em que a espécie bovina sofre com as condições climáticas, ao contrário da cutia, que é resistente ao clima nessas regiões.

A população rural adquiriu o hábito de incluir na sua alimentação a carne destes roedores. Ao longo dos anos, este hábito evoluiu para uma prática indiscriminada e predatória, ameaçando a presença desse mamífero no habitat. A conscientização promovida por grupos ambientalistas, nas comunidades rurais permitiu a manutenção da espécie em seu ambiente natural. As ações resultantes de pesquisadores das áreas da biologia e da reprodução animal traduziram-se pela implantação de criatórios credenciados junto ao IBAMA (Instituto Brasileiro do Meio Ambiente e dos Recursos Naturais Renováveis), voltados para a preservação e a utilização da espécie como animal de produção, e como modelo experimental, para investigações.

A facilidade da reprodução em cativeiro contribuiu inegavelmente para que os estudos dos processos reprodutivos fossem desenvolvidos na cutia. Os trabalhos morfológicos descritos na espécie tratam do sistema reprodutor masculino e feminino. Assim nossos objetivos visam obter dados sobre a reprodução desses animais, estudando a morfologia da placenta e suas estruturas, particularizando a região da subplacenta, exclusiva dos roedores 
histricomorfos. Nesta sub-ordem estão representados animais como: a paca, a capivara, a chinchila, o mocó e a cobaia, entre outros.

O termo subplacenta foi utilizado pela primeira vez por Minot $^{1}$ (1889 apud DAVIES et al., 1961b, p. 457) referindo-se a placenta do coelho, e mais tarde foi aplicado à placenta da cobaia. Entretanto, foi Mossann (1937), quem identificou a placenta acessória ou subplacenta, definitivamente descrita em apenas dois animais, na cobaia e no porco-espinho, ambos membros do grupo de roedores histricomorfos. Perrotta (1959) demonstrou a presença da subplacenta em outros membros do grupo histricomorfa, ou seja, na nutria, chinchila, cutia e viscacha. Especialmente na cutia a placenta foi descrita como do tipo hemocorial, labiríntica e estruturada em lóbulos, apresenta duas regiões distintas: o centro e o labirinto, os quais encontram-se separados pelos interlóbulos placentários (RODRIGUES et al., 2003).

A vascularização da subplacenta ocorre exclusivamente por vasos fetais, segundo Tafani ${ }^{2}$ (1886, apud DAVIES et al., 1961b, p.457), Wislocki ${ }^{3}(1921$, apud DAVIES et al., 1961b, p.457), sendo que no terço médio de gestação a subplacenta é vascularizada principalmente por vasos fetais (MIGLINO et al., 2004). Um grande ramo da artéria umbilical segue a faixa central do mesênquima fetal na base da placenta principal, e, então, fornece ramos a subplacenta. Os vasos subplacentários seguem um curso tortuoso, com dilações e constrições, tais como aqueles encontrados em glândulas endócrinas, como os ovários. Alguns ramos das artérias maternas suprem a subplacenta, tais quais encontrados na capivara e paca, demonstrados por injeção de látex, Neoprene corado (MIGLINO et al., 2004).

\footnotetext{
${ }^{1}$ MINOT, C.S. Uterus and embryo. I. Rabbits. II Man. J. morph. 2:341-60, 1889.

${ }^{2}$ TAFANI, A. Sulle condizioni utero-placentari della vita fetale. Firenze, (1886).

${ }^{3}$ WISLOCKI, G.B. Futher experimental studies on fetal absorption. Contr. Embryol. Carnegie Instn., 13: 89-101, 1921.
} 
Com relação as possíveis funções da subplacenta, ressaltam-se os trabalhos sobre a atividade gonadotrófica da mesma, em outros roedores histricomorfos, como é o caso da chinchila e da cobaia, descritos por Davies et al. (1961b) e Kaufmann (1977), respectivamente.

Por tratar-se de animal comum na América do Sul, ideal para reproduzirse em cativeiro, pensou-se utilizar a cutia para este estudo, visando estabelecer neste momento sua estrutura macro, microscópica e ultra-estrutural, inferindo, se possível, sobre suas prováveis funções. 


\section{OBJETIVOS}

\subsection{OBJETIVOS GERAIS}

A presente pesquisa tem como objetivo descrever os aspectos morfológicos da subplacenta da cutia (Dasyprocta leporina).

\subsection{OBJETIVOS ESPECÍFICOS}

1- Analisar a organização histológica da subplacenta da cutia durante a gestação.

2- Descrever a ultra-estrutura da subplacenta e suas formas de associações entre os terços médio e final de gestação.

3- Identificar os componentes da interface da subplacenta por métodos citoquímico e imunocitoquímicos, nos terços médio e final de gestação.

4- Avaliar os componentes vasculares microvasculares da subplacenta.

5- Inferir sobre as possíveis funções subplacentárias. 


\section{REVISÃO DE LITERATURA}

\subsection{MORFOLOGIA DA SUBPLACENTA DOS ROEDORES HISTRICOMORFOS}

A subplacenta é um termo utilizado por $\operatorname{Minot}^{1}$ (1889 apud DAVIES et al., 1961b, p. 457) para a placenta do coelho, e, aplicada mais tarde, na placenta da cobaia. Na cobaia, a subplacenta é encontrada entre a placenta principal e a decídua.

De acordo com Grosser (1927 apud AMOROSO, 1952 p.273), a subplacenta é uma estrutura de considerável tamanho, que está situada no fundo da escavação central do disco placentário e é composta por células gigantes, as quais por sua vez são o resultado de uma peculiar transformação da camada sincicial periférica.

Davies (1956), ao estudar a placenta do coelho, descreve o tecido decidual nas áreas da subplacenta e paraplacenta, contendo grande quantidade de glicogênio. Segundo o autor, as células deciduais contêm glicogênio, e estão situadas na região subplacentária. Essas células dispõem-se numa lâmina contínua, e formam assim a chamada "zona de separação". As partículas de glicogênio aparecem diminutas nas preparações fixadas com Bouin. Já com outros fixadores, tais como álcool absoluto, elas distribuem-se difusamente dentro das células. Em relação à invasão trofoblástica, na zona superficial da subplacentária, a decídua mostra várias áreas de necrose, com concomitantes liberações de glicogênio intracelular. As células gigantes endoteliais da região subplacentária são fortemente basófilas, mostrando uma atividade fosfatase alcalina.

\footnotetext{
${ }^{1}$ MINOT, C.S. Uterus and embryo. I. Rabbits. II Man. J. morph. 2:341-60, 1889.
} 
De acordo com Perrota (1959), a placenta do porco-espinho possui uma placenta "acessória", que praticamente desaparece no final da gestação. O autor descreve esta placenta "acessória" como subplacenta, apresentando uma região "germinal" do trofoblasto e do mesoderma alantóico, na qual novos lóbulos do labirinto diferenciam-se, os quais são adicionados à placenta durante seu crescimento. Este processo cessa no terço final da gestação, quando a subplacenta começa a degenerar.

Tibbitts e Hillemann (1959) descreveram na chinchila doméstica (Chinchilla lanígera) uma placenta discóide, do tipo corioalantoidiana, que ocupa a região mesometrial. Esta encontra-se envolta pela decídua que recobre quase que totalmente o concepto, exceto a face embrionária do disco. Segundo os autores, a subplacenta forma-se a partir do 25o e 30 dias de gestação. Ela é composta inicialmente por uma lâmina de ectoderma coriônico, mais mesoderma. A subplacenta é encontrada na região mesometrial da escavação placentária central. Alguns vasos maternos maiores foram observados na periferia da subplacenta. Estes por sua vez, não estão aparentemente envolvidos no suprimento sangüíneo desta estrutura.

Davis, Dempsey e Amoroso (1961a) descreveram a subplacenta da cobaia como uma zona especializada do córion, derivada da proliferação do ectoderma fetal no assoalho da "escavação" central, ou centro mesodermal da placenta corioalantóica. Consiste em lamelas de citotrofoblasto que cercam a superfície do mesênquima fetal corioalantóico, dando origem ao trofoblasto sincicial. O sincício da subplacenta difere da placenta corioalantóica, pois é uma região exclusivamente vascularizada por vasos de origem fetal. Contém, no lugar dos canais de sangue materno, um sistema de espaços lacunares preenchidos por 
material amorfo. Esses autores relatam, ainda, que, a partir do 45o dia de gestação até o final, a atividade citotrofoblástica da subplacenta da cobaia diminui pela escassez de mitoses, e pela redução a uma camada simples. Em muitas áreas, o citotrofoblasto desaparece, restando somente o sinciciotrofoblasto, diretamente em contato com a membrana basal. O septo de mesênquima entre as lamelas de citotrofoblasto encontra-se menos celularizado, mais fibroso, contendo menos vasos. O sincício degenera, e, um progressivo acúmulo de material acidófilo e PAS-positivo encontra-se entre os resíduos do sinciciotrofoblasto. O padrão característico de gotículas no interior do sincício, pode se perder, ou persistir até o 60 dia de gestação. A placenta a termo mostra evidências de sua organização histológica inicial, sendo a camada de citotrofoblasto formada por fileiras descontínuas de núcleos picnóticos, que envolvem ilhas de material acidófilo e PAS positivo. As paredes dos vasos maternos são mantidas até o final da gestação, e mostrando um pequeno indício de degeneração, a partir da deposição de material semelhante à fibrina, ao longo de suas paredes internas, contíguas ao lúmen.

Segundo Davies, Dempsey e Amoroso (1961b), a subplacenta da cobaia surge a partir do 16o dia de gestação, com a especialização do cório do assoalho do centro mesenquimal ou "escavação central" da placenta. Seu aspecto consiste no citotrofoblasto em contato com o mesênquima fetal, dando origem ao trofoblasto sincicial. A atividade proliferativa da camada citotrofoblástica e a formação do sincício estão em sua atividade máxima do 18o ao 25o dia de gestação. Após este período, o citotrofoblasto torna-se reduzido em espessura, e o sincício torna-se mais compacto. A subplacenta começa a degenerar-se depois do 50 o dia de gestação. A característica histoquímica saliente da subplacenta é a 
presença de grande quantidade de material PAS-positivo dentro das lacunas do trofoblasto sincicial. Os autores relatam que os vasos maternos rodeiam a subplacenta, e, muitas vezes, o endotélio dos mesmos é substituído por elementos trofoblásticos invasivos da subplacenta. A parede do vaso modificada recebe o nome de "endotrofoblasto", contendo material PAS-positivo, semelhante ao encontrado na subplacenta.

Hillemann e Gaynor (1961) verificaram na placenta da nutria (Myocastor coypus) uma grande subplacenta, ocupando uma área central e mesometrial do disco, possuíndo um aspecto lobulado, como a placenta principal. Ao longo da margem fetal, a subplacenta espalha-se e interdigita-se com os lobos da placenta principal é esta área que confere um aspecto mesometrial ao disco. Esses autores relatam que a subplacenta apresenta células pequenas e de tamanho uniforme, as quais aparecem entrelaçadas a uma matriz de tecido conjuntivo frouxo, e permeadas por vasos.

Fischer (1971) descreveu a subplacenta do castor (Castor canadensis) no início de gestação, e relatou a formação da subplacenta. Ela é, segundo o autor, formada por numerosos vilos mesenquimais que se estendem do labirinto à decídua basal. É bem vascularizada ao centro e está cercada por trofoblasto. A microscopia eletrônica revela uma simples camada de sinciotrofoblasto e a algumas células citotrofoblásticas estão também presentes no interior dos vilos. Entre estes vilos, aparece uma massa composta de células arredondas vacuolizadas, células de sangue extravasado e abundante glicogênio intra e extracelular. Nenhum tecido conjuntivo, capilares ou fibras reticulares estão presentes entre os vilos. Á microscopia eletrônica, as áreas de intervilos apresentam células de eritrócitos e células constituídas por grânulos de 
glicogênio, retículo endoplasmático rugoso, mitocôndrias e gotículas de lipídios. As células sinciciais íntegras assemelham-se às camadas exteriores dos túbulos trofoblásticos do labirinto. Mitocôndrias, retículo endoplasmático rugoso e conteúdo de glicogênio, sugerem que elas possam representar a camada mais externa da subplacenta. Células semelhantes estão presentes entre filetes de sinciotrofoblasto na formação inicial da subplacenta e, de acordo com o autor, o sinciciotrofoblasto certamente está presente na formação da subplacenta.

Fischer e Floyd (1972) observaram a glândula subplacentaria do gerbil durante o desenvolvimento. Segundo os autores, a placenta torna-se um disco côncavo e ligeiramente afinado, por causa da expansão do concepto. Sua porção central, por causa da degeneração decidual, torna-se exposta às células gigantes, e neste momento começa a regredir. Há neste caso várias áreas de núcleos pinocíticos, e, a maioria dos cordões mais próximos ao concepto forma massas multinucleadas, com citoplasmas degenerados. No meio basal é bem desenvolvido. Muitas figuras mitóticas estão presentes, e, cordões glandulares continuam a invadir a decídua basal. Todavia, o suprimento sangüíneo da glândula subplacentária é exclusivamente derivado de sinusóides, drenando o trofoespôngio. Esses sinusóides grandes cercam quase completamente cada cordão da glândula, drenando para vênulas da decídua basal.

Roberts e Perry (1974) relataram que a subplacenta origina-se do ectoderma coriônico, da "escavação central", na placenta da cobaia. A zona juncional forma uma região de íntima relação materno-fetal, sendo composta por tecido necrótico derivado principalmente da decídua.

De acordo com King e Tibbitts (1976), a chinchila apresenta um arranjo histológico simples da subplacenta, o qual consiste de lamelas dobradas por 
citotrofoblasto que desenvolvam sinciciotrofoblasto na superfície oposta ao mesênquima fetal. O sinciciotrofoblasto é cercado por espaços ou lacunas. O mesênquima fetal carrega com ele os vasos fetais, que vascularizam a subplacenta, e está cercado por citotrofoblasto recoberto por sincício. O sinciciotrofoblasto da subplacenta tem várias características distintas dos sincícios encontrados em outras regiões placentárias. Uma das suas características é a presença de numerosos grânulos esféricos distribuídos por todo o citoplasma. Uma segunda característica da subplacenta é a presença de grandes acúmulos de glicogênio, e de retículo endoplasmático rugoso. O citoplasma também contém aparelho de Golgi extensamente espalhado, poucas mitocôndrias e numerosos "maços" de filamentos. A superfície do sincício que limita as lacunas possui numerosos microvilos. As lacunas contem freqüentemente uma substância eletrondensa finamente-granular. As células citotrofoblásticas formam uma camada contínua no início da gestação, o seu citoplasma possui numerosos poliribossomos livres, poucos retículos endoplasmáticos, poucas mitocôndrias e aparelho de Golgi pequeno. As células citotrofoblásticas são unidas umas às outras por desmossomos e por lâminas basais, fortalecendo as células citotrofoblásticas. Os espaço intercelulares variam consideravelmente. No final de gestação, a camada de citotrofoblasto torna-se descontínua. O endotélio do capilar fetal é contínuo do tipo não fenestrado.

Kaufmann e Davidoff (1977) relataram que a placenta da cobaia a partir do terço médio de gestação, é constituída por três regiões: placenta principal, subplacenta e a placenta vitelina. A subplacenta está organizada por dobras de trofoblasto, que ligam a placenta principal com a zona juncional, servindo como fonte de invasão do trofoblasto no endométrio. 
Estudando a placentação da cobaia, Uhlendorf e Kaufmann (1979) descreveram que o pedúnculo da placenta é composto por uma reduzida conexão entre a placenta principal e a parede do útero, formada por um tecido maternofetal, a zona juncional. O centro desta região é preenchido pela subplacenta. Esta, por sua vez, é composta por uma camada côncava de sinciciotrofoblasto na qual está encaixado primeiramente o citotrofoblasto, e, mais internamente, o mesênquima. Ambas as camadas trofoblásticas são divididas por numerosos septos que se estendem centralmente pelo mesênquima central, formando os lóbulos, os quais contribuem para a diminuição da comunicação com a face externa da subplacenta. Esta região degenera-se do $55^{\circ}$ até $058^{\circ}$ dia de vida embrionária, aproximadamente uma semana antes do parto, perfazendo uma zona de demarcação, para o desprendimento da placenta principal no parto.

Oduor-Okelo e Gombe (1982) analisaram a placenta discoidal no rato (Thryonomys swinderianus) e encontraram cinco zonas distintas, que estão organizadas de com a ordem seguinte: labirinto, esponjo, subplacenta, zona juncional e decídua. A subplacenta consiste em células uniformemente pequenas que ocorrem em grupos ou ninhos, encaixadas numa matriz de mesênquima fetal. Os espaços extracelulares dentro destes cachos de células contêm uma diástase resistente, e material PAS-positivo. Algumas células da subplacenta migram para a zona juncional e aparecem agregadas na forma de células trofoblásticas gigantes.

King (1982) aludiu que as chinchilas apresentam uma estrutura interessante conhecida como subplacenta, localizada na região materna do disco placentário. A subplacenta surge no início de gestação e depois involui durante 
os últimos estágios de gestação. O trofoblasto nesta região apresenta numerosos grânulos, que são PAS-positivos.

Oduor-Okelo (1984) descreveu que a subplacenta no rato (Thryonomys swinderianus) consiste tanto de citotrofoblasto quanto de sinciciotrofoblasto. $\mathrm{O}$ sinciciotrofoblasto tem numerosos microvilos que se projetam nos espaços intercelulares. Possuem ainda retículo endoplasmático granular, um complexo de Golgi bem desenvolvido e numerosos grânulos elétron-densos de tamanho uniforme. Os espaços intercelulares ou lacunas contêm um precipitado de densidade eletrônica moderada, sendo similares em textura ao precipitado intracelular da região da margem da escavação do sinciciotrofoblasto.

Segundo Fischer (1985), a subplacenta do castor canadense consiste de vilos como a placenta humana. Esta possui um centro mesenquimal circundado por uma camada incompleta de citotrofoblasto e uma camada mais externa de sinciotrofoblasto. O espaço existente entre os vilos é preenchido por células fetais grandes e pequenas (sinciciotrofoblasto e citotrofoblasto, respectivamente), sustentadas por uma rede laminar fibrosa, contendo células sanguíneas maternas.

Segundo Soiron (1993), a placenta da capivara a termo é como uma placenta corioalantoidiana, discoidal, labiríntica e fixada à parede uterina mediante a subplacenta.

Bosco, Diaz e Borax (1997) observaram no Octodon degus aos $60^{\circ}$ gestação, uma subplacenta volumosa imbricada entre a placenta e a decídua basal. Esta é constituída por células citotrofoblásticas individuais, escasso sinciciotrofoblasto e alguns capilares fetais. Na constituição da subplacenta, se 
observa-se um falso sincício labiríntico, aparentemente separado do sincício verdadeiro, também labiríntico, por escasso tecido mesenquimal com vasos sangüíneos fetais. Na placenta a termo (90 dias de gestação) não se observa a subplacenta. Neste caso, o falso sincício ocorre em menor proporção que o sincício verdadeiro.

Carter et al. (1998), realizando reações de imunohistoquímica na placenta da cobaia, descreveram que a subplacenta é separada da placenta principal por uma camada de mesênquima, contendo vasos fetais, comprovados mediantes reação positiva para vimentina. Segundo os autores, a subplacenta, no $65^{\circ}$ dia da gestação, mostrou uma extensiva degeneração do citotrofoblasto e acúmulo de material acidófilo.

Bonatelli et al. (2001) classificaram a placenta da paca como do tipo vitelina e do tipo corio-alantoidiana, sendo esta hemomocorial e labiríntica, dotada de um pedúnculo, e de uma subplacenta, tal como descrito para os roedores histricomorfos.

Em estudo comparativo sobre a placenta de alguns roedores histricomorfos, Miglino et al. (2002) descreveram a subplacenta da paca como não sendo claramente separada da placenta principal por uma camada de mesênquima. Na reação de imunohistoquímica para citoqueratina da subplacenta, os autores descreveram que a marcação ocorria fracamente no citotrofoblasto. Descreveram também que as reações de vimentina mostravamse positivas na zona juncional, incluindo o pedúnculo ou mesoplacenta. Algumas áreas com núcleos pequenos e saudáveis e outras com núcleos fragmentados reagiram fracamente. A reação de túnel para apoptose e evidenciou que haviam muitos núcleos reativos na mesoplacenta, e vasos maternos que permaneceram 
abertos, possuíam poucos núcleos reativos. Ocorreu reação positiva nos núcleos das paredes dos vasos.

Mess (2003) descreveu em sua revisão sobre placentação em roedores, uma região distinta chamada de subplacenta. Esta foi descrita pela primeira vez para o Petromus e o Octodon respectivamente. A autora proferiu que a subplacenta apesar de ser uma estrutura muito conhecida, tem ainda sua função desconhecida servindo como uma região especial no crescimento do citotrofoblasto, ou como um órgão de secreção endócrina.

Kaufmann (2004) descreveu a subplacenta como uma zona de crescimento para a proliferação do trofoblasto na lobulação do disco placentário. Sugeriu ser o órgão um possível local de atividade placentária endócrina. Neste, ocorre uma degeneração alguns dias antes do parto, restando apenas uma massa de detritos celulares no local da separação placentária.

Segundo Oliveira (2004), a subplacenta do mocó está inserida na decídua e apresenta uma zona juncional, situada entre a placenta principal e a subplacenta. O autor descreve a subplacenta histologicamente como sendo lamelar, com natureza sincicial. Os eixos das lamelas são preenchidos por um tecido de natureza mesenquimal, com pequenos vasos. Apoiada sobre ela está o citotrofoblasto e, em seguida, o sinciciotrofoblasto. A vascularização da subplacenta do mocó é predominantemente fetal.

Oliveira, et al. (2005) descreveram que a subplacenta de mocó está situada entre a placenta principal e a decídua basal. É separada da placenta principal, por uma camada de tecido conjuntivo, o mesênquima fetal, o qual carrega vasos sangüíneos fetais, dividindo a subplacenta em lóbulos irregulares. 
Estes septos são revestidos por lamelas dobradas de células de citotrofoblasto, e em seguida por sinciotrofoblasto. O sinciciotrofoblasto tem núcleos grandes com heterocromatina difundida e os microvilos projetam-se nos espaços intercelulares entre as células do citotrofoblasto. O sinciciotrofoblasto da subplacenta possui núcleos mais regulares que os do labirinto da placenta principal, apresentando um citoplasma relativamente pequeno, e com uma aparência granulada. A evidência de degeneração celular é vista na subplacenta, especialmente no decídua basal. A presença de neutrófilos polimorfonucleares pode ser um sinal deste colapso celular.

Segundo Bonatelli (2005), a subplacenta da paca está localizada no ápice da placenta corioalantoidiana, separada desta por um tecido mesenquimal, e inserida na parede uterina em íntimo contato com o tecido materno. A subplacenta consiste de estruturas lamelares, com eixos de tecido mesenquimal fetal, sobre os quais apoiavam-se arranjos epiteliais de cito e sinciciotrofoblastos. Nas áreas de interface dos perímetros da subplacenta em contato com o tecido materno foram encontradas populações de células trofoblásticas gigantes multinucleadas. Nos espaços interlamelares do interior da subplacenta, em meio ao sinciciotrofoblasto, foram encontrados materiais amorfos resultante da degeneração do tecido endometrial, retido durante a progressão e crescimento da placenta para o interior da parede uterina. Nestes espaços não foram encontrados vasos sangüíneos, porém, no eixo mesenquimal da subplacenta, foram constatados vasos sangüíneos de pequeno calibre, todos vimentina positivos, sugerindo a ausência de vascularização da subplacenta através de sangue materno. Pela localização estratégica, acima da subplacenta principal, e pelos aspectos ultra-estruturais das células citotrofoblásticas presentes nas lamelas, juntamente com sua intensa marcação pelo PCNA, presume-se que as 
células da subplacenta possam originar as demais células trofoblásticas, particularmente as sinciciais e as gigantes, ao longo do terço médio de gestação. 


\subsection{VASCULARIZAÇÃO DA SUBPLACENTA}

Quanto à vascularização da subplacenta, Hillemann e Gaynor (1961) descreveram que na nutria (Myocastor coypus), a maioria dos vasos arteriais maternos desviavam da subplacenta. Entretanto, poucos passavam entre os lóbulos da subplacenta. A maioria deles passava externamente à área subplacentária, e, portanto, entre os lóbulos adjacentes da placenta corioalantóica, em direção à zona central de cada lóbulo.

De acordo com Fischer (1985), a subplacenta do castor, parece não se ajustar facilmente à qualquer função placentária conhecida. Não há nenhuma circulação de sangue materno eficiente, e nenhuma indicação de um padrão de fluxo ativo nela presente. Apenas poucos eritrócitos foram achados nas regiões centrais do subplacenta, porém, as células de sangue materno estavam intactas. Embora vasos capilares fetais estivessem presentes, em íntima relação com os vilos de sinciciotrofoblasto, a presença deles seguramente devia-se somente, ao apoio metabólico do componente interviloso da própria subplacenta.

Segundo Fischer e Floyd (1972), o fornecimento sanguíneo para a glândula subplacentária do Mongolian gerbil era derivado exclusivamente de sinusóides que escoavam do espongiotrofoblasto. Estes grandes sinusóides cercavam toda a glândula quase completamente, e, então, drenavam as vênulas da decídua basal.

Kaufmann e Davidoff (1977) relataram a circulação da subplacenta surgindo, a partir do 2o dia aproximadamente. Uma circulação promovida por vasos maternos ocorria inicialmente, e, ao redor do 28 dia, esta cessava sua função nas regiões subplacentárias. Embora houvesse alguns vasos fetais na escavação central, durante a formação da subplacenta, eles não entravam em 
contato com o trofoblasto. Entre o 23 e 27ㅇ dias de gestação, período durante o qual a circulação materna retrocedia, os primeiros vasos fetais penetravam mais profundamente entre os lóbulos de trofoblasto. A vascularização fetal da subplacenta só era completada no 32 dia. Depois do 55 dia, os vasos eram obliterados no curso dos processos degenerativos da subplacenta. Do 58 dia em diante, havia apenas alguns poucos vasos fetais nessa região. Segundo os autores a subplacenta da cobaia não era vascularizada simultaneamente pelos sangues materno e fetal. Consequentemente, não pode ser considerado um órgão de troca de substâncias materno-fetal como foi sugerido. A vascularização aparece, segundo os autores, para nutrir e servir somente o tecido subplacentário.

Wolfer e Kaufmann (1980) observaram que, ultraestruturalmente, a subplacenta da cobaia, nas primeiras semanas do desenvolvimento do concepto era vascularizada por sangue materno, ou seja, as lacunas maternas começam a se formar, porém logo desapareciam nos dias 20a a 28으, devido à oclusão dessas lacunas. Os capilares fetais formavam-se completamente por volta do 32 dia, nunca existindo uma dupla circulação, razão pela qual essa região não podia ser considerada uma região de troca.

Na capivara, Kaufmann (2004) descreveu que o fluxo de sangue materno das lacunas cessava poucas semanas após a concepção do embrião, depois disso ocorria, segundo o autor, a capilarização fetal na subplacenta. Conseqüentemente, em nenhum estágio da gravidez, a subplacenta era vascularizada por sangue materno e fetal simultaneamente, não podendo conseqüentemente servir como um órgão da troca. 
Miglino et al. (2004) descreveram a subplacenta dos roedores histricomorfos (capivara, cutia, paca e mocó) e nestes o órgão vascularizado principalmente por vasos fetais. Uma grande artéria fetal proveniente do cordão umbilical percorre centralmente a placenta principal, e, então fornece ramos a subplacenta. Os vasos subplacentários seguem um curso tortuosos, com dilatações e constrições, semelhante aqueles encontrados nas glândulas endócrinas, tais como os ovários. Alguns ramos das artérias maternas suprem a subplacenta da capivara e da paca. Estes foram observados por injeção de látex - Neoprene corado.

Para Bonatelli et al. (2005), a vascularização da subplacenta de paca, avaliada pela perfusão de látex Noprene colorido, e pela técnica de corrosão e análise microscopia eletrônica de varredura, comprovou a ausência de vasos de origem materna. Os autores demonstraram uma irrigação oriunda da artéria fetal a qual, após capilarização na subplacenta, dirige-se para os lóbulos da placenta principal. Esta disposição lembra uma circulação do tipo portal, com uma possível capilarização dos vasos oriundos da subplacenta junto à placenta principal, onde o sangue efetuaria as trocas metabólicas, para retornar como sangue oxigenado, antes de confluir para as veias fetais do cordão umbilical. 


\section{MATERIAL E MÉTODO}

\subsection{ANIMAIS}

Para esta pesquisa utilizaram-se 6 cutias fêmeas, gestantes (Dasyprocta leporina), provenientes do Criatório Osvaldo Roberto Scabine, localizado no município de Tanabi, Estado de São Paulo, credenciado pelo Instituto Brasileiro do Meio Ambiente e dos Recursos Naturais Renováveis - IBAMA sob o registro no 2/35/1998-000288-3.

Neste trabalho foram utilizadas 9 placentas de cutias, em diferentes fases de gestação, conforme demonstrado na Tabela-1.

Tabela 1 - Caracterização da gestação da cutia (Dasyprocta leporina). Dados obtidos no Criatório Osvaldo Scabine de Tanabi - SP, (F1 - feto 1; F2 - feto 2). São Paulo - 2005

\begin{tabular}{|c|c|c|c|c|c|c|}
\hline Animal & $\begin{array}{c}\text { Tempo } \\
\text { de } \\
\text { gestação }\end{array}$ & $\begin{array}{c}\text { Corno } \\
\text { uterino } \\
\text { gestante }\end{array}$ & $\begin{array}{l}\text { Comprimento } \\
\text { do Feto }(\mathrm{cm})\end{array}$ & $\begin{array}{l}\text { Comprimento } \\
\text { do Funículo } \\
\text { (cm) }\end{array}$ & $\begin{array}{l}\text { Peso do } \\
\text { feto (gr) }\end{array}$ & $\begin{array}{c}\text { Peso da } \\
\text { placenta } \\
\text { (gr) }\end{array}$ \\
\hline 01 & $1 / 3$ inicial & F1 - Esquerdo & -- & -- & -- & 15 \\
\hline \multirow{2}{*}{02} & \multirow{2}{*}{$1 / 3$ inicial } & $\mathbf{F 2}$ - Esquerdo & 2 & 2 & 15 & 13 \\
\hline & & F2 - Direito & 2 & 2 & 15,5 & 12 \\
\hline 03 & $1 / 3$ médio & F1 - Direito & 10 & 9,5 & 42 & 37 \\
\hline \multirow[b]{2}{*}{04} & \multirow[b]{2}{*}{$1 / 3$ médio } & F1 - Esquerdo & 10 & 9 & 42 & 36 \\
\hline & & F2 - Esquerdo & 10 & 9 & 40 & 34 \\
\hline 05 & $1 / 3$ medio & F1 - Direito & 10,5 & 9,5 & 41 & 36 \\
\hline \multirow{2}{*}{06} & \multirow{2}{*}{$1 / 3$ final } & F1 - Direto & 16 & 13 & 100 & 78 \\
\hline & & F2 - Esquerdo & 12,5 & 9 & 76 & 50 \\
\hline
\end{tabular}

Os animais foram examinados mediante exame ultrassonográfico para detectar o estágio de gestação. Em seguida, os animais foram mantidos em jejum de sólidos por um período de dez horas, e jejum líquido por um período de 
seis horas, antes da cirurgia. Após esse período eles foram encaminhados para o centro cirúrgico para a coleta do material.

\subsection{COLETA DO MATERIAL}

Os procedimentos cirúrgicos foram realizados em dois hospitais veterinários: no Hospital Veterinário "Governador Laudo Natel" no Departamento de Reprodução Animal da Faculdade de Ciências Agrárias e Veterinárias de Jaboticabal (UNESP), e no Hospital Veterinário "Dr. Halim Atique" do Centro Universitário de Rio Preto (UNIRP) em São José do Rio Preto, São Paulo.

Os tranqüilizantes, anestésicos, analgésicos e antibióticos utilizados nas cutias foram aplicados via intramuscular nos membros pélvicos. A tranqüilização foi obtida com azaperone ${ }^{a}$ na dose de $4 \mathrm{mg} / \mathrm{kg}$ de peso corporal. Após 10 minutos, aplicou-se $0,06 \mathrm{mg} / \mathrm{kg}$ de sulfato de atropina ${ }^{\mathrm{b}}$, seguindo-se, após mesmo intervalo, a administração da associação de cloridratos de quetamina ${ }^{c}$ $(20 \mathrm{mg} / \mathrm{kg})$ e de xilazina ${ }^{d}(1,5 \mathrm{mg} / \mathrm{kg})$, para indução da anestesia. Realizou-se tricotomia abdominal ampla com lâmina de aço inoxidável e a anestesia geral foi obtida mediante inalação por máscara de halotano, juntamente com $750 \mathrm{~cm}^{3}$ de oxigênio puro por minuto.

A incisão da pele foi feita na linha média, sentido pré-retroumbilical, abrangendo cerca de 12 centímetros, devido ao considerável volume do corno uterino prenhe. O ovário foi identificado e mantido suspenso e exteriorizado mediante incisão, procedendo-se, então, sua ligadura.

\footnotetext{
a Stresnil@ - Janssen Pharmaceutica.

${ }^{b}$ Sulfato de atropina ${ }^{\circledR}$ - Ariston Ltda.

${ }^{c}$ Ketamina $50 \AA$ - Holliday - Scott S.A.

d Coopazine ${ }^{\circledR}$ - Coopers Brasil Ltda.
} 
Imediatamente, após a cirurgia, foi realizado curativo local com solução de iodo a $2 \%$, colocado esparadrapo hipoalergênico ${ }^{e}$ sobre a sutura de pele e aplicados antibióticos ${ }^{f}(15.000 \mathrm{U} / \mathrm{kg}$ de benzilpenicilina benzatina, $7.500 \mathrm{U} / \mathrm{kg}$ de benzilpenicilina procaína, $7.500 \mathrm{U} / \mathrm{kg}$ de benzilpenicilina potássica, $6,25 \mathrm{mg} / \mathrm{kg}$ de sulfato de diidroestreptomicina e $6,25 \mathrm{mg} / \mathrm{kg}$ de sulfato de estreptomicina) e 0,020 mg/kg de buprenorfina ${ }^{9}$ para analgesia. Depois de 48 horas, outra dose dos antibióticos foi administrada e o esparadrapo mantido até a retirada dos pontos da pele, o que ocorreu após sete dias de cirurgia (OLIVEIRA et al., 2003).

As placentas coletadas foram fixadas em soluções de paraformoldeído e glutaraldeído no local e processadas nos laboratórios do Departamento de Anatomia - área de Anatomia dos Animais Domésticos da Faculdade de Medicina Veterinária e Zootecnia da Universidade de São Paulo (FMVZ - USP).

\subsection{ANÁLISE MACROSCÓPICA}

O corno uterino gestante retirado foi dissecado cuidadosamente, separando o feto e as porções placentárias. Em seguida, foram aferidas com paquímetro as medidas do feto e dos anexos fetais realizadas e fotodocumentadas.

As placentas coletadas para a microscopia de luz foram fixadas e paraformaldeído ${ }^{h}$, e em seguida, cortadas transversalmente tornando possível à identificação da subplacenta, parte esta isolada para análise.

\footnotetext{
e Micropore ${ }^{\circledR}$ - 3M do Brasil Ltda.

f Pentabiótico Veterinário ${ }^{\circledR}$ - Fort Dodge Saúde Animal Ltda.

${ }^{9}$ Temgesic $\circledast$ - Schering-Plough Ltda.

h Paraformoldeído: paraform - Aldehyde, Sigma Chemical Co., USA.
} 


\subsection{PROCESSAMENTO PARA INCLUSÃO EM PARAFINA}

Os fragmentos da subplacenta foram cuidadosamente recortados e fixados por imersão em solução de paraformaldeído 4\% em tampão fosfato de sódio $\left(0,1 \mathrm{M}, \mathrm{pH} 7,4\right.$ a $\left.4^{\circ} \mathrm{C}\right)$. Após a fixação os fragmentos placentários foram submetidos aos procedimentos rotineiros de desidratação, diafanização e inclusão em parafina contendo plastificante (Histosec $®$, Brasil).

O material incluído foi submetido a microtomia em cortes de $5 \mu \mathrm{m}$, em lâminas histológicas, e os cortes desidratados e corados pelas técnicas: hematoxilina - eosina ( $\mathrm{HE})$, tricrômicos de Mallory e picrossirius. Essas lâminas foram montadas em resina, analisadas e documentadas no fotomicroscópio (Leica DMR)

\section{5 - REAÇÕES CITOQUÍMICAS E IMUNOHISTOQUÍMICAS}

\subsection{1-Reação de PAS (Ácido Periódico-Shiff)}

Os cortes histológicos $(5 \mu \mathrm{m})$ foram submetidos à reação de PAS com e sem tratamento prévio pela digestão de amilase 1\% (Sigma St Louis, USA), por 30 min. a 370 C, de acordo com a técnica de Lillie. Após a reação, os cortes foram contra-corados com hematoxilina e processados para montagem permanente em bálsamo do Canadá. As análises e fotodocumentações foram realizadas no microscópio de luz Nikon-Eclipse 800. 


\subsubsection{Reações Para Citoqueratina, Vimentina, PCNA}

Foram realizadas reações imunocitoquímicas utilizando-se os anticorpos anti-citoqueratina policlonal de coelho (cód. PU071-UP, Biogenex), anti-PCNA monoclonal de camundongos (cód.107904, Novocastra, UK), anti-vimentina e anti-caspase-3 policlonal de cabra (cód. SC-1226, Santa Cruz Biotechnology, USA). Como anticorpo secundário foi utilizado Kit LSABß - HRP Peroxidase (DAKO K0690; DAKO Corporation, Carpinteria, CA, EUA). Os cortes histológicos desparafinizados e hidratados foram equilibrados em tampão TRis-HCL 0,1M pH

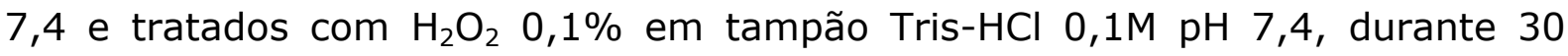
minutos à temperatura ambiente. Em seguida, os cortes foram tratados com tampão citrato $0,1 \mathrm{M}$ pH 6,0 e irradiados em microonda de uso caseiro (Sanyo), na potência máxima $(700 \mathrm{MHz}) 3$ vezes durante 3 minutos. Os cortes foram em seguida equilibrados em tampão fosfato-salina (PBS) $0,1 \mathrm{M} \mathrm{pH} \mathrm{7,4} \mathrm{e} \mathrm{tratados} \mathrm{com}$ leite desnatado a $2 \%$ em PBS por 20 minutos. As incubações com os anticorpos primários foram realizadas em câmara úmida, durante 12 horas, à temperatura de $0-4^{\circ} \mathrm{C}$. Após esse período, os cortes foram lavados e incubados com os anticorpos secundários, conjugados com peroxidase e revelados pelo sistema diaminibenzidina $/ \mathrm{H}_{2} \mathrm{O}_{2}$ em tampão tris- $\mathrm{HCl}$ pH 8,2. Os cortes foram contracoradas com Hematoxilina de Harris e montados com resina sintética - Entellan (Merck, Darmstadt, Alemanha).

As análises e fotodocumentações foram realizadas no microscópio de luz Leica DMR. 


\subsection{PROCESSAMENTO DO MATERIAL PARA MICROSCOPIA ELETRÔNICA DE TRANSMISSÃO}

Os fragmentos coletados foram fixados em glutaraldeído 2,5\% (Polyscience Inc., USA) em tampão fosfato de sódio $\left(0,1 \mathrm{M}, \mathrm{pH} 7,4\right.$ a $\left.4^{\circ} \mathrm{C}\right)$, por um período mínimo de 24 horas, na seqüência, lavadas em tampão fosfato, e pós-fixadas em tetróxido de ósmio $1 \%$ (Polyscience Inc., USA) em tampão fosfato $0,1 \mathrm{M}$ por uma hora e desidratadas em concentrações crescentes de etanol ( $70 \%$ a $100 \%)$ e óxido de propileno (Polysciences, Inc., USA). Em seguida, os fragmentos foram embebidos em resina Spurr (Electron Microscopy Science, Co. USA) e a polimerização induzida à temperatura de $60^{\circ} \mathrm{C}$, por 72 horas.

Em seguida, foram confeccionados cortes semifino, obtidos através do ultramicrótomo e corados em Azul de Toluidina, para seleção das regiões onde foram feitos os cortes ultrafinos, para serem analisados. Os cortes ultrafinos foram de $60 \mathrm{~nm}$ obtidos no ultramicrotomo (Leica ULTRA-CUT UCT) e coletados em tela de cobre, e os cortes foram contrastados pelo acetato de uranila $2 \%$ (cinco minutos), pelo citrato de chumbo 0,5\% (dez minutos).

As amostras foram analisadas e documentadas no microscópio eletrônico de transmissão (JEOL1010). 


\subsection{PERFUSÃO DA REDE VASCULAR DA PLACENTA}

\subsubsection{Injeção de látex}

Para a técnica de injeção de látex foi utilizada uma placenta no terço médio de gestação, na qual o leito vascular foi preenchimento pela substância Neoprene látex "650" (Du Pont do Brasil S/A) corada com pigmento específico (corante Suvinil, Glasurit do Brasil S/A) em 3 diferentes colorações (amarelo, verde, e vermelho).

As artérias e veias fetais foram canuladas e injetadas com substância Neoprene látex, natural (cor branca), para as artérias, e corada com pigmento de coloração verde para as veias fetais.

O mesmo procedimento foi efetuado com as artérias e veias maternas nas quais injetou-se látex corado em vermelho nas artérias e látex corado em amarelo nas veias maternas.

Após a injeção, as peças foram fixadas por imersão na solução aquosa de formaldeído a $10 \%$, e na seqüência realizaram-se cortes sagitais e paramedianos para análise da distribuição vascular na subplacenta.

\subsubsection{Injeção de Mercox}

Duas placentas no terço meio de gestação foram utilizadas para a técnica de preenchimento vascular por um cimento acrílico, o qual se caracteriza por fluir através do leito capilar (Mercox'). A obtenção desse cimento, que se polimeriza à

\footnotetext{
'Mercox (Vilene Hospital CL=2) produzido Okenhji, Co.Ltd.Japan
} 
temperatura ambiente, ocorre pela adição ao polímero da solução catalisadora. A injeção ocorreu nos vasos arteriais uterinos, após o preenchimento e polimerização em temperatura ambiente, as amostras foram lavadas em água destilada e, em seguida, imersas em solução de hidróxido de sódio (NAOH) 5$10 \%$ a $60^{\circ} \mathrm{C}$. Foram feitas trocas periódicas da solução de $\mathrm{NaOH}$ até a completa corrosão do material orgânico. Após a corrosão do material orgânico obtive-se um molde que foi lavado em água destilada e secado em estufa em $40^{\circ} \mathrm{C}$.

Posteriormente, os moldes vasculares foram incluídos em solução de gelatina incolor a $20 \%$, levados à geladeira para garantir maior resistência ao molde e em seguida foram obtidos pequenos fragmentos que foram novamente corroídos em hidróxido sódio, lavados em água corrente. Após nova secagem em estufa, montaram-se os fragmentos selecionados em bases metálicas e procedeu-se a metalização com ouro, utilizando o metalizador (EMITECH K550). As análises e documentações foram realizadas no microscópio eletrônico de varredura Carl ZEISS (LEO 435 VP). 


\section{RESULTADOS}

\subsection{ANÁLISE MACROSCÓPICA DA SUBPLACENTA}

A placenta da cutia (Dasyprocta leporina) no terço inicial de gestação apresenta-se implantada na região mesometrial, na qual se mantêm até o final, com formato discóide (Figuras 1A, 1B). Em corte sagital, na região mediana identifica-se duas regiões distintas: a placenta principal de coloração avermelhada, que ocupa a maior parte da circunferência placentária e a subplacenta, que apresenta a coloração esbranquiçada e está localizada no ápice do cone, em íntimo contato com o tecido materno (Figuras 1C,1D). 


\subsection{ANÁLISE HISTOLÓGICA DA SUBPLACENTA}

A placenta da cutia revela-se organizada em duas regiões distintas: a placenta principal e a subplacenta, e, esta organização é constante tanto do terço inicial quanto no final de gestação (Figuras 2 A, 2B).

A subplacenta observada em uma vista panorâmica, apresenta-se como uma região à parte, delimitada pelo tecido mesenquimal de origem fetal, próximo à placenta principal, região chamada de zona transicional. Neste mesênquima encontram-se vasos de diversos calibres, com parede delgada e recoberta pelo endotélio (Figuras $3 \mathrm{~A}, 3 \mathrm{~B}$ ).

Na região lateral e no ápice da subplacenta, a zona juncional é contornada por um tecido amorfo, que se localiza próximo ao estroma endometrial contendo resíduos de células degeneradas (Figura 3C). Lateralmente são encontrados vasos sanguíneos, cujas paredes são destituídas de endotélio, mas revestidas de massas de células gigantes ou multinucleadas (Figura 3 C).

$\mathrm{Na}$ cutia (Dayprocta leporina) a subplacenta está organizada em projeções lamelares irregulares, as quais possuem um eixo de tecido mesenquimal fetal, contendo vasos sanguíneos do tipo venoso de pequeno calibre por capilares sanguíneos indiferenciados (Figura 4 A). Recobrindo o eixo de tecido mesenquimal, dispõem-se uma camada contínua de citotrofoblasto caracterizado por suas células de formato colunar, mononucleares, com núcleos esféricos, citoplasma eosinófilo e pólo basal voltado para o mesênquima lamelar. Acima dessa camada de citotrofoblasto, encontram-se as camadas de sinciciotrofoblasto, identificadas como massas celulares multinucleadas o sinciciotrofoblasto apresenta núcleos de forma e tamanho variados, citoplasma basófilo e limites celulares indefinidos (Figura 4B). 
Durante a gestação, algumas características modificam o sinciciotrofoblasto, o qual torna-se mais vacuolizado, enquanto que as células citotrofoblásticas, que estavam dispostas em multicamadas, passam a apresentar apenas uma ou nenhuma camada.

Ao redor da subplacenta nota-se o sinciciotrofoblasto em íntima relação com tecidos de origem materna (Figura 3C), porém, nas regiões mais internas da subplacenta, não é possível distinguir o tecido materno do fetal. O espaço interlamelar é ocupado principalmente pela massa de sinciciotrofoblasto entremeada por um material amorfo acelular.

Nas preparações correspondentes ao terço médio de gestação, o espaço interlamelar é ocupado predominantemente pelo sinciciotrofoblasto, porém, em algumas áreas pode-se notar além do material amorfo, a presença de restos celulares de origem provavelmente materna.

Na região entre a decídua e a subplacenta, nota-se a presença de células trofoblásticas do tipo gigantes. Estas células são multinucleadas podendo estar isoladas ou agregadas e espalham-se no tecido endometrial, e próximos aos vasos sanguíneos do endométrio. Muitos desses vasos estão preenchidos por sangue (Figuras 3C, 3D). Em alguns pontos, as células gigantes estão dispostas em rede, delimitando ou ocupando a luz do vaso, não permitindo identificar se são estes venosos ou arteriais. Nessas regiões, o tecido endometrial apresentase pouco organizado não permitindo distinguir a sua celularidade. Nota-se nestes locais restos celulares distribuídos em meio a um estroma de aspecto amorfo.

Na região apical da subplacenta da cutia, próximo ao perímetro das lamelas, encontra-se agregados de células gigantes. Às vezes, junto a estes agregados de células trofoblásticas, encontra-se sangue extravasado, porém, sem vestígio de vasos sangüíneos (Figuras 5A, 5B). 


\subsection{HISTOQUÍMICA E IMUNOHISTOQUÍMICA}

\subsection{1 - Reação de PAS e Alcian Blue}

Na subplacenta de cutia, durante a gestação, a reação de PAS (Ácido Periódico de Shiff) apresenta reação positiva à massa de sinciciotrofoblasto, com redução de intensidade pela ação prévia da amilase. Já para o citotrofoblasto apresenta reação fraca ou ausente (Figuras 4C, 4D). A massa amorfa que entremeia o sinciciotrofoblasto apresenta intensa reação PAS positiva, amilase resistente, nas regiões basal e lateral da subplacenta (Figura 5B).

Quanto à reação histoquímica com Alcian Blue $\mathrm{pH} 2,5$, a reação é fracamente positiva junto à massa celular sincicial das lamelas da subplacenta (Figura 5D ). O mesmo ocorre nas células trofoblásticas gigantes, estando a reação ausente no final da gestação.

\subsection{2 - Reações para Citoqueratina, Vimentina e PCNA}

A imunohistoquímica para citoqueratina apresenta intensa reação positiva para células localizadas no interior da placenta, na subplacenta, e nos agregados celulares, distribuídos junto aos tecidos endometriais, localizados nas regiões de interface com a subplacenta.

Há reação positiva para o citotrofoblasto e o sinciciotrofoblasto das lamelas (Figura 6 A), e com menor intensidade nas células gigantes localizadas nas regiões basal e lateral da subplacenta, e sendo negativa para a massa amorfa (Figura $5 \mathrm{C}$ ). 
A vimentina apresenta intensa reação positiva no revestimento endotelial dos vasos sanguíneos, os quais estão distribuídos no interior da placenta principal e da subplacenta. Nesses preparados confirmam-se a rede vascular, que acompanha o tecido mesenquimal, do eixo central das lamelas da subplacenta, constituída essencialmente por vasos sanguíneos do tipo venoso e por capilares. Não são constatados vasos do tipo arterial (Figuras 6C, 6D). Não se verifica reação positiva para vimentina junto à parede dos leitos vasculares que permeiam o tecido materno da interface subplacenta-decídua (Figura 6C). Estes resultados não apresentam variações entre as diferentes fases gestacionais analisadas.

A reação de PCNA (proliferating cell nuclear antigen) apresenta reatividade positiva no citotrofoblasto das lamelas da subplacenta, no terço médio de gestação. O mesmo ocorre em algumas células do sincício, assim como, em algumas células trofoblásticas gigantes, distribuídas no estroma endometrial e junto à parede dos vasos maternos.

No terço final de gestação, verificam-se marcações positivas nos núcleos das células citotrofobláticas das lamelas da subplacenta, porém em proporções menores quando comparado as demais fases (Figura 7A). As células sinciciais e trofoblásticas gigantes raramente apresentam reação PCNA positiva em seus núcleos no final da gestação. 


\subsection{MICROSCOPIA ELETRÔNICA DE TRANSMISSÃO}

Para a descrição ultra-estrutural da subplacenta foram utilizadas amostras do terço médio de gestação. Identificou-se nesta fase a presença de duas populações trofoblásticas distintas: o citotrofoblasto e o sinciciotrofoblasto (Figura 8A).

Os eixos das lamelas são formados por um tecido, cuja matriz extracelular é pouco preservada nessa técnica, característica também evidente no tecido conjuntivo mesenquimal (Figura 8B). Neste nota-se a presença de vasos sanguíneos de pequeno calibre, em sua maioria vênulas e capilares. Na lâmina basal, que separa o eixo de mesênquima, estão apoiadas as células citotrofoblásticas (Figura 8B), caracterizadas por apresentarem poucas mitocôndrias, retículo endoplasmático rugoso pouco desenvolvido e núcleos esféricos. Estas estão distribuídas homogeneamente. E contêm um citoplasma finamente granular (Figura 8C). As células citotrofoblásticas apresentam junções celulares do tipo adesiva e desmossomos, para unir células lateralmente próximas, situadas nos estratos acima, as quais mantêm junções com as células sinciciais (Figuras 8B, 8C). Quando estas células são unidas por estas junções, delimitam espaços intercelulares irregulares.

As células sinciciais, localizadas ao redor das lamelas, são facilmente identificadas por apresentarem vários núcleos no seu interior (Figura 9B) e pela presença de grânulos eletrodensos de contornos irregulares. Situam-se envoltas por uma membrana, em meio ao citoplasma finamente granular, contendo glicogênio, mitocôndrias, retículo endoplasmático granular e complexos de Golgi (Figura 9C). Na superfície livre do sinciciotrofoblasto, que delimita seus espaços, 
ou seja, na camada mais próxima ao citotrofoblasto, pode-se observar projeções citoplasmáticas semelhantes à microvilos curtos e irregulares (Figuras 8D, 9C).

O sinciciotrofoblasto no terço final de gestação possui muitas lacunas, nas quais a membrana plasmática projeta-se em numerosos e longos microvilos (Figura $9 \mathrm{~A}$ ).

$\mathrm{Na}$ interface subplacenta e decídua foram encontradas as células trofoblásticas gigantes. À medida que se afastavam deste ponto estas tornavamse maiores, além de multinucleadas. Tais células caracterizavam-se pelo citoplasma granular, espaços citoplasmáticos vazios, em conseqüência da extração do glicogênio, mitocôndrias e retículo endoplasmático rugoso disperso. As células trofoblásticas gigantes em sua superfície livre apresentam microvilos semelhantes àqueles encontrados nos espaços intercelulares do sinciciotrofoblasto (Figuras 10A, 10B).

Na subplacenta não foram encontrados vasos maternos. Somente vasos fetais achavam-se distribuídos no mesênquima, os quais apresentavam íntima relação com a membrana basal do citotrofoblasto. 


\subsection{VASCULARIZAÇÃO DA SUBPLACENTA}

Para a identificação dos vasos que irrigam a subplacenta, injetou-se pelas artérias uterinas, látex Neoprene, corado em vermelho, e em amarelo as veias uterinas. Na face fetal injetou-se através da artéria umbilical látex Neoprene da cor branca (natural) e de cor verde a veia umbilical, este procedimento nos permitiu detectar na cutia (Dasyprocta leporina) que a vascularização da subplacenta ocorre principalmente através da artéria fetal. Entretanto, na interface com a subplacenta e decídua, a presença de artérias maternas foi constante (Figuras 11A, 11B).

A análise do molde vascular obtido através da injeção de Mercox, mostrou que a subplacenta é vascularizada exclusivamente pela artéria fetal (Figuras 11A, 11B). A veia materna forma um anel venoso disposto ao redor da subplacenta, como mostra a Figura 11A.

O molde vascular, quando analisado ao microscópio eletrônico de varredura, evidenciou ramos maiores inseridos na subplacenta. Este divide-se em vários outros ramos de menor calibre (Figura 12A), os quais perfazem um curso tortuoso com dilatações sinusóidais e constrições na luz dos vasos (Figuras 12C, 12D).

A impressão dos elementos vasculares endoteliais na parede dos vasos, mostra sobre as superfícies dos moldes, núcleos alongados, típicos de arteríolas e áreas de estrangulamento (Figura 12B), as quais sugerem válvulas controladoras do fluxo sangüíneo, presentes na entrada do sistema capilar sanguíneo (Figuras 12C, 12D). 

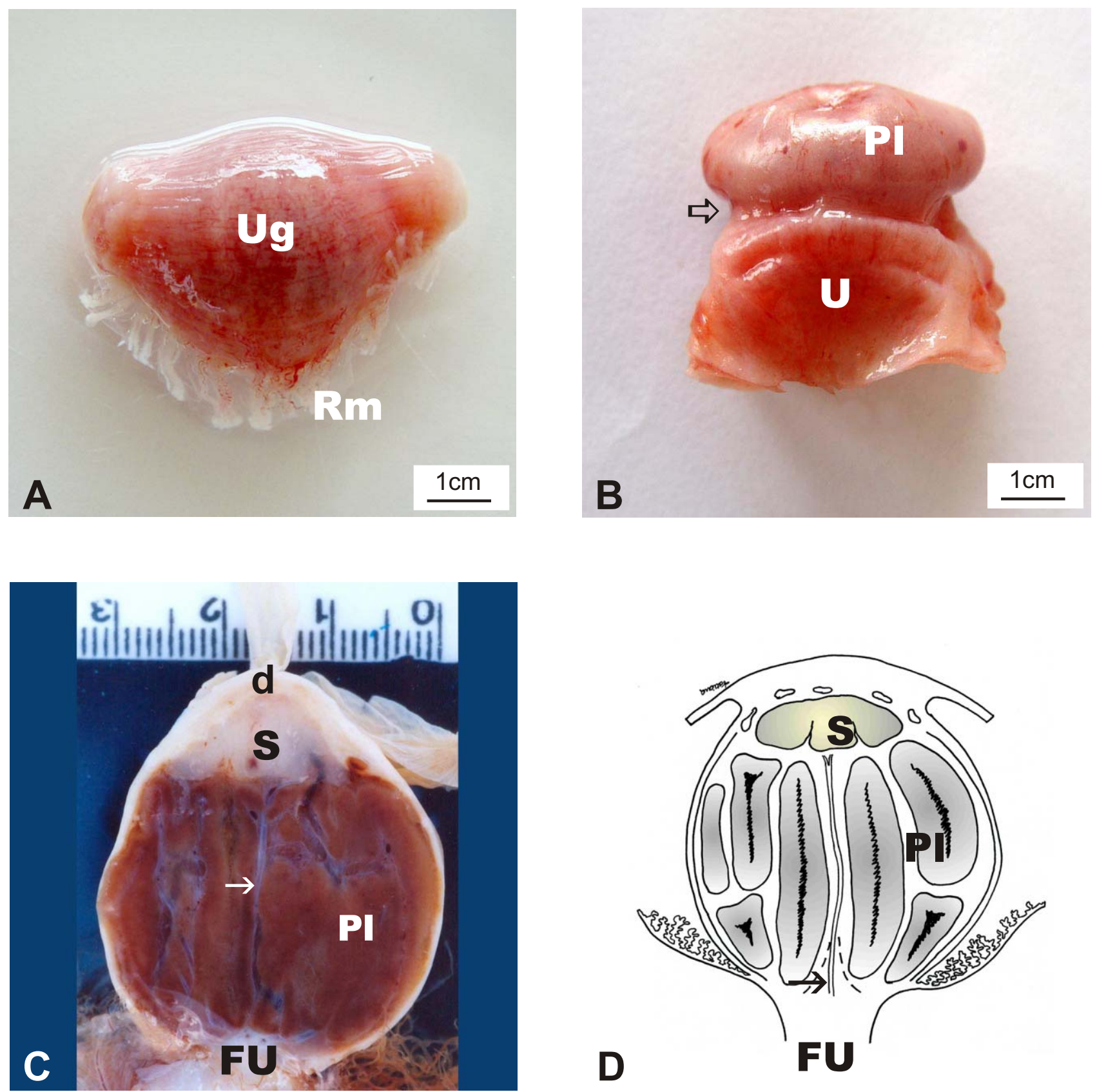

Figura 1 Aspectos macroscópicos da placenta de cutia (Dasyprocta leporina). A) Corno uterino gravídico $(\mathrm{Ug})$ dilatado pela placenta e feto inserido na face mesometrial $(\mathrm{Rm})$. B) Útero aberto expondo a conexão entre o útero (U) e a placenta principal (PI). C-D) Corte sagital mediano de placenta após fixação em formol no terço médio e esquema representativo. Notar as duas regiões: placenta principal (PI) e subplacenta (S) em íntimo contato com a decídua (d). Atravessando a placenta principal encontra-se um vaso (seta) proveniente do funículo umbilical (FU) 

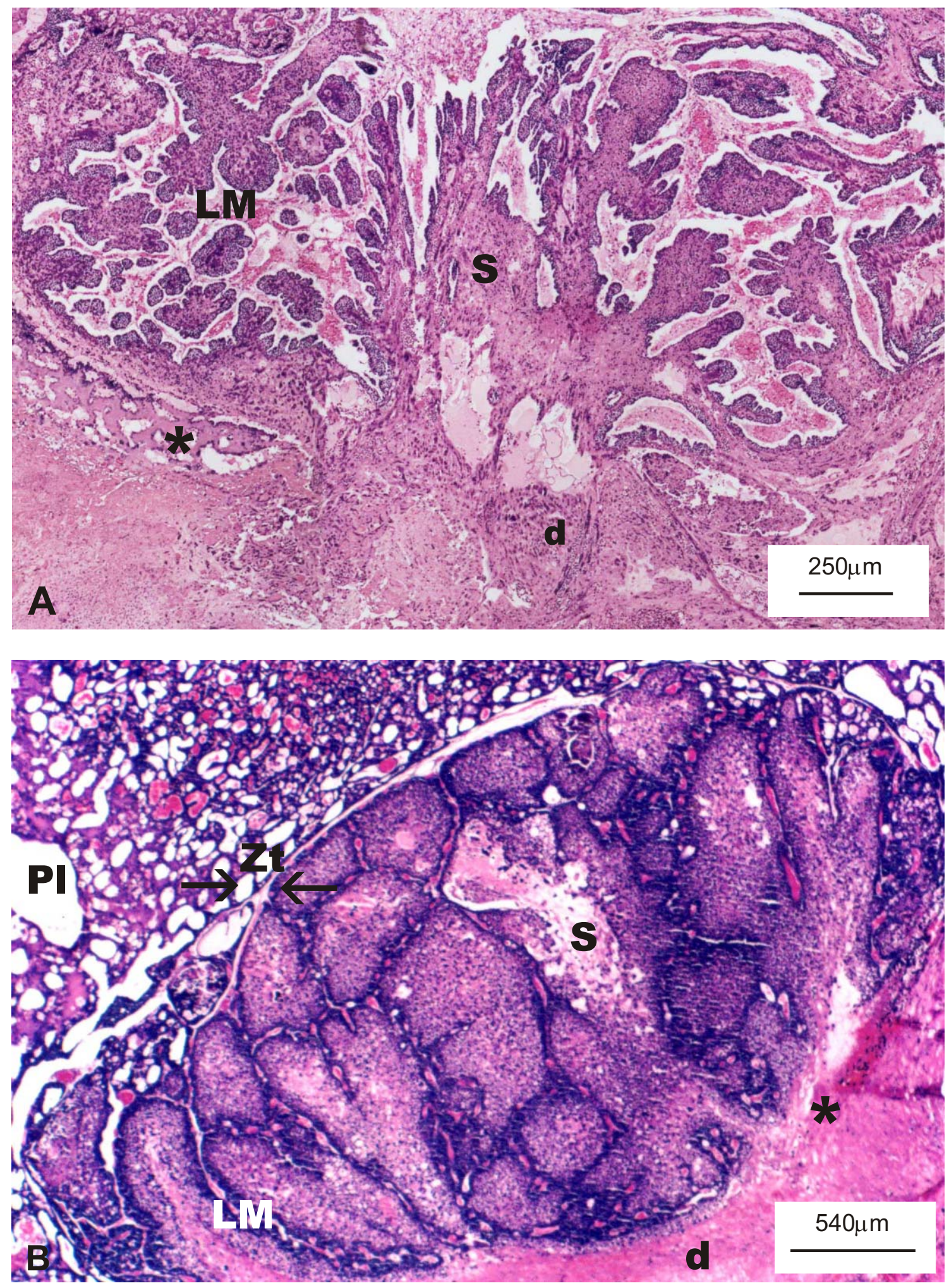

Figura 2 Fotomicrografia da subplacenta da cutia em início A) e terço médio de gestação B). Notar o íntimo contato da decídua (d) com a subplacenta (S) resultando em áreas com tecido amorfo (*). As lamelas (LM) desenvolvem-se e modificam seu arranjo. Entre a placenta principal, $(\mathrm{PI})$ e a subplacenta $(\mathrm{S})$ observa-se à zona transicional (Zt). Parafina, H.E 
Figura 3 - Fotomicrografia da subplacenta da cutia (Dasyprocta leporina). A) Zona transicional (Zt), no terço médio de gestação, notar a presença de um tecido mesenquimal fetal que separa as duas regiões e que penetra entre as lamelas (LM) da subplacenta (S) e a distinta histoarquitetura entre a placenta (PI) e a subplacenta (S). B) Detalhe da zona transicional ( $\mathrm{Zt}$ ), observar o tecido mesenquimal fetal evidenciando a presença de vaso $(v)$ entre a placenta e subplacenta. C) Região em que o tecido endometrial comprometido (*) apresenta vasos sanguíneos (V) destituído de revestimento endotelial e substituídas por células trofoblásticas $(\Leftrightarrow)$. Parafina, H.E. 


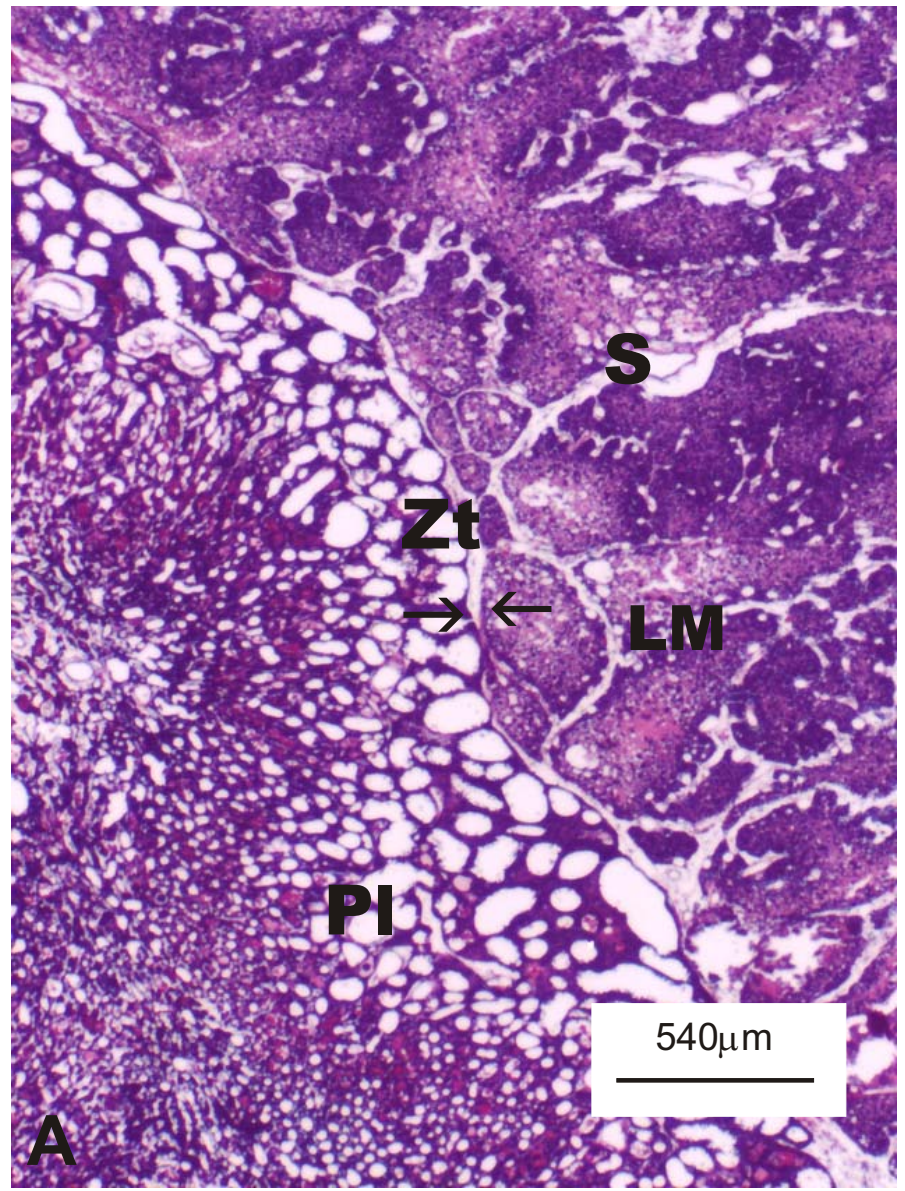

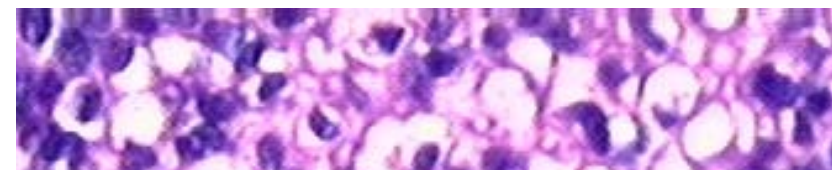

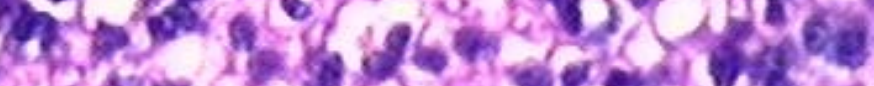

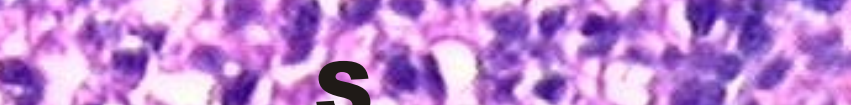
- a

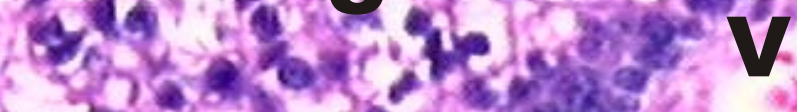

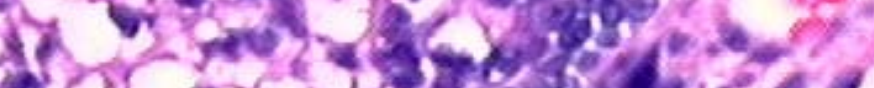

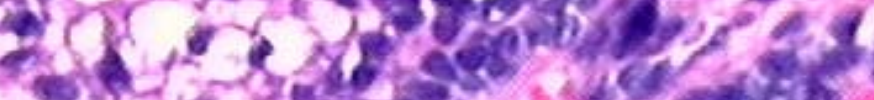

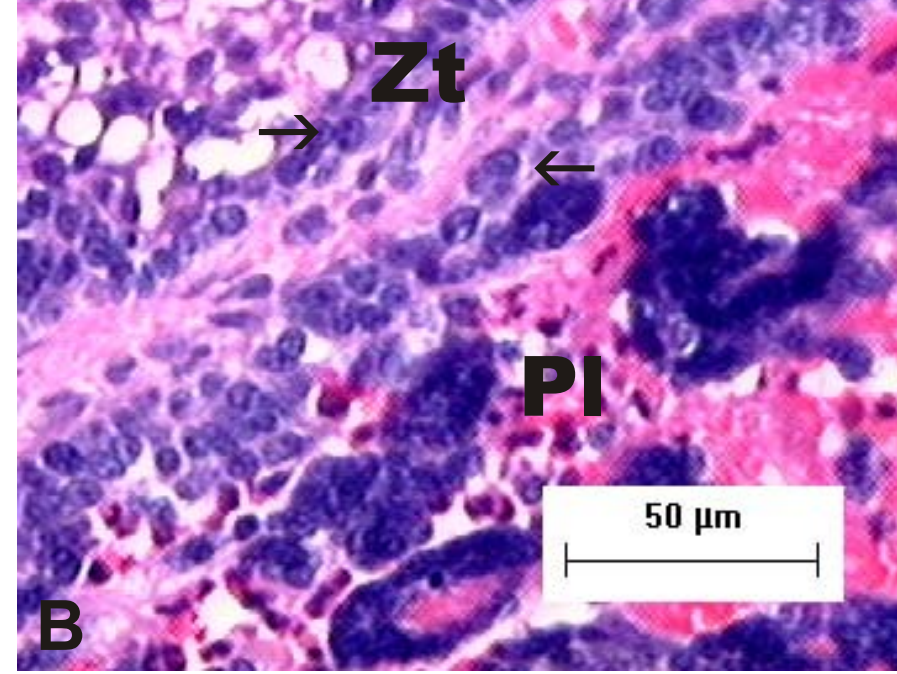
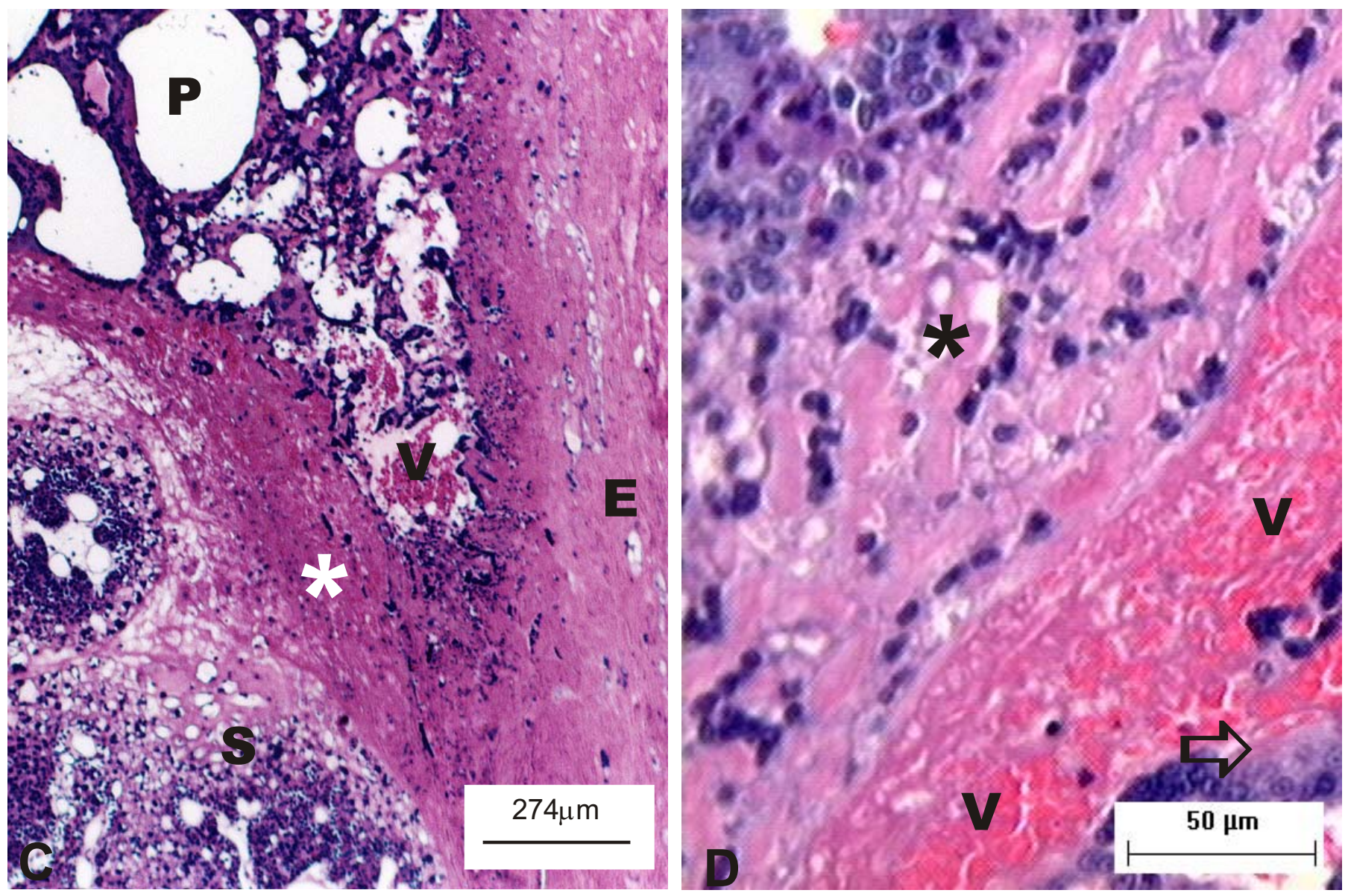
Figura 4 - Fotomicrografia da subplacenta da cutia (Dasyprocta leporina). A) Organização lamelar da subplacenta, com o eixo constituído de tecido conjuntivo mesenquimal (M) de origem fetal e pequenos vasos (V). Neste eixo apóia-se um arranjo epitelial de células citotrofoblásticas (Ct) que continua com o sinciciotrofoblasto (St). B) Detalhe de uma lamela com o seu eixo mesenquimal $(M)$ e capilares $(V)$. Os citotrofoblastos apóiam-se no tecido mesenquimal em arranjo epitelial contínuo e mais externamente os sinciciotrofoblastos. Parafina, H.E. C-D) Reação PAS positiva no sinciciotrofoblasto (St) e negativa para o citotrofoblasto (Ct), sem tratamento C) e com D) amilase, mostrando ligeiramente redução de intensidade. Parafina, PAS. 

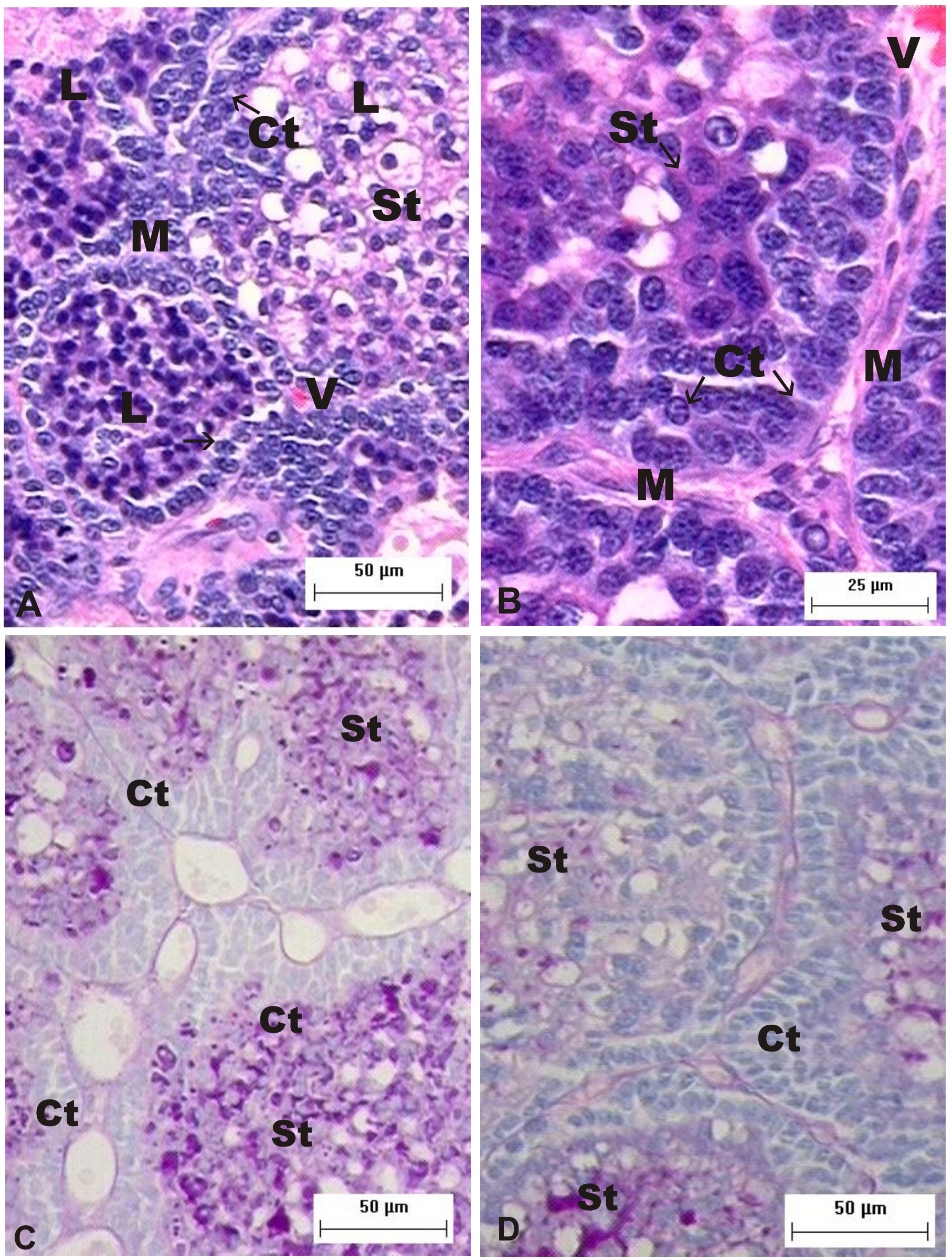
Figura 5 - A) Fotomicrografia das células trofoblásticas gigante (G) na subplacenta da cutia (Dasyprocta leporina) próximo a vasos sangüíneos materno $(V)$ e a interposição de uma camada de tecido endometrial amorfo $(\star)$ entre as células gigantes. B) tecido amorfo (*) que entremeiam as células trofoblásticas gigantes $(G)$ localizadas no perímetro da subplacenta (S) apresenta reação positiva ao PAS mesmo após tratamento enzimático pela amilase. C) reação imunoperoxidase para citoqueratina, reação positiva presente nas células trofoblásticas gigantes (G). D) massa sincicial (St) que apresenta fraca reação positiva ao Alcian Blue e negativa para o citotrofoblasto. Parafina, A) H.E.; B) PAS; C) Citoqueratina. 

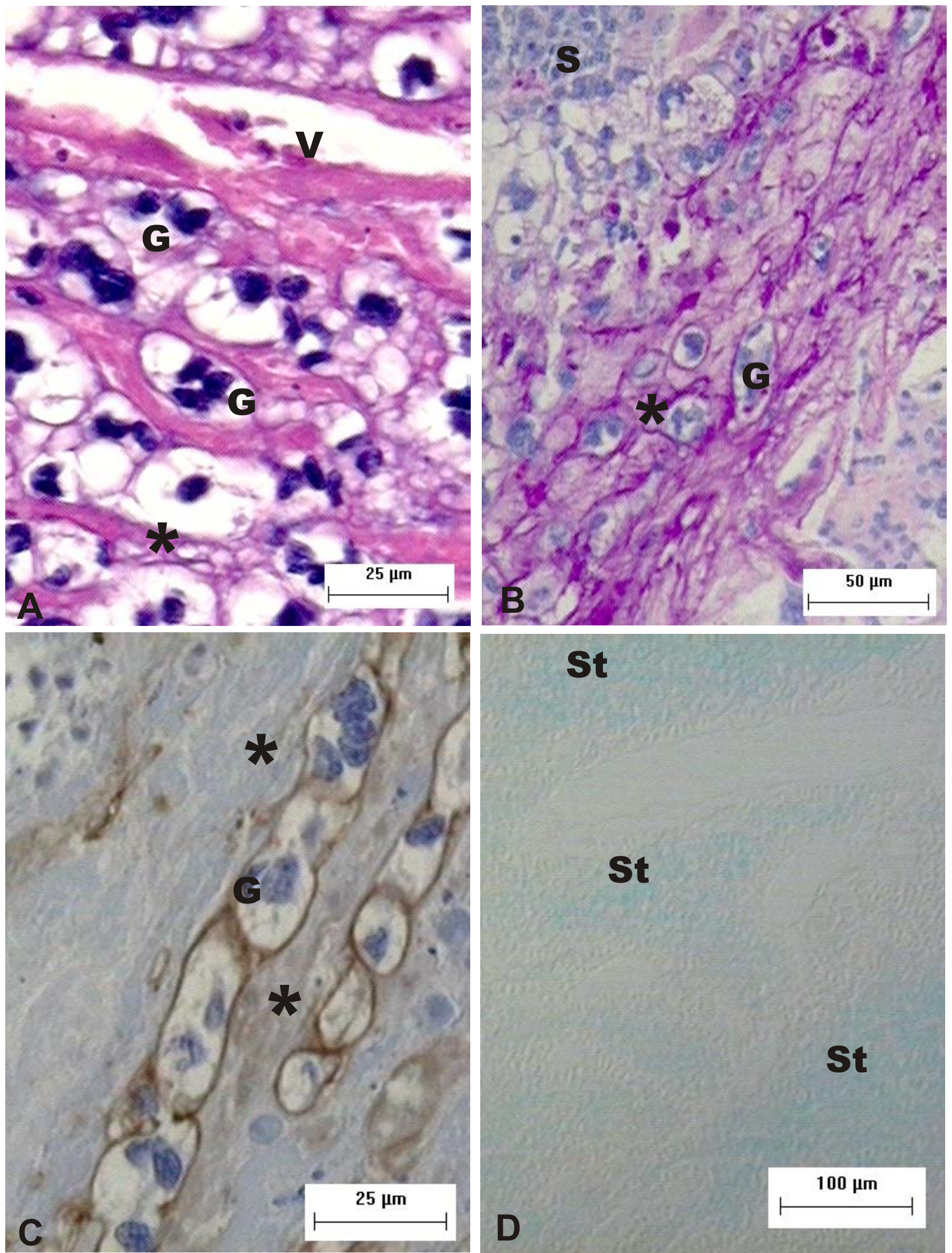

St

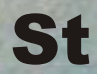

St 
Figura 6 - Fotomicrografias das reações de imunoperoxidase para citoqueratina e vimentina na subplacenta no terço médio de gestação. A) Detalhe da reação positiva para citoqueratina presente no citotrofoblasto $(C t)$ e no sincício trofoblasto (St). B) No mesênquima fetal $(M)$ a reação é negativa para citoqueratina enquanto no citotrofoblasto (Ct) e no sincício trofoblasto (St) a reação é positiva. C) Na parede dos vasos sanguíneos maternos (V), encontrados no endométrio próximo a região da subplacenta, a reação é negativa para vimentina. Observar a reação positiva nos vasos presentes no mesênquima das lamelas da subplacenta. D) Notar a reação positiva para vimentina nos vasos fetais (Vf) encontrados no interior das lamelas da subplacenta 

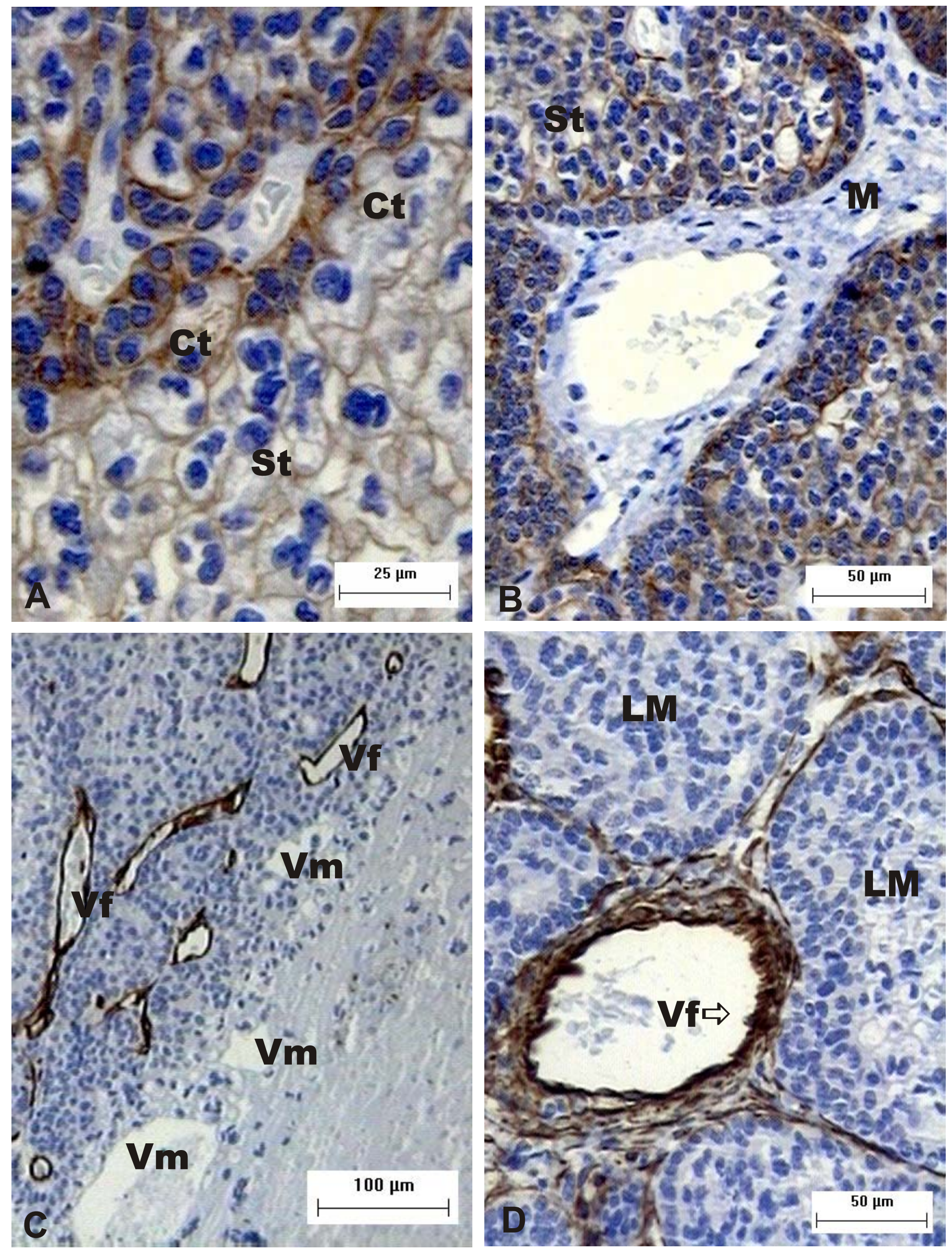


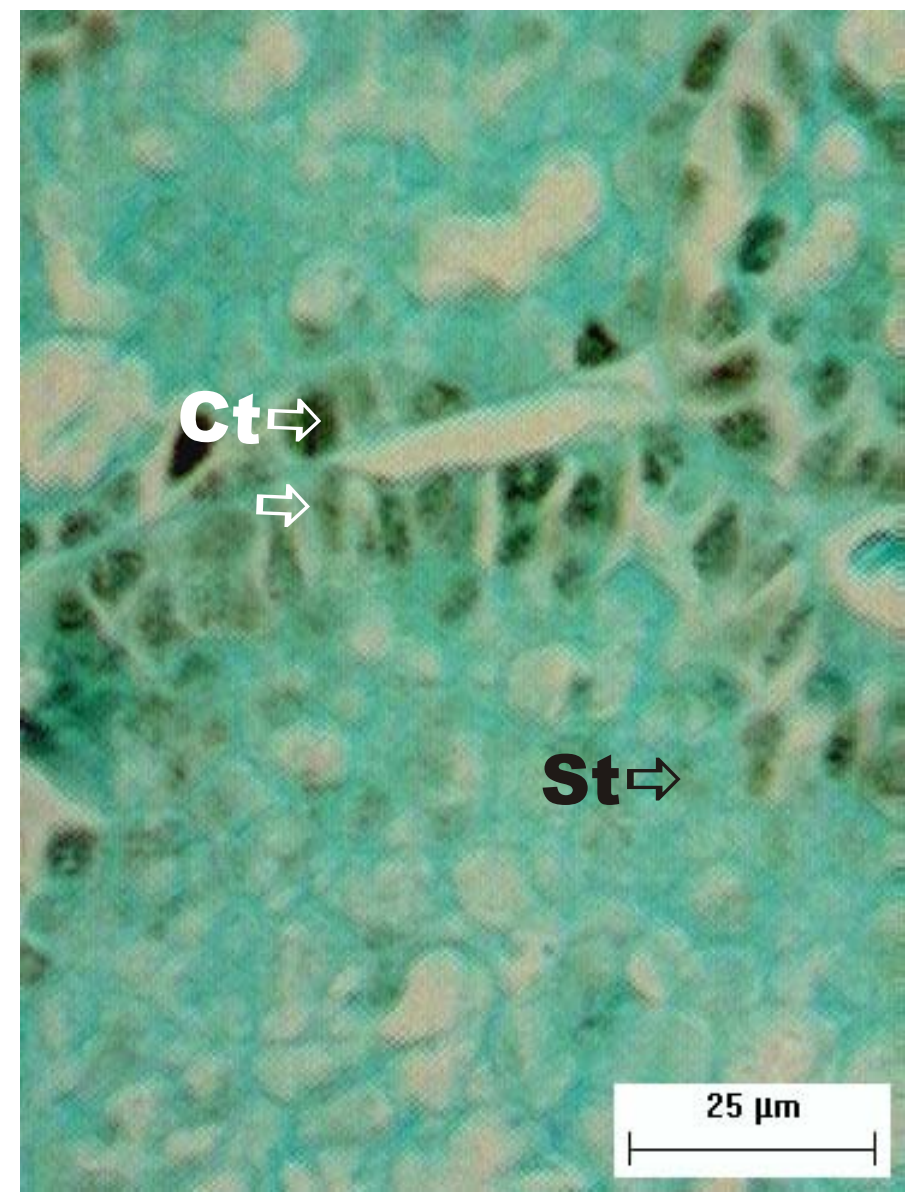

Figura 7 Fotomicrografia da subplacenta de cutia, no terço final de gestação, observar a reação positiva nos núcleos das células do citotrofoblasto $(\mathrm{Ct})$ das lamelas da subplacenta. Notar a marcação positiva ao PCNA de algumas células do sincícios (St). 
Figura 8 - A) Lamela (LM) constituída por um eixo de tecido mesenquimal fetal (M) com a presença de vasos (V). Nele apóia-se o citotrofoblasto (Ct) e mais externamente o sinciciotrofoblasto (St). Corte semi-fino. Azul de Toluidina. Eletromicrografias, B) Observar 0 aspecto do tecido conjuntivo mesenquimal (M) encontrado no eixo de uma lamela e camadas de células citotrofoblásticas (Ct) alinhadas em arranjo epitelial. Notar a presença dos espaços intersticiais formados entre os prolongamentos citoplasmáticos formados entre as células trofoblásticas que aparentemente não apresentam qualquer conteúdo. C) As células citotrofoblásticas (Ct) unem-se com as sinciciais (St) através das junções celulares $(\Rightarrow)$ e os espaços bem nítidos $(*)$. O citotrofoblasto (Ct) apresenta poucas mitocôndrias $(\mathrm{m})$ e retículo endoplasmático rugoso (re) incompleto, além de apresentar um único núcleo. D) Espaços dilatados formam-se entre as células do citotrofoblasto (Ct) através de seus prolongamentos citoplasmáticos. O sinciciotrofoblasto (St) pode ser distinguido do citotrofoblasto (Ct) pela presença de grande quantidade de microvilos na sua superfície e faz união com citotrofoblasto através de desmossomos $(\Longleftrightarrow)$. 


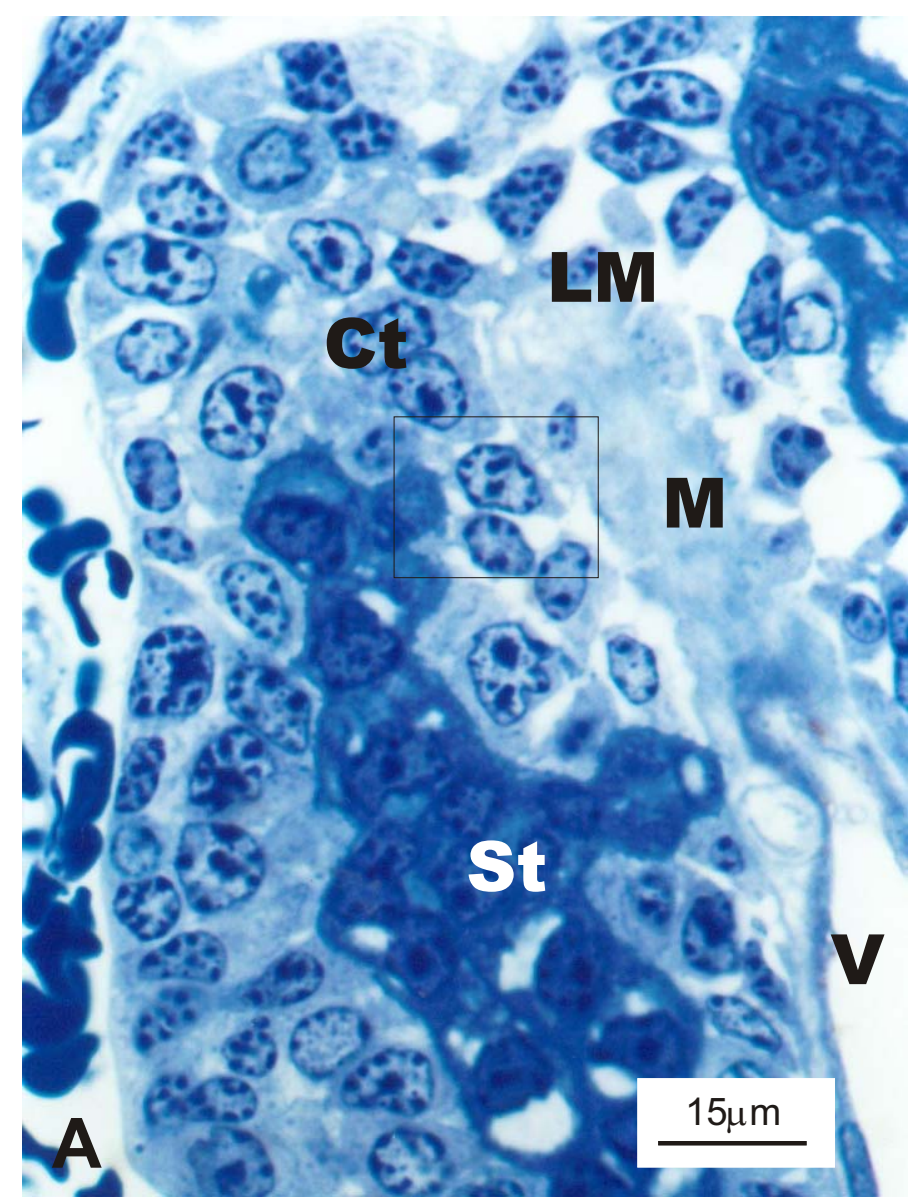

ar

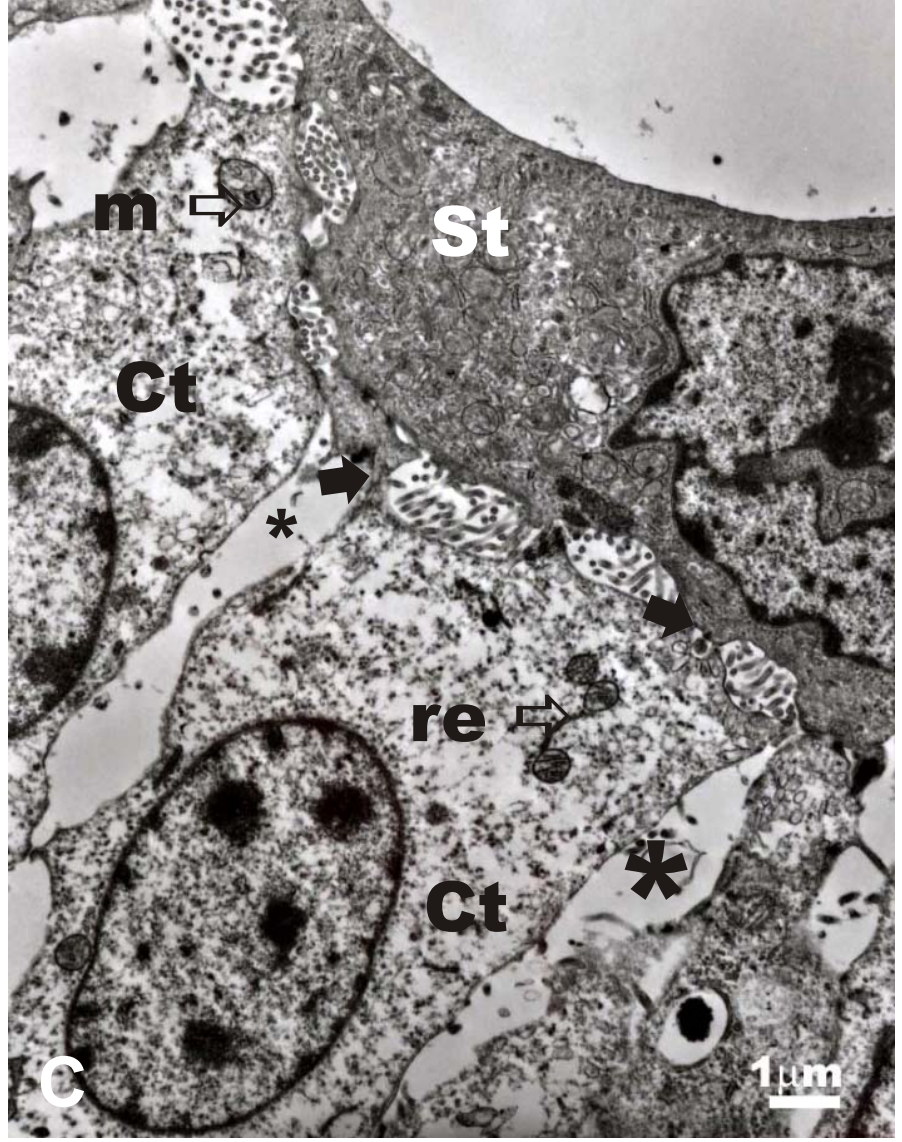

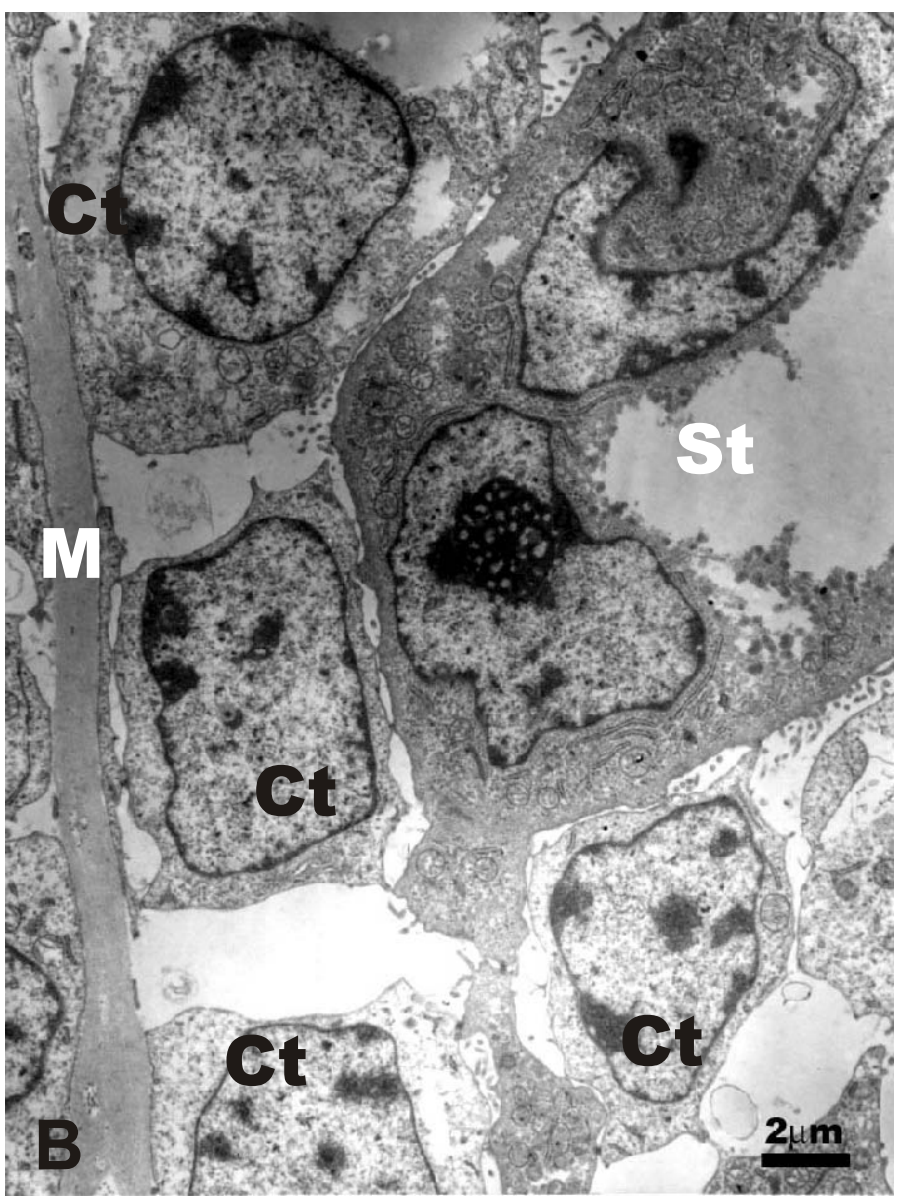
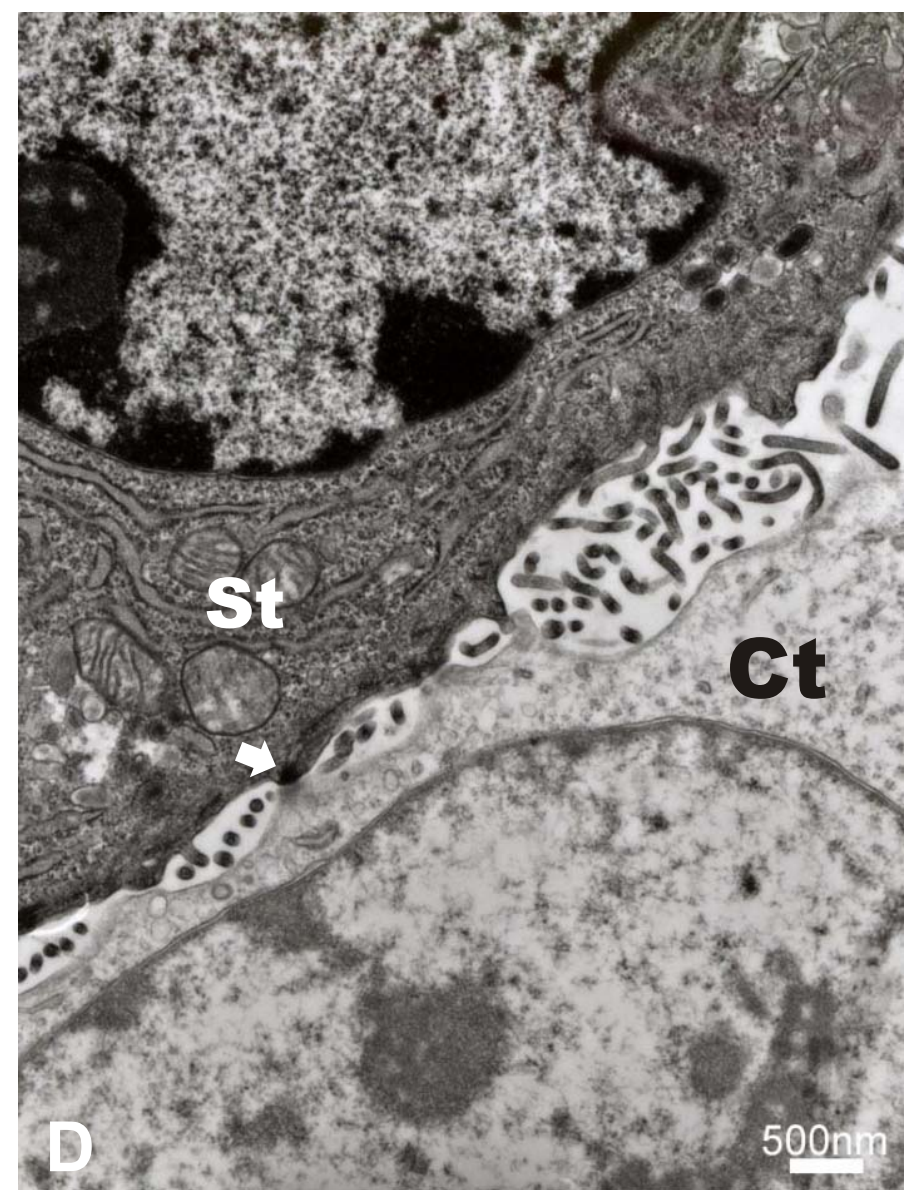
Figura 9 - Eletromicrografias da subplacenta de cutia. A) Lamelas no sinciciotrofoblasto (St), sem nenhum conteúdo, a presença dos múltiplos núcleos e ausência de limite do citoplasma nas células sincicias. B) As células sinciciais (St) encontradas centralmente nas lamelas da subplacenta apresentam múltiplos núcleos $(\mathrm{N})$, contendo nucléolo evidente, além de áreas de extração $(\triangle)$ do citoplasma ao lado de grandes lacunas (I). C) Observar em detalhe o citoplasma do sinciciotrofoblasto $(\mathrm{St})$, retículo endoplasmático rugoso (re), pequenos grânulos eletrodensos, núcleo $(\mathrm{N})$ irregular e microvilos na superfície. 

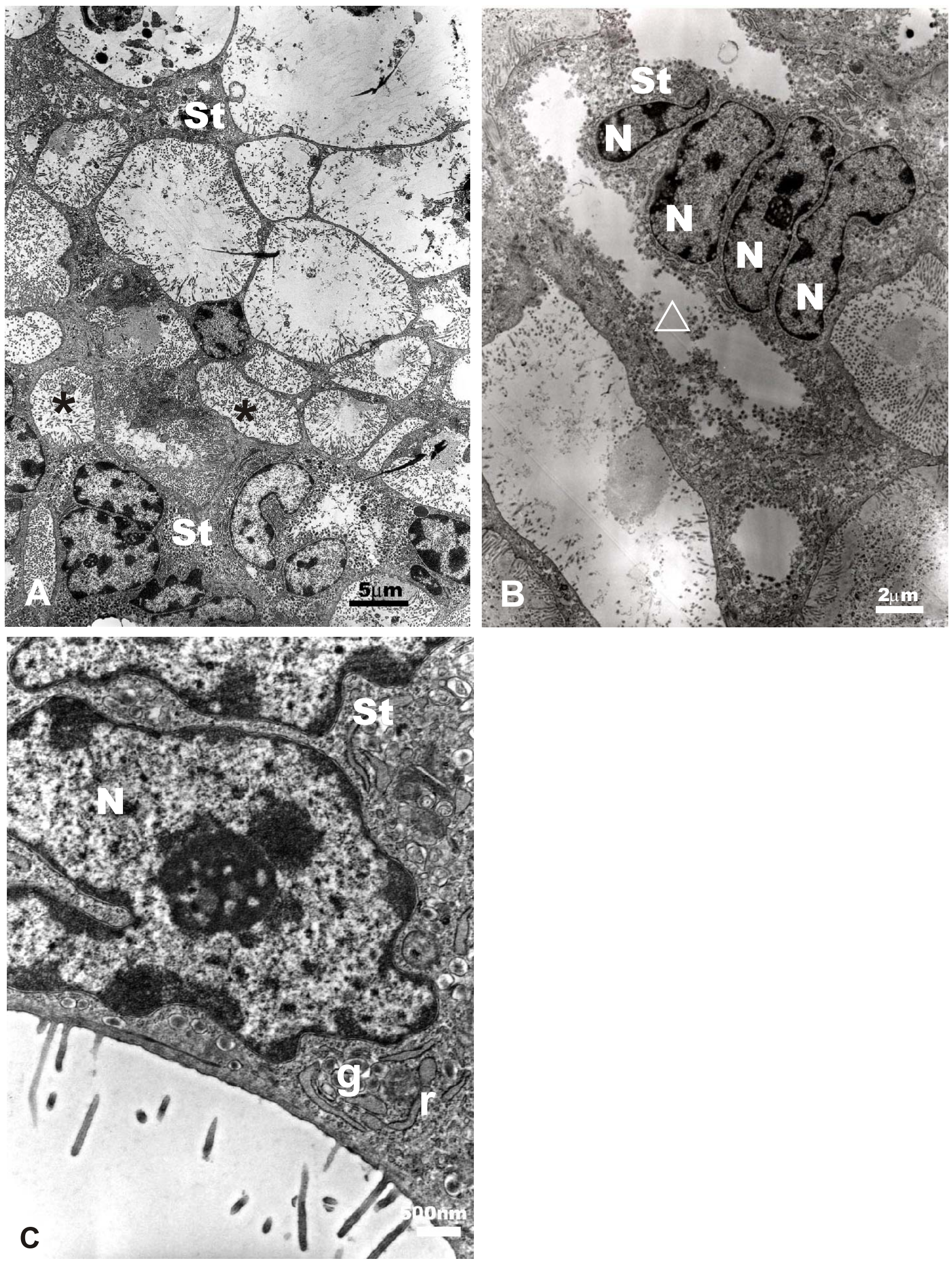

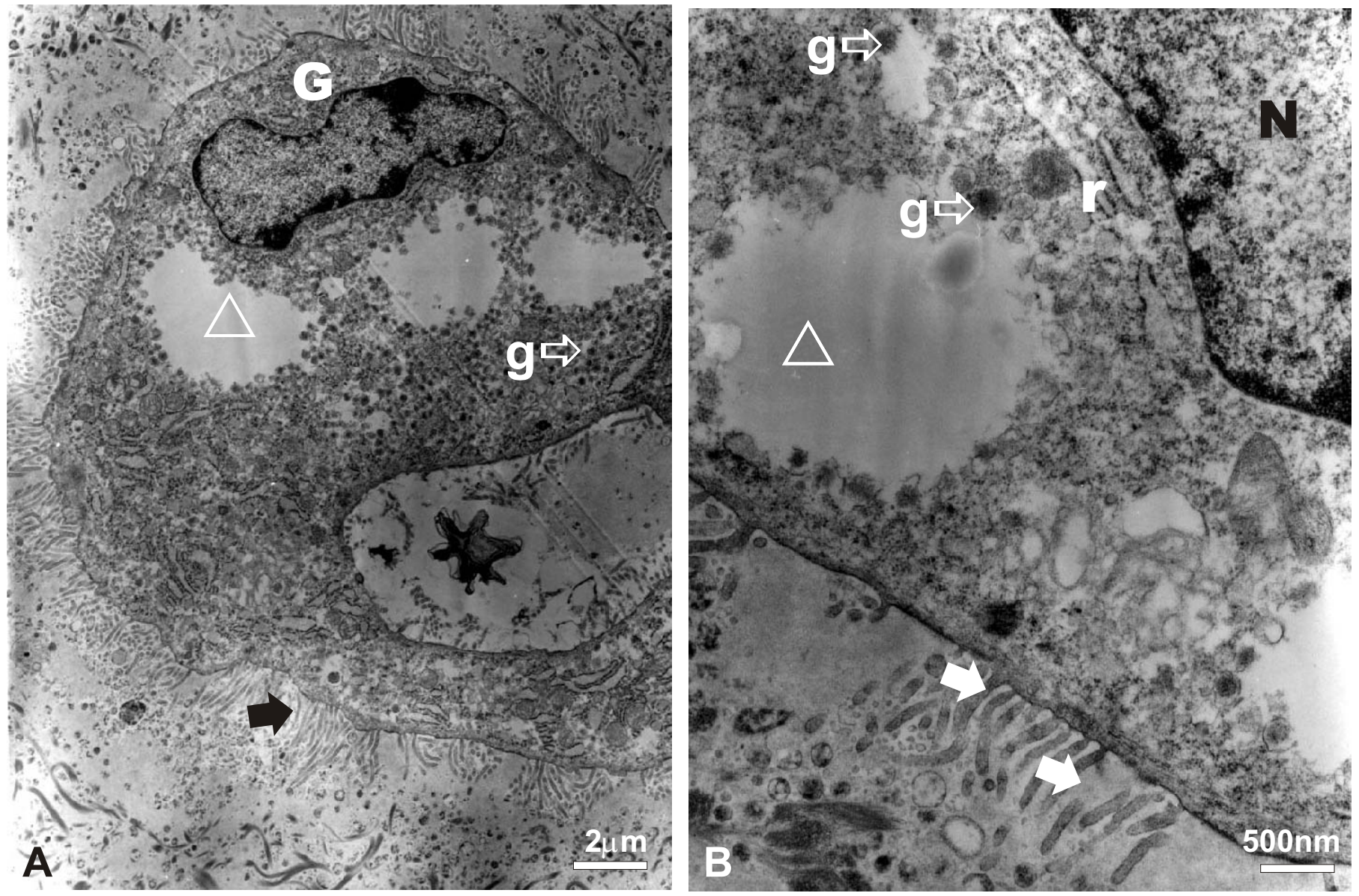

Figura 10 Eletromicrografias da subplacenta de cutia. A-B) células trofoblásticas gigantes apresentando áreas de extração citoplasmática (triângulo) grânulos eletrodensos $(\mathrm{g})$ e margens livres das células com microvilos (setas), reticulo endoplasmático rugoso ( $\mathrm{r}$ ) e núcleos $(\mathrm{N})$. 

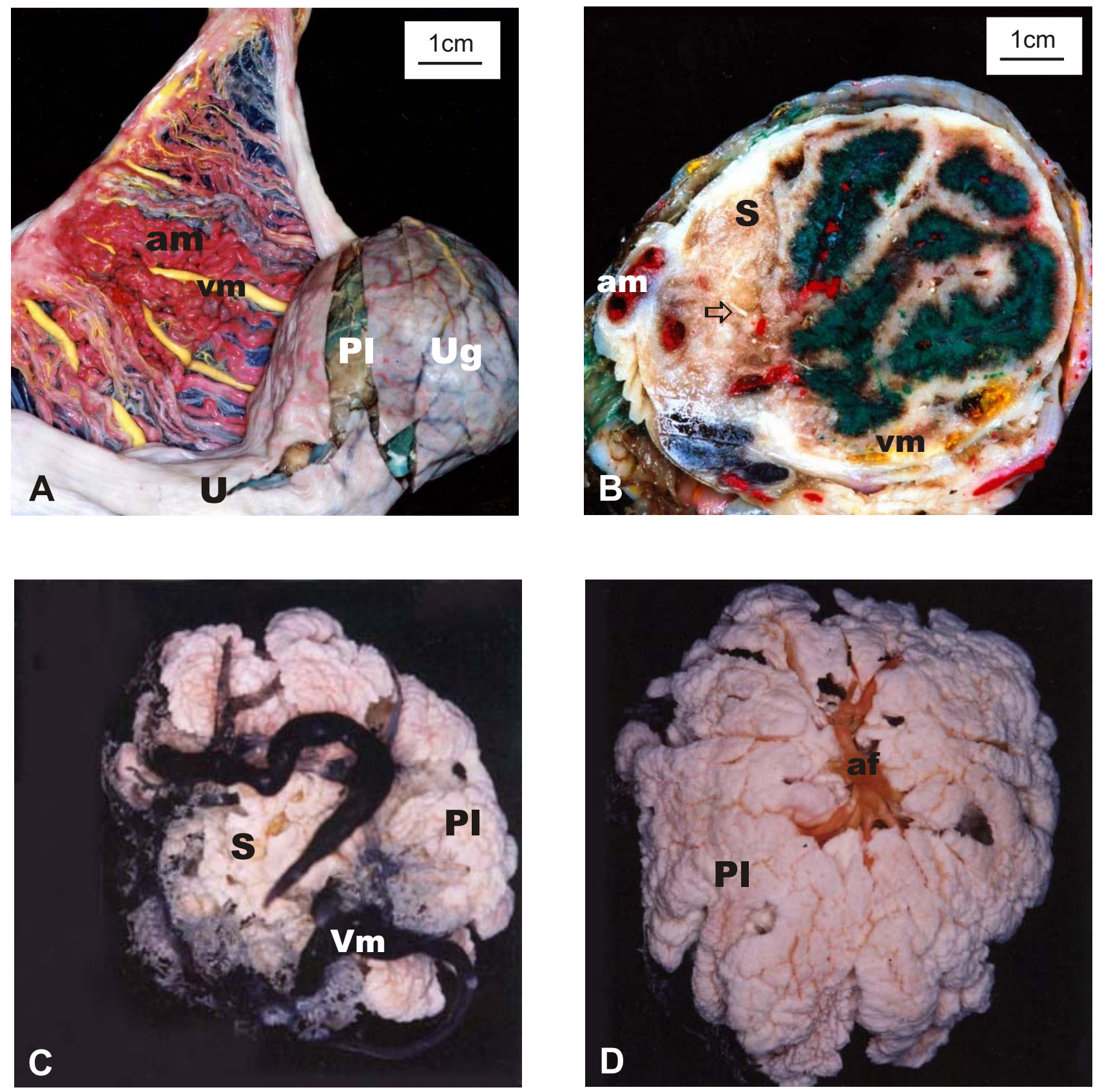

Figura 11 Fotografias da placenta de cutia após injeção por látex (A-B) e Mercox (C-D). A) As artérias maternas (am) estão em vermelho, as veias maternas (vm) em amarelo enquanto que a artéria fetal esta em branco, além de identificarmos a placenta $(\mathrm{PI})$ no útero gravídico $(\mathrm{Ug})$ e o útero não prenhe $(\mathrm{U})$. B) Em corte sagital mediano notar a vascularização da subplacenta (Sp), no terço médio de gestação, irrigada pelas as artérias fetais (seta), que estão em branco, enquanto que as artérias maternas (am), em vermelho, situam na região decidual. C) As veias maternas (vm) estão coradas em azul, e formam um anel em torno da subplacenta denominado "anel venoso". Observar que a subplacenta não é vascularizada pelos vasos maternos ( $\mathrm{vm})$ e sim pela artéria fetal, em vermelho. D) A artéria fetal (af), corada em vermelho, irriga toda a placenta principal (PI) inclusive a subplacenta (S), observado na figura anterior 

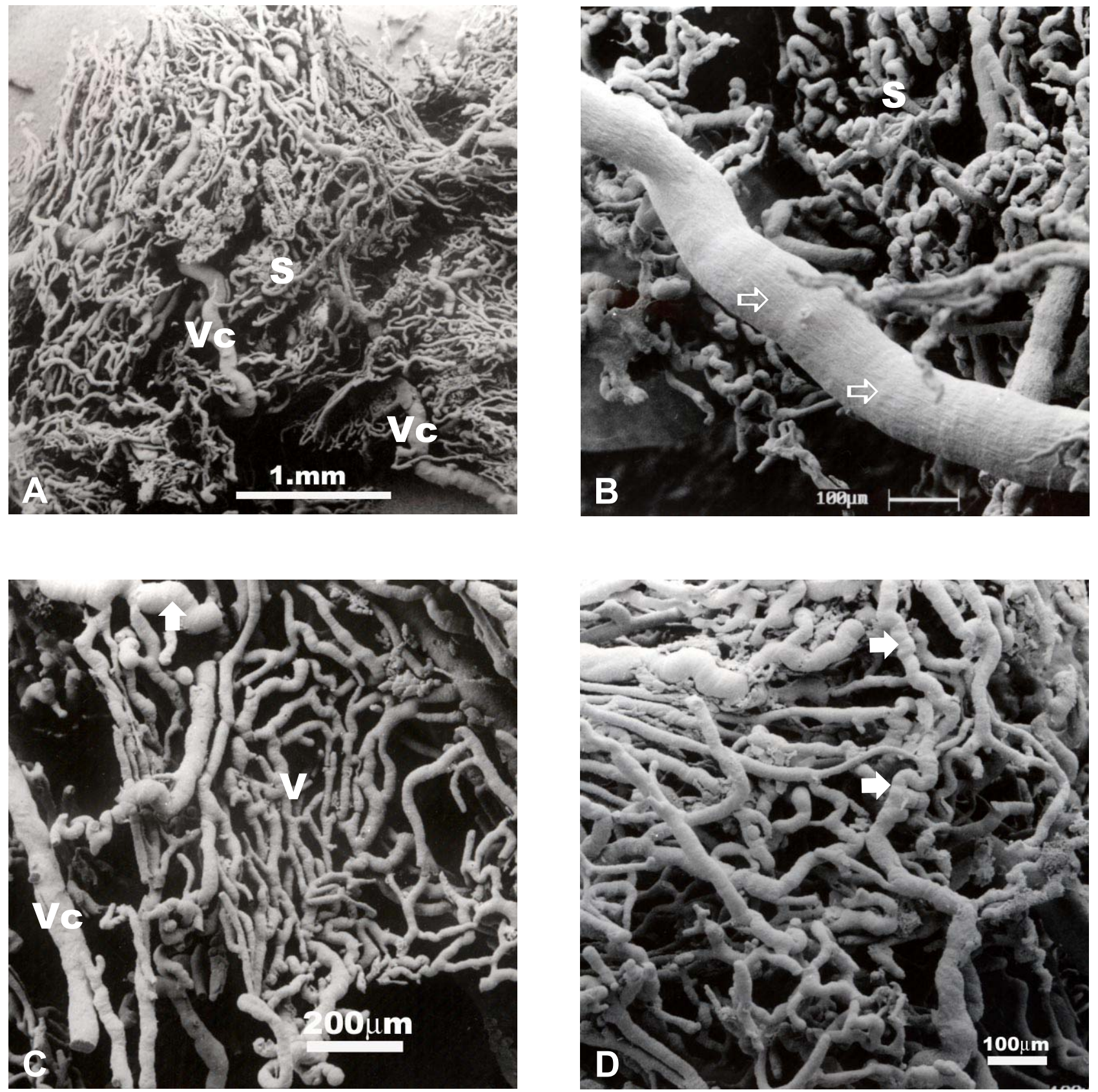

Figura 12 Eletromicrografias de varredura de molde vascular da placenta de cutia. A) Vista geral da rede vascular da subplacenta com a presença de vasos centrais (Vc) oriundos da placenta principal, que se ramificam. B) Observar a artéria fetal com a impressão negativa dos núcleos das células endoteliais delgadas e dispostas longitudinalmente (seta vazada) na subplacenta (S). C) Notar a rede vascular (V) que se forma a partir de um vaso central $(\mathrm{Vc})$ que se ramifica e observar vasos que apresentam na sua superfície luminal estrangulamentos (seta cheia). D) Detalhe dos vasos com seus trajetos tortuosos e de estrangulamentos (seta cheia) em suas superfícies. 


\section{DISCUSSÃO}

A subplacenta é uma estrutura encontrada principalmente em roedores da sub-ordem histricomorfos, como é o caso da cutia (Dasyprocta leporina). Nestes animais ela encontra-se inserida no endométrio, e em íntimo contato com a placenta principal durante as fases da gestação. Tal aspecto é evidente nos outros roedores histricomorfos (GROSSER, 1927 apud AMOROSO, 1952; MOSSANN, 1937) tais como a cobaia (DAVIES; DEMPSEY; AMOROSO 1961b; KAUFMANN; DAVIDOFF, 1977), o Octodon degus (BOSCO; DIAZ; BORAX, 1997), o mocó (OLIVEIRA, 2004; OLIVEIRA et al., 2005), a capivara (SOIRON, 1993) e a paca (BONATELLI, 2005). Somente Hillemann e Gaynor (1961) relatam que na nutria a subplacenta encontra-se junto aos lóbulos da placenta principal.

A histologia da subplacenta na cutia caracteriza-se como lamelar. Cada eixo das lamelas apresenta tecido conjuntivo mesenquimal, apoiado por camadas de citotrofoblasto e de sinciciotrofoblasto. Esta característica também é encontrada em outros roedores histricomorfos tais como: cobaia (DAVIES; DEMPSEY; AMOROSO, 1961b; KAUFMANN; DAVIDOFF, 1977), nutria (HILLEMANN; GAYNOR, 1961), rato de cana (ODUOR-OKELO; GOME, 1982), Octodon degus (BOSCO; DIAZ; BORAX, 1997), mocó (OLIVEIRA, 2004) e paca (BONATELLI, 2005). No terço médio de gestação, a subplacenta da cutia apresenta uma estratificação do citotrofoblasto bem definida, e sobre esta a de sinciotrofoblasto a qual, em alguns pontos, ainda apresenta um íntimo contado com o tecido em degeneração; observação também descrita na paca (BONATELLI, 2005). 
As células sinciciotrofoblásticas possuem vários núcleos. Tais características morfológicas não diferem daquelas relatadas no sinciciotrofoblasto das vilosidades coriônicas da placenta humana, ou das lamelas das placentas de outros roedores tais como: cobaia (KAUFMANN; DAVIDOFF, 1977), capivara (KAUFMANN, 2004), mocó (OLIVEIRA, 2004) e paca (BONATELLI, 2005).

Quando a cutia atinge o terço final de gestação, as áreas delimitadas pelo sinciciotrofoblasto das lamelas da subplacenta apresentam um material amorfo nitidamente acelular, PAS positivo e amilase resistente, observação também descrita por Bonatelli (2005) na paca. Este achado do sinciciotrofoblasto, deve ser resultante do resíduo da degeneração do tecido endometrial confinado entre as lamelas, como também acredita Bonatelli (2005). A presença deste material de aspecto e consistência similar também disposto na interface da subplacenta com a decídua sugere a expansão e o crescimento placentário, proporcionando o avanço da subplacenta para o interior da parede uterina, comprometendo o tecido endometrial, como sugere Bonatelli (2005).

As células trofoblásticas quando analisadas ultra-estruturalmente constituem as lamelas, apresentando em seu território células de características distintas. A camada de células que se apóia na lâmina basal, constitui-se tipicamente de células de arranjo epitelial com junções celulares do tipo desmossomas e adesivas. Estas unem várias células que estão dispostas em uma ou mais camadas. A união de uma célula a outra forma espaços intercelulares irregulares, cujo interior não apresenta nenhum tipo de material. Seu conteúdo citoplasmático é parecido aos descritos para o citotrofoblasto das lamelas de subplacenta de outros histricomorfos tais como a cobaia (DAVIES; DEMPSEY e AMOROSO, 1961b; WYNN, 1964), o castor (FISCHER, 1971), a chinchila (KING; TIBBITTS, 1976), o mocó (OLIVEIRA, 2004) e a paca (BONATELLI, 2005). 
Em geral, as células citotrofoblásticas têm sido apontadas como células indiferenciadas da placenta, com alto poder proliferativo, e fonte de outras células trofoblásticas em placentas de roedores como a capivara por Kaufmann (2004). No porco-espinho, Perrota (1959) sugere que a subplacenta seja uma região "germinal" do trofoblasto e do mesoderma alantóico, na qual novos lóbulos do labirinto se diferenciam, e são adicionados à placenta durante o crescimento. Tibbitts e Hillemann (1959) e Davies, Dempsey e Amoroso (1959) relatam que a subplacenta da chinchila e da cobaia respectivamente sejam formadas no início do desenvolvimento da placenta coriônica. Bonatelli (2005) sugere a possibilidade do citotrofoblasto contribuir para o crescimento e desenvolvimento tanto da subplacenta quanto da placenta principal da paca. Se o modelo dos histricomorfos é similar, tal inferência pode igualmente ser aplicada para a cutia.

O sinciciotrofoblasto, quando analisado ao microscópio eletrônico, revela ser multinucleado, com células unidas entre si e ao citotrofoblasto por junções celulares. Apresentam espaços intercelulares com variadas dimensões, e projeções citoplasmáticas do tipo microvilosidade em toda sua superfície. Isto permite diferenciá-las do citotrofoblasto que não apresenta esses microvilos. Os espaços intercelulares delimitados pelos sinciciotrofoblasto, encontrados nos terços médio e final da gestação, contêm materiais de eletrodensidade variável. No citoplasma das células são visualizadas pequenas vesículas com conteúdo eletrodenso, podendo ser estes grânulos lisossomais, que promovem a digestão intracelular. Essa observação foi também relatada por Oliveira (2004) e por Bonatelli (2005).

A reação positiva para o PAS, no interior das células sinciciais, após a digestão enzimática pela amilase, pode ser decorrente deste material fagocitado 
e parcialmente digerido, que também se confunde com os materiais degenerados retidos nos interstícios dos sinciciotrofoblastos. Mas, após o tratamento com a amilase, a reação PAS no citoplasma do sinciciotrofoblasto diminui, sugerindo a presença de longas cadeias de polissacarídeos neutros do tipo glicogênio. Por outro lado, a reatividade mantida após a amilase, comprova a existência de outras formas de glicoconjugados não susceptíveis a esta enzima. Alguns autores investigaram a presença de material PAS-positivo na subplacenta, tais como Roberts e Perry (1974) que analisaram a presença deste material em vários caviomorfos. Os autores sugerem a possibilidade da subplacenta estar envolvida no transporte de nutrientes, principalmente de substâncias de pesos moleculares elevados, tais como os polissacarídeos, da decídua para o feto. A subplacenta da cutia não tem estrutura especializada para o transporte dessas substâncias de forma eficaz.

Davies, Dempsey e Amoroso, (1961b) e King e Tibbitts (1976) acreditam que a subplacenta tenha células com potencial endócrino durante a gestação. Já Mess (2003) relata que este conteúdo amorfo retido entre as células sinciciais seja parte de seu produto de secreção, como, a produção de uma proteína ligante concentradora de progesterona. Os aspectos ultra-estruturais dessas células não indicam polarização que determine uma possível secreção. A interposição de duas ou mais camadas de citotrofoblasto entre o sincício e o leito vascular fetal, presente no eixo das lamelas, não condiz com a eficiência esperada de tecidos epiteliais, notadamente endócrinos, encontrados em outros órgãos.

Na cutia, neste material amorfo em degradação, foi constatado a presença de carboidratos ácidos (sulfatados e carboxilados), pela coloração de Alcian Blue $\mathrm{pH} 2,5$. Estes devem ser resíduos remanescentes dos componentes da matriz 
extracelular do estroma endometrial, resultado também encontrado por Bonatelli (2005) na subplacenta de paca.

Na subplacenta da cutia, a perfusão de látex Neoprene corado com cores distintas, mostra o trajeto dos vasos fetais e maternos. É notório que a subplacenta não receba drenagem direta do sangue materno, e sim de sangue fetal. Este resultado foi também observado em outros roedores (TAFANI, 1886 apud DAVIES et al., 1961b; WISLOCKI, 1921, apud DAVIES et al., 1961b), na nutria (HILLEMANN; GAYNOR, 1961), no mocó (OLIVEIRA, 2005), e na paca (BONATELLI, 2005). Foi também observado na análise comparativa entre os roedores realizados por Miglino et al., 2005. No castor (FISCHER, 1985) não se observou circulação materna eficiente e padrão de fluxo ativo nestas espécies. A maioria dos autores, acreditam que vasos maternos contornam a subplacenta indo em direção à placenta principal. Na placenta da cutia, a técnica de injeção de Mercox mostra um anel venoso disposto ao redor da subplacenta. A análise microvascular demonstra que a subplacenta é irrigada principalmente pelo sangue arterial proveniente de um vaso do funículo umbilical, que atravessa toda a placenta principal e insere-se na base da subplacenta. Ele ramifica-se em vasos com pequena luz que formam uma rede. Estas observações foram confirmadas nos preparados histológicos e nos de microscopia eletrônica. Ramos venosos de pequeno calibre e capilares dispõem-se em meio ao tecido mesenquimal, que preenche as lamelas. Estes resultados foram encontrados também por Miglino, et al. (2004) e por Bonatelli (2005).

A análise imunocitoquímica com anti-vimentina e anti-citoqueratina, atesta que os vasos sanguíneos localizados na subplacenta da cutia, apresentam revestimento endotelial íntegro, sem a presença de células trofoblásticas. Comprova ainda ser a vascularização intra-subplacentária realizada 
exclusivamente por vasos fetais. Estas características também foram encontradas em outros histricomorfos, tais como, cobaia (KAUFMANN; DAVIDOFF, 1977; WOLFER; KAUFMANN, 1980), paca (BONATELLI, 2005) e descritas em roedores sul-americanos (MIGLINO, et al. 2004). Como é fato que a subplacenta não recebe sangue arterial materno, ou apresente qualquer organização que lembre uma possível drenagem do tipo contracorrente entre o sangue materno e fetal, como aquela descrita por Miglino, et al. (2004) na placenta principal. Por sua vez, Bonatelli (2005) sugere que a nutrição e oxigenação das células da subplacenta ocorram exclusivamente através do sangue venoso oriundo do feto, e trazido pela artéria do funículo umbilical. A ocorrência da capilarização no interior da subplacenta é inegável, percorrendo junto ao eixo de tecido mesenquimal e a confluência desses capilares para vasos venosos. Bonatelli (2005) acredita que esses vasos venosos podem estar trazendo metabólitos e catabólitos, produtos da interação com as diversas células do interior da subplacenta que devem ser depurados e oxigenados antes de serem devolvidos ao feto, por meio do ramo venoso do funículo umbilical. $\mathrm{Na}$ cobaia, a vascularização da subplacenta ocorre através de uma artéria central que se capilariza na subplacenta e retorna em ramos de vasos venosos que confluem com os ramos venosos oriundos da placenta principal e direciona-se diretamente ao cordão umbilical (KAUFMANN, 2004). Bonatelli (2005) elucida que o destino do sangue venoso oriundo da subplacenta deva ser adequadamente oxigenado antes do retorno à circulação fetal.Todos esses relatos foram observados pelas diversas técnicas empregadas no presente trabalho. Pode-se perceber que há semelhança entre as espécies descritas acima e a cutia. Na paca a existência de ramos vasculares menores que percorrem perpendicularmente à região interface subplacenta/placenta, ao longo da base da 
subplacenta, possibilitaria a nosso ver, que estes ramos drenassem os capilares da subplacenta, e o direcionassem para os lóbulos da placenta principal. A existência desses vasos entre a subplacenta e a placenta principal, também foi descrita por (OLIVEIRA, 2004; OLIVEIRA et al., 2005). Dessa forma, o sangue oriundo da subplacenta, pode realizar as trocas metabólicas normais através da circulação contra-corrente, no labirinto da placenta principal, antes de retornar à circulação fetal (MIGLINO et al., 2004). Bonatelli, (2005) descreve esta, como uma circulação portal própria da placenta de histricomorfos, que desenvolvem uma estrutura subplacentária independente da placenta principal. A circulação portal da subplacenta torna-se atraente do ponto de vista funcional, fortalecendo a hipótese do controle fetal desta estrutura. Acredita-se que ocorra o mesmo na subplacenta de cutia.

A zona juncional da placenta da cutia, que une a placenta principal a subplacenta, é constituída de tecido mesenquimal de origem fetal. Ela pode ser encontrada também nos roedores histricomorfos tais como no Octodon degus (BOSCO; DIAZ; BORAX, 1997), na cobaia (AMOROSO, 1952; DAVIES; DEMPSEY; AMOROSO, 1961a; UHLENDORF; KAUFMANN, 1977; CARTER et al., 1998), na chinchila (KING; TIBBITTS, 1976) no rato (ODUOR-OKELO; GOMBE, 1982), no mocó (OLIVEIRA, 2004) e na paca (BONATELLI, 2005).

Na cutia, as células gigantes estão localizadas na região da interface subplacenta e decídua, localização descrita nos outros roedores: Octodon degus (BOSCO; DIAZ; BORAX, 1997), cobaia (AMOROSO, 1952; DAVIES; DEMPSEY; AMOROSO, 1961a; KAUFMANN, DAVIDOFF 1977; CARTER, et al. 1998), chinchila (KING; TIBBITTS, 1976), no coelho (DAVIES, 1956), rato (ODUOR-OKELO; GOMBE, 1982), mocó (OLIVEIRA, 2004) e paca (BONATELLI, 2005; BONATELLI, et al. 2005). Ao serem analisadas ao microscópio eletrônico estas apresentaram 
um citoplasma preenchido por diversas organelas, pequenas vesículas eletrodensas, e, em suas superfícies celulares inúmeras projeções do tipo microvilosidade. Além de serem multinucleadas, o citoplasma é vacuolizado, observações estas descritas na paca (BONATELLI, et al. 2005; BONATELLI, 2005) e no mocó (OLIVEIRA, 2004; OLIVEIRA, et al. 2005).

Na cutia, as células trofoblásticas gigantes apresentam material PASpositivos amilase-resistentes, semelhantes àqueles encontrados no interior dos espaços interlamelares da subplacenta. Isto denota o acometimento do tecido endometrial num processo de degeneração igual àquele encontrado junto a subplacenta, da paca (BONATELLI, et al. 2005) e do mocó (OLIVEIRA, et al. 2005).

Na região de interface subplacenta e parede uterina, os vasos sanguíneos são revestidos por células trofoblásticas gigantes e sinciciais, fato este também descrito por Bonatelli (2005). Nos animais de placentação hemocorial, que não apresentam o sinciciotrofoblasto, como ratos e camundongos, o papel invasivo é desempenhado pelas células trofoblásticas gigantes (BEVILACQUA; ABRAHAMSOHN, 1988). Na cutia tanto o sinciciotroblasto quanto às células trofoblásticas gigantes, desempenham funções invasivas.

Esse predomínio de ocupação da parede dos vasos arteriais maternos do endométrio pelas células trofoblásticas, sugere que elas assumem o controle do fluxo sangüíneo destinado à irrigação do labirinto placentário. Este por sua vez, é imprescindível para a nutrição do feto em desenvolvimento. Tal controle relacionado à vascularização materna é um fenômeno ímpar no ambiente uterino, permitindo futuramente estudos para a compreensão do mistério da interação materno-fetal durante a gestação destes animais. 


\section{CONCLUSÕES}

Os resultados obtidos neste trabalho permitem as seguintes conclusões:

1. Na cutia (Dasyprocta leporina), a subplacenta está inserida no endométrio, com íntima relação com a placenta principal. Sua interface maior ocorre com o tecido materno durante toda a gestação.

2. A subplacenta apresenta uma histoarquitetura lamelar, em que o eixo é composto por tecido mesenquimal fetal contendo vasos fetais. Sobre este se apóiam as camadas de cito e sinciciotrofoblastos.

3. As células trofoblásticas gigantes são encontradas nas faces laterais e apicais da subplacenta e a decídua. No interior das lamelas, as células sinciciais apresentam materiais amorfos PAS-positivos.

4. A subplacenta da cutia é vascularizada principalmente por vasos fetais. A integração da vascularização entre a subplacenta e a placenta principal sugere a ocorrência de uma circulação de controle fetal.

5. Ultra - estruturalmente a subplacenta apresenta duas populações de células: as células sinciciais e citotrofoblásticas.

6. A subplacenta apresenta células com potencial endócrino durante a gestação. O conteúdo amorfo retido entre as células sinciciais sugere que estes possam fazer parte de seu produto de secreção. 


\section{REFERÊNCIAS}

AMOROSO, E. C. Placentation. In: PARKERS, A. S. Marshall's physiology of reproduction. 3. ed. Londres: Longmans, 1952, v.2, p.128, 272-274.

BEVILACQUA, E. M. A. F.; ABRAHANSOHN, P. A. Ultrastructure of trophoblast giant cell transformation during the invasive stage of implantation of the mouse embryo. Journal of Morphology, v.198, p.341-351, 1988.

BONATELLI, M. Subplacenta da paca (Agouti paca). 2005. 128f. Tese (Doutorado) - Faculdade de Medicina Veterinária e Zootecnia. Universidade de São Paulo. São Paulo. 2005.

BONATEШI, M.; CARTER, A. M.; MACHADO, M. R.;OLIVEIRA, M. F.; LMA, M. C.; MILGINO, M. A. Placentation in the paca (Agouti paca L.). Reproductive Biology and Endocrinology, v.3, 2005. Disponível em: http://www.pubmedcentral.nih.gov/articlerender.fcgi?tool= pubmed\&pubmedid=15737234. Acesso em: 2005

BONATELLI, M.; MACHADO, M.R.F.; CRUZ, C.; MIGLINO, M.A. Análise morfológica da placenta da paca (Agouti paca, Linnaeus, 1766): estudo ao microscópio de luz e à microscopia eletrônica de transmissão. Brazilian Journal Veterinária and Research Animal Science, v. 38, n. 5, p. 224-228, 2001.

BOSCO, C.; DIAZ, S.V.; BORAX, J. Sincíciotrofoblasto em placenta de termino de Octodon degus. Estúdio ultramicroscópico de transmision y barrido. Revista Chilena de Obstetricia y Ginecologia, v. 62, n. 4, p. 249-256, 1997.

CARTER, A.M.; TANSWELL, B.; THOMPSON, K.; HAN, K.M. Immunohistoquimical identification of epithelial and mesenchymal cell types in the chorioallantoic and yolk sac placentae of the guinea-pig. Placenta, v. 19, p. 489-500, 1998.

DAVIES, J. Histochemistry of the rabbit placenta. Journal of Anatomy, v. 90, n. 1 , p. 135-142, 1956.

DAVIES, J.; DEMPSEY, E. W.; AMOROSO, E. C. The subplacenta of the guinea pig: an electron microscopy study. Journal of Anatomy, v. 95, n. 4, p. 311324, 1961a. 
DAVIES, J.; DEMPSEY, E. W.; AMOROSO, E. C. The subplacenta of the guinea pig: development, histology and histochemistry. Journal of Anatomy, v. 95, n. 4, p. 457-473, 1961b.

FISCHER, T.V. Placentation in the American beaver (Castor canadensis). American Journal of Anatomy, v. 131, n. 2, p. 159-184, 1971.

FISCHER, T.V. The subplacenta of the beaver (Castor canadensis). Placenta, v. 6, n. 4, p. 311-321, 1985.

FISCHER, T.V.; FLOYD, A.D. Placental developmente the mogolian gerbi (Meriones unguiculatus). II From the establishment of the labyrinth to trm. American Journal of Anatomy, v. 134, n. 3, p. 321-336, 1972.

HILLEMANN, H.H.; GAYNOR, A. I. The definitive architecture of the placenta of nutria, Myocastor coypus (MOLINA). The American Journal of Anatomy, v. 109, p. 299-317, 1961.

KAUFMANN, P. Capybara - Hydrochoeris hydrochoeris. In: BENIRSCHKE, K. Comparative Placentation. 2004. Disponível em: http://medicine.ucsd.edu/cpa/ capyfs.htm. Acesso em 05 nov.2004.

KAUFMANN, P.; DAVIDOFF, M.: The guinea-pig placenta. Advances in Anatomy Embryology Cell Biology, v. 53, n. 2, p. 5-90, 1977.

KING, B.F. Comparative anatomy of the placental barrier. Biblthca. anat., v. 22, p. 13-28, 1982.

KING, B.F.; TIBBITTS, F.D. The fine structure of the chinchilla placenta. The American Journal of Anatomy, v. 145, p. 33-56, 1976.

MESS, A. Evolutionary transformations of chorioallantoic placental characters in rodentia with special reference to hystricognath species. Journal of Experimental Zoology. Part A, Comparative Experimental Biology, v. 299, n. 1, p. 78-98, 2003.

MIGLINO M. A.; CARTER A. M.; AMBROSIO C. E.; BONATELLI M.; OLIVEIRA M. F.; SANTOS FERRAZ R. H.; RODRIGUES R. F.; SANTOS, T. C. Vascular organization of the hystricomorph placenta: a comparative study in the agouti, capybara, guinea pig, paca and rock cavy. Placenta, v. 25, p. 438-448, 2004. 
MIGLINO, M. A., CARTER, A. M., SANTOS FERRAZ, R. H., FERNANDES MACHADO, M.R. Placentation in the capybara (Hydrochaerus hydrochaeris), agouti (Dasyprocta aguti) and paca (Agouti paca). Placenta, v. 23, p. 416-428, 2002.

MOSSMAN, H. W. Comparative morphogenesis of fetal membranes and accessory uterine strutures. Contr. Embryol. Carneg. Inst., v. 26, p. 129-246, 1937.

ODUOR-OKELO, D. An electron microscopic study of the chorio-allantoic placenta and the subplacenta of the cane rat (Thryonomys swinderianus Temminck). Placenta, v. 5, p. 433-442, 1984.

ODUOR-OKELO, D.; GOMBE, S. Placentation in the cane rat (Thryonomys swinderianus). African Journal of Ecology, v. 20, p. 49-66, 1982.

OLIVEIRA, F. S.;TONIOLLO, G. H.; MACHADO, M. R. F.; Hemiovariossalpingohisterectomia em pacas prenhes e posterior ocorrência de prenhez (Agouti paca, Linnaeus, 1766). Ciências Rural, v. 33, n. 3, p. 547-551, 2003.

OLIVEIRA, M. F. Placentação em mocós, Kerodon rupestris, Wied 1820. 2004. 208 f. Tese (Doutorado) - Faculdade de Medicina Veterinária e Zootecnia. Universidade de São Paulo. São Paulo.2004.

OLIVEIRA, M.F.; CARTER, A.M.; BONATELLI, M.; AMOROSO, C.E.; MIGLINO, M.A. Placentation in the rock cavy, Kerodon rupestris (Wied). Placenta, 2005. (In Press).

PERROTTA, C. A. Fetal membranes of the canadian porcupine (Erithizon dorsatum). The American Journal of Anatomy, v. 104, p. 35-59, 1959.

ROBERTS, C. M.; PERRY, J. S. Hystricomorph embryology. Symposia Zoological Society London, v. 34, p. 333-360, 1974.

RODRIGUES, R. F.; MIGLINO, M. A.; FERRAZ, R. H. S. Placentação em cutias (Dasyprocta aguti, CARLETON, M.D.1984): aspectos morfológicos. Brazilian Journal of Veterinary Research and Animal Science, v. 40, p. 133-137, 2003.

SOIRON, M. L. Das Südamerikanische wasserschwein (Hydrochoerus hydrochaeris, L. 1766). Physiologisch-anatomische und klinische untersuchungen unter dem aspect der versuchstierkundlichen eignung. Aachen, Giessen, 1993. 133 f. Tese (Doutorado) - Fachbereich Veterinärmedizin, JustusLiebig-Universität Gießen. 
TIBBITTS, F. D.; HILLEMANN, H. H. The development and histology of the chinchilla placentae. Journal of Morphology, v. 105, p. 317-365, 1959.

UHLENDORF, B.; KAUFMANN, P. Die entwicklung des plazentastieles beim meerschweinchen. Zbl. Vet. Med. C. Anat. Histol. Embryol., v. 8, p. 15681594, 1962.

WOLFER, J.; KAUFMANN, P. Die Ultrastruktur der Meerschweinchen-Subplazenta. Zbl. Vet. Med. C. Anat. Histol. Embryol., v. 9, p. 29-43, 1980.

WYNN, R. M. Ultrastructure of the deciduotrophoblastic junction of the guinea pig. Am. J. Obste. \& Gynic., v. 1, p. 690-693, 1964. 


\title{
Vascular Organization of the Hystricomorph Placenta: a Comparative Study in the Agouti, Capybara, Guinea Pig, Paca and Rock Cavy
}

\author{
M. A. Miglino ${ }^{a}$, A. M. Carter ${ }^{\text {b, }}$, C. E. Ambrosioc ${ }^{\text {, M. Bonatellid }}{ }^{\text {, M. F. De Oliveira }}{ }^{\text {, R. H. Dos Santos }}$ \\ Ferraz $^{f}$, R. F. Rodrigues ${ }^{a}$ and T. C. Santos ${ }^{a}$ \\ a Department of Surgery, School of Veterinary Medicine, University of São Paulo, São Paulo, Brazil; ${ }^{b}$ Department of \\ Physiology and Pharmacology, University of Southern Denmark, Winsloewparken 21, Third Floor, DK-5000 Odense, \\ Denmark; ' ${ }^{c}$ Otavio Bastos Foundation, São João da Boa Vista, São Paulo, Brazil; ${ }^{d}$ Paulista State University, Jaboticabal, \\ São Paulo, Brazil; ${ }^{e}$ Mossoró Superior School of Agriculture, Rio Grande do Norte, Brazil; ${ }^{\dagger}$ Paulista State University, \\ Araçatuba, São Paulo, Brazil
}

Paper accepted 6 November 2003

\begin{abstract}
The placental vasculature of five hystricomorph rodents was examined by latex injection of the blood vessels, immunohistochemistry and scanning electron microscopy of vessel casts. The pattern of branching of the vessels is described at the level of fine structure. The placenta is divided into lobes separated by interlobular trophoblast. Fetal arteries course through the interlobular areas and give rise to capillaries from which blood drains into veins at the centre of the lobes. Maternal blood reaches the placenta through spiral arteries that pass around the perimeter of the subplacenta. They supply large maternal blood sinuses, lined by trophoblast, which run through the interlobular areas and into the centre of the lobes. Here they supply fine channels that run parallel to the fetal capillaries, so that maternal blood flows from the centre of the lobe to the periphery. This arrangement provides the morphological basis for countercurrent exchange. The maternal channels of the labyrinth drain into spaces formed by the latticework of the interlobular trophoblast and thence through venous lacunae to a basal venous lacunar ring. The subplacenta is supplied by a single fetal artery. The vessels within the subplacenta pursue a tortuous course with dilatations and constrictions as in an endocrine gland.
\end{abstract}

Placenta (2004), 25, 438-448

(C) 2003 Elsevier Ltd. All rights reserved.

\section{INTRODUCTION}

The hystricomorph rodents have a lobulate and haemomonochorial placenta with a characteristic subplacenta [1]. Until now the vascular organization of the placenta has been inferred largely from observations in the light microscope and interpretation of vascular casts at the macroscopical level. The most satisfactory of these descriptions is that given by Hilleman and Gaynor [2] for the nutria. They suggest that, in each lobe, maternal blood and fetal blood flow in opposite directions, allowing for countercurrent exchange. A similar interpretation has been given for the placentae of the guinea pig [3,4] and chinchilla [4]. However, alternative vascular arrangements have been suggested [5] and there are significant gaps in our knowledge of how the vessels reach the lobes and of the vascular supply of other structures, including the subplacenta.

To address these questions, we used three complementary techniques. Firstly, we made latex injections to verify the overall distribution of fetal and maternal vessels within the placenta and its accessory structures, including the uterine

\footnotetext{
* To whom correspondence should be addressed. Tel.: +45-65503716; Fax: +45-6613-3479; E-mail: acarter@health.sdu.dk
}

$0143-4004 / \$-$ see front matter wall. Secondly, we applied histology and immunohistochemistry to distinguish maternal and fetal vessels in tissue sections. Finally, we used scanning electron microscopy of vessel casts to identify the pattern of branching of the vessels at the level of fine structure. Together these enabled us to reconstruct the likely pattern of fetal and maternal blood flow in the hystricomorph placenta.

Our material comprised five South American rodents from three families. Details of reproduction in agouti, capybara and paca are given elsewhere [6]. A female rock cavy weighs $700-800 \mathrm{~g}$ and carries a litter of 1-2 young (usually one). Gestation lasts about 70 days and the newborn weigh around $90 \mathrm{~g}$. At term the placenta is $2.5 \mathrm{~cm}$ in diameter and weighs about $14 \mathrm{~g}$. The guinea pig is a close relative of the rock cavy and in the wild its reproduction is similar [7], but laboratory guinea pigs have been bred for larger litters.

\section{MATERIAL AND METHODS}

\section{Tissue collection}

The observations are based on material collected from 3 agoutis (Dasyprocta aguti), 4 capybaras (Hydrochaeris hydrochaeris), 4 guinea pigs (Cavia porcellus), 3 pacas (Agouti paca) 
and 5 rock cavies (Kerodon rupestris) between midgestation and term of pregnancy. Material was collected from the following breeding centres: Center for Experimental Breeding of Capybara, Paulista State University, Araçatuba, São Paulo; Center for Experimental Breeding of Paca, Paulista State University, Jaboticabal, São Paulo; Center for Experimental Breeding of Agouti, Federal University of Piaui, Teresina, Piaui; and Center for Breeding of Wild Animals, Mossoro. The guinea pig was a laboratory animal (Otavio Bastos Foundation, São João da Boa Vista, São Paulo, Brazil). The research was authorized by the Brazilian Institute of the Environment and Renewable Natural Resources (IBAMA).

Paca were sedated with azaperone (Stresnil; $0.1 \mathrm{mg} / \mathrm{kg}$ I.M.) and given atropine (0.5 mg I.M.). Anaesthesia was induced with xylazine (Coopazine, Coopers Brasil, São Paulo, S.P., Brazil; $1 \mathrm{mg} / \mathrm{kg}$ I.M.) and ketamine (Holliday Scott S.A., Brazil; $20 \mathrm{mg} / \mathrm{kg}$ I.M.). Hemihysterectomy was then performed under aseptic conditions during inhalation anaesthesia with halothane (Hoechst, Frankfurt, Germany). Postoperatively the animals were treated with benzyl penicillin and streptomycin (Pentabiotico ${ }^{\circledR}$, Fort Dodge, Campinas, S.P., Brazil; 8000-24 000 IU/kg I.M.) and an analgetic (metamizol, Dipirona).

Bilateral hysterectomy was performed in capybara and agouti. The animals were premedicated with acepromazine (Univet, São Paulo, S.P., Brazil; 0.1-1.0 mg/kg I.M.). Anaesthesia was induced with xylazine $\left(\right.$ Dorcipec $^{\circledR}$, Vallée S.A., Montes Claros, M.G., Brazil; 0.5-1.0 mg/kg) and ketamine (Cristália, Itapira, S.P., Brazil; 5-10 mg/kg I.M.) and continued with halothane (Hoechst, Frankfurt, Germany; 1 per cent) or enflurane (Etrane ${ }^{\circledR}$, Abbott, São Paulo, S.P., Brazil) in oxygen. Postoperative treatment included antibiotic coverage with benzyl penicillin and streptomycin (Pentabiotico ${ }^{\circledR}$, Fort Dodge, Campinas, S.P., Brazil; 8000-24 000 IU/kg I.M.) and analgesia as required with flunixin meglumine (Banamine ${ }^{\circledR}$, Schering-Plough, Rio de Janeiro, R.J., Brazil).

Rock cavies were premedicated with midazolam (Dormine, Cristália, Itapira, S.P., Brazil; $1 \mathrm{mg} / \mathrm{kg}$ ) and ketamine (Cristália, Itapira, S.P., Brazil; $15 \mathrm{mg} / \mathrm{kg}$ I.M.). Hemihysterectomy was then performed under aseptic conditions during inhalation anaesthesia with isoflurane (Cristália, Itapira, S.P., Brazil) in 100 per cent oxygen. Postoperative treatment included antibiotic coverage with amoxicillin (Bactrosina, Bayer, São Paulo, S.P., Brazil; 22 mg/kg).

Bilateral hysterectomy was performed in guinea pigs anaesthetized with a tiletamine/zolazepam mixture $(90 \mathrm{mg} / \mathrm{kg}$ of each I.M.; Zoletil 50; Virbac, São Paulo, S.P., Brazil).

\section{Histology and immunohistochemistry}

Tissues collected for histology and immunohistochemistry were immersion fixed in 4 per cent paraformaldehyde in $70 \mathrm{~mm}$ phosphate buffer for $48 \mathrm{~h}$, and then washed in cold, phosphate buffered $\mathrm{NaCl}$ solution for $72 \mathrm{~h}$.

For histology, tissues were processed by standard procedures for embedding in paraplast or glycol methacrylate
(Historesin ${ }^{\circledR}$, Leica, Germany). Sections were cut at $2 \mu \mathrm{m}$ (Historesin) or $5 \mu \mathrm{m}$ (paraplast) and transferred to glycerin coated slides. They were stained with haematoxylin and eosin or toluidine blue.

For immunohistochemistry, tissues were processed for embedding in paraffin by standard methods. Five $\mu \mathrm{m}$ thick sections were transferred to Superfrost Plus slides (VWR, Mississauga, Ontario, Canada). Immunohistochemistry for cytokeratin (to identify epithelial cells and trophoblasts) and vimentin (to identify mesenchymal cells and stromal decidua) was performed as previously described [6]. Tissue sections were incubated with either a rabbit polyclonal antibody for wide spectrum screening of cytokeratins (1 : 500; Z622, Dako, Mississauga, Ontario, Canada) or a monoclonal mouse antibody against vimentin ( $1: 50$; clone V9, Dako, Mississauga, Ontario, Canada) at $4^{\circ} \mathrm{C}$ for $24 \mathrm{~h}$. Immunostaining was identified by the avidin-biotin-peroxidase technique, using a Vectastain kit (Vector Laboratories, Burlingame, CA, USA) with diaminobenzidine (DAB) as the chromogen. Sections were counterstained with methyl green. To control for nonspecific binding of the primary antibody, we used normal rabbit IgG for cytokeratins and normal mouse IgG for vimentin, each at a concentration matching the IgG content of the primary antibody.

We have previously described the histology and immunohistochemistry of the placenta in guinea pig [8], capybara, agouti and paca [6]. For the present study we examined histological sections and immunostained sections from two rock cavy placentae.

\section{Vascular casts}

To study the microvasculature, term placentae were injected with Mercox ${ }^{\text {TM }}$ CL-2R (Okenshoji Co., Ltd, Tokyo, Japan) as described by Hodde et al. [9]. The procedures were similar to those applied by others to a wide range of placental types $[10,11]$. A maternal and/or fetal vessel was cannulated and the resin injected under manual control. Tissues were digested by immersion of the preparation in several changes of 20 per cent $\mathrm{NaOH}$ solution at $50-60^{\circ} \mathrm{C}$. The casts were rinsed thoroughly in distilled water and dried in an oven at $37^{\circ} \mathrm{C}$. They were then refrigerated in 20 per cent gelatin. For scanning electron microscopy, pieces of the casts were rinsed in distilled water to remove the gelatin, dried, and mounted on stubs with conductive carbon cement (Neubauer, Münster, Germany). They were then coated with gold using a sputter coater (Model K550, Emitech Products Inc., Houston TX, USA) and examined in a scanning electron microscope (Model $435 \mathrm{VP}$, Leo Electron Microscopy Ltd, Cambridge, UK).

Vascular casts were made of near term placentae in 3 agoutis, 2 capybaras, 4 guinea pigs, 1 paca and 3 rock cavies and of a mid-gestation placenta in 1 capybara and 1 paca.

As a further aid to understanding vessel distribution, some placentae were injected with coloured latex (Neoprene 650, DuPont, Brazil; Latex Stain, Suvinil, Glassurit do Brazil S/A, 

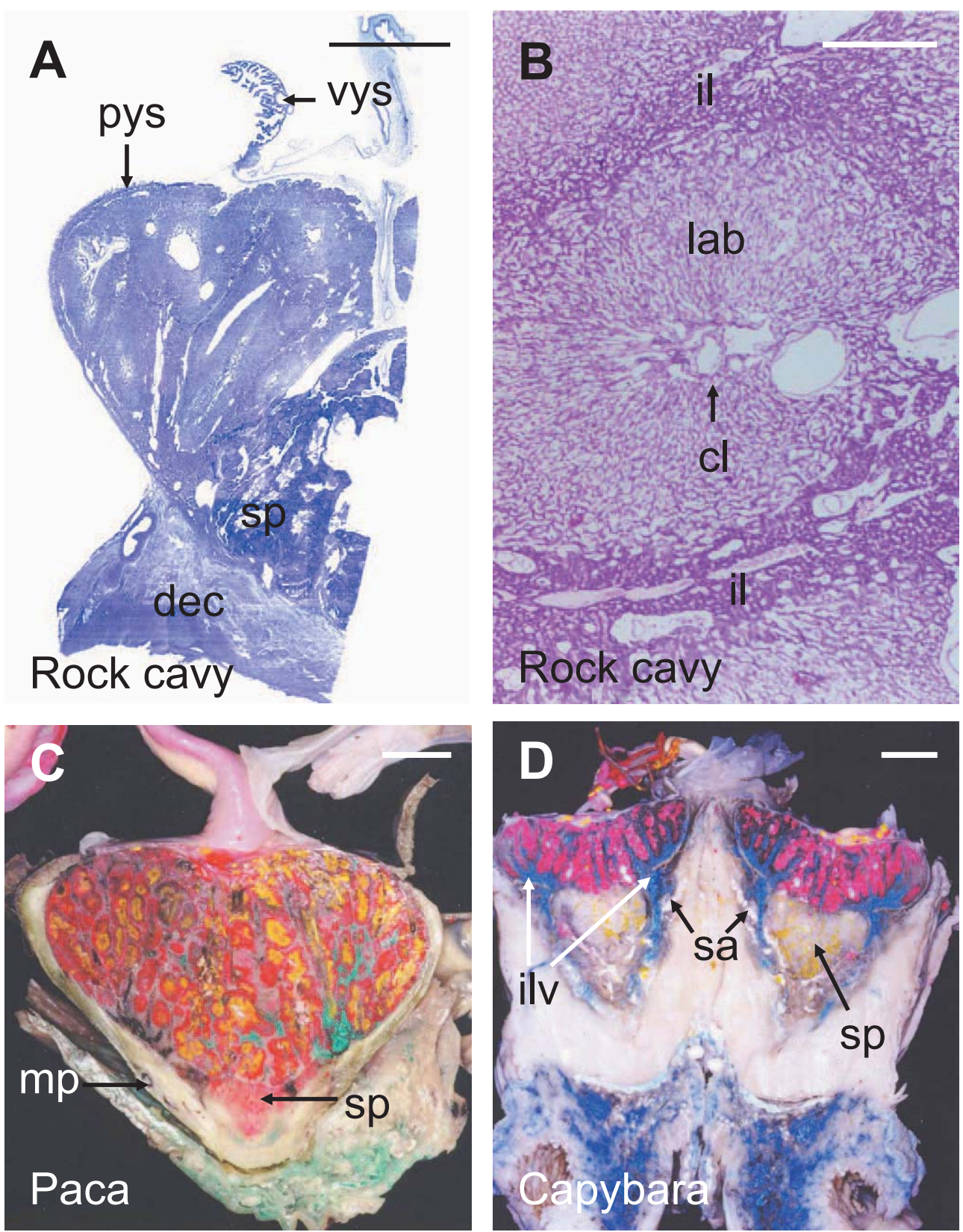

Figure 1. A. Low power view of a rock cavy placenta to show the lobular structure, parietal yolk sac epithelium (pys), visceral yolk sac (vys), subplacenta (sp) and decidua (dec). Hematoxylin and eosin, Scale bar $3 \mathrm{~mm}$. B. Rock cavy placenta to show division of the labyrinth (lab) into lobes by interlobular trophoblast (il). Large vessels are confined to the interlobium and the centre of the lobe (cl). Haematoxylin and eosin, Scale bar $300 \mu \mathrm{m}$. C. Section through paca placenta following latex injection of a uterine artery (white), uterine vein (green), umbilical artery (red) and umbilical vein (yellow). Note that the centre of each lobe is filled by the fetal venous route and the periphery by the fetal arterial route. The subplacenta (sp) is supplied by the fetal arterial route. The mesoplacenta (mp) is poorly vascularized. Scale bar $1 \mathrm{~cm}$. D. Section through capybara placenta following latex injection of a uterine artery (white), uterine vein (blue), umbilical artery (yellow) and umbilical vein (red). The subplacenta ( $\mathrm{sp}$ ) is supplied by the fetal arterial route. The main placenta is supplied by spiral arteries (sa) that skirt around the subplacenta. The interlobular venous channels (ilv) empty into a basal venous lacunar ring, which is drained by branches of the mesometrial veins. Scale bar $1 \mathrm{~cm}$.

São Bernardo do Campo, S.P., Brazil). Different colours were injected in a uterine vein, a uterine artery, an umbilical artery and the umbilical vein. The placentae were then immersion fixed in 10 per cent formalin.

Latex injections were made in one mid-gestation capybara and one paca near term of pregnancy.

\section{RESULTS}

\section{Gross morphology}

As shown for the rock cavy (Figure 1A-B), the main placenta comprises several lobes separated by areas of interlobular syncytium. Large vessels are confined to the centre of the lobes 


\section{IR-CYTOKERATIN}
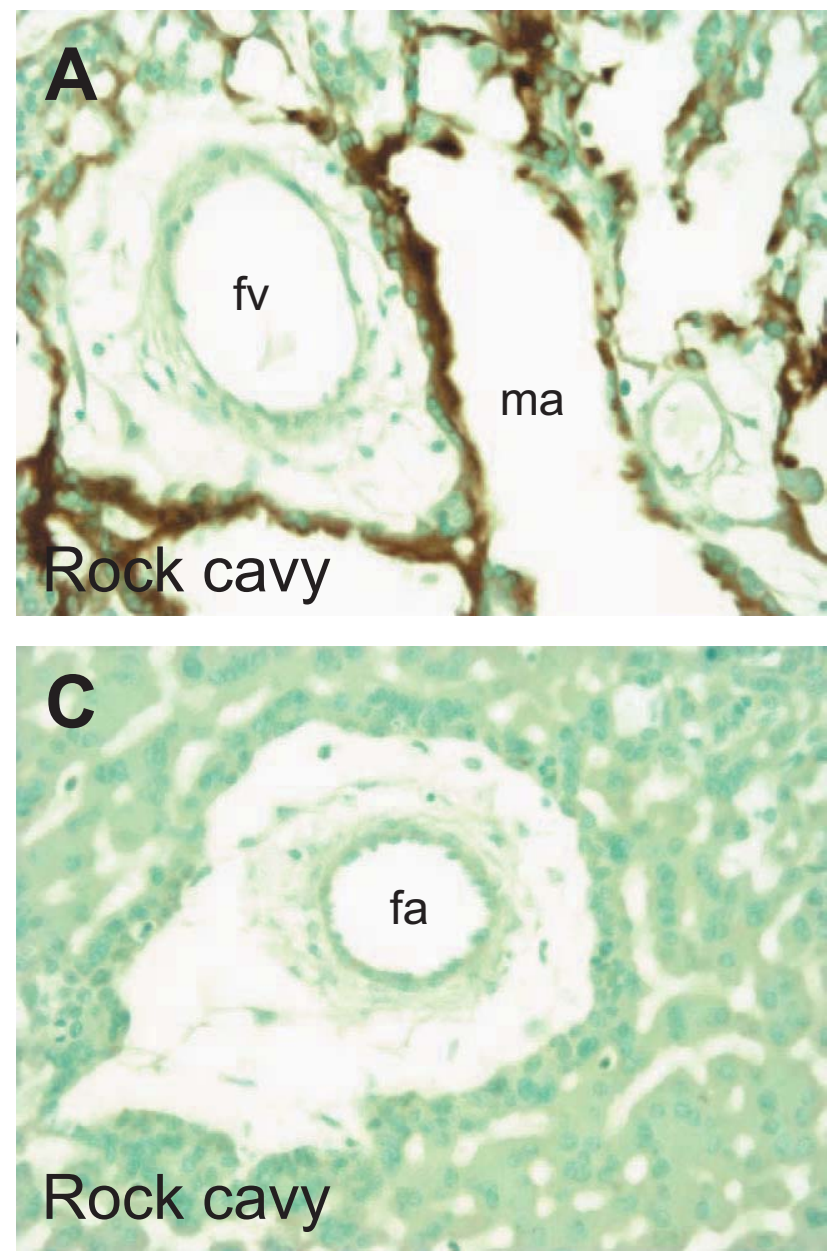

IR-VIMENTIN
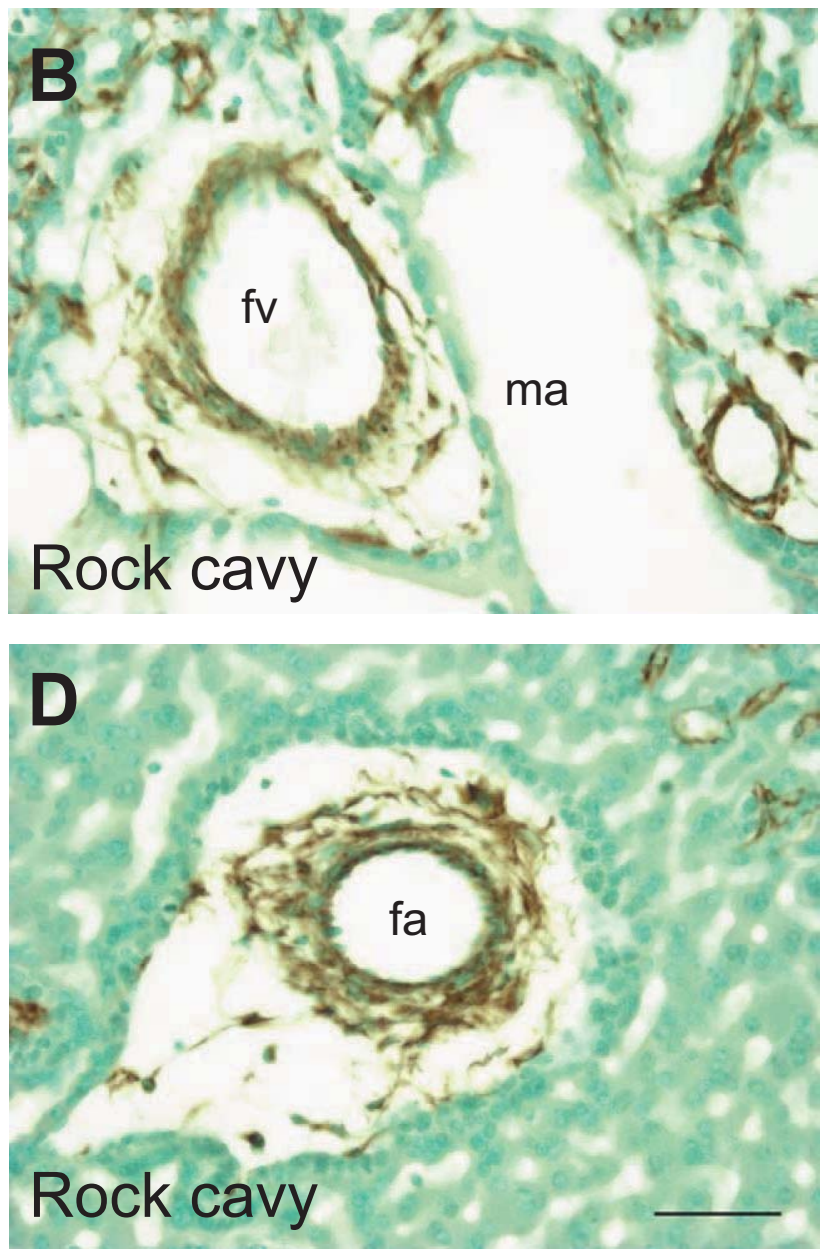

Figure 2. Sections of rock cavy placenta immunostained for cytokeratin (A, C) or vimentin (B, D) and counterstained with methyl green. A-B. Central part of a lobe showing maternal arterial channels lined by cytokeratin-positive trophoblast (ma) and a vimentin-positive fetal vein (fv). C-D. Interlobular region showing connective tissue with a vimentin-positive fetal artery (fa). Scale bar $50 \mu \mathrm{m}$.

and the interlobular areas (Figure 1B). The biggest vessels at the centre of the lobes are often irregular in shape and are lined by trophoblast that is strongly cytokeratin-positive (Figure 2A). Clearly they are maternal blood channels. The smaller vessels at the centre of the lobes are rounder in shape and their walls are vimentin-positive (Figure 2B). Vimentin-positive vessels also occur in the interlobular areas (Figure 2D). As previously seen in agouti and paca [6], the interlobular trophoblast of the rock cavy failed to immunostain for cytokeratin (Figure 2C). When latex of different hues is injected simultaneously in an umbilical artery and vein, the centre of the lobes is filled by the venous route and the periphery from the arterial route (Figure 1C). Thus the vimentin-positive vessels in the interlobular areas are fetal arteries, whilst those at the centre of the lobes are fetal veins. On the maternal side, venous drainage is through interlobular vessels that are filled by latex injected through a branch of the uterine vein (Figure 1D). They drain a latticework of venous channels in the interlobular areas, but these are not strongly cytokeratin-positive (not shown). A few large, round vessels lined by trophoblast are found in the interlobular areas (not shown). We surmise that these are the maternal arterial channels that supply the trophoblast-lined vessels at the centre of the lobes.

Below the main placenta, and separated from it by a layer of fetal mesenchyme, is the subplacenta (Figure 1A, C-D), a structure unique to the hystricomorph rodents. The uterine decidua forms a placental stalk or pedicle and, in agouti and paca (Figure 1C), a placental capsule or mesoplacenta. The following sections deal first with the fetal and maternal vessels of the main placenta and then with the vascular supply of the subplacenta and the decidual components of the placenta.

\section{Fetal arterial supply}

The cord carries five blood vessels: the two umbilical arteries, an umbilical vein and a vitelline artery and vein that supply the yolk sac placenta. The umbilical arteries attach at the centre of 

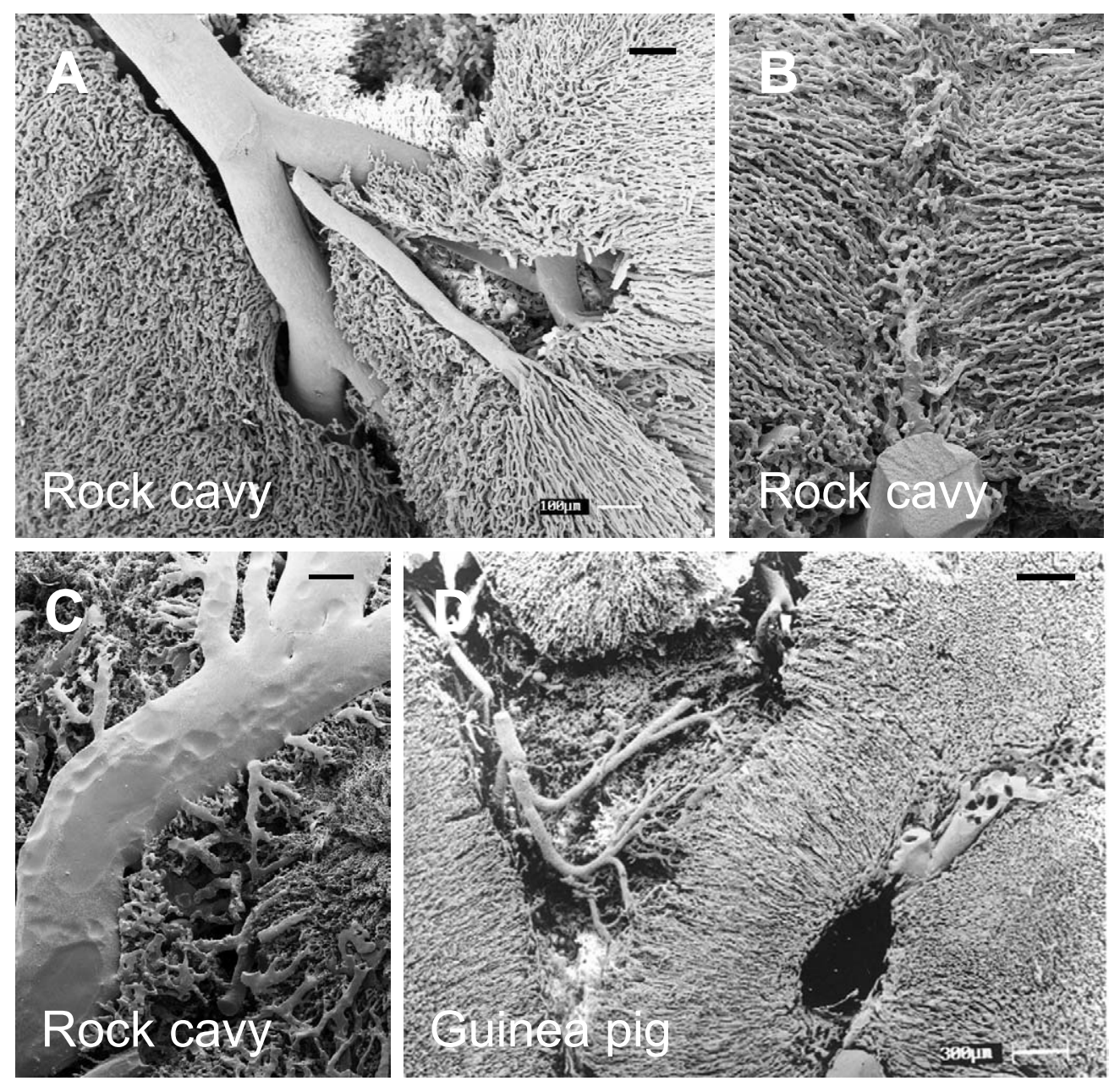

Figure 3. Fine structure of placental vasculature of the rock cavy $(A-C)$ and guinea pig $(D)$ in late gestation. Vascular casts were made by injection of Mercox in an umbilical artery and a maternal vein. A. Fetal arteries supplying several lobes. One vessel passes into the interlobium to supply a deeper lying lobe. Scale bar $100 \mu \mathrm{m}$. B. Interlobium with maternal venous channel receiving the drainage from two lobes. Scale bar $100 \mu \mathrm{m}$. C. Maternal channels draining the labyrinth empty into a large maternal lacuna in the interlobular region. This shows the negative impressions of the nuclei of the syncytiotrophoblast. Scale bar $200 \mu \mathrm{m}$. D. Overview showing an interlobular region and parts of three lobes. Fetal interlobular arteries are seen supplying the capillaries of the labyrinth. At right, the large vessel at the centre of the lobe is likely a maternal arterial sinus. Scale bar $300 \mu \mathrm{m}$.

the placenta, where there is a layer of fetal mesenchyme. They then branch across the fetal surface of the placenta. From here arteries descend perpendicular to the surface either to supply the more superficial lobes or to pass through the interlobular areas to reach deeper lying lobes, as shown for the rock cavy (Figure 3A). The interlobular arteries ramify across the outer surface of the lobes, as shown for paca (Figure 4B), before suddenly dividing to send bursts of capillaries towards the centre of the lobe, shown for guinea pig (Figure 3D), paca (Figure 4D, Figure 5B) and agouti (Figure 6A, B). Within the lobes, the capillaries are arranged in radial fashion with anastomoses between them (Figure 4C, Figure 7E).

\section{Fetal venous drainage}

At the centre of the lobe, the fetal capillaries drain into small veins, as can be seen in tissue sections (Figure 2B) and vascular casts (Figure 7A-B). These form one or more larger veins that leave through the base of the lobe to drain into a network of veins below the surface of the placenta. This network feeds into branches of the umbilical vein that run across the fetal surface of the placenta.

\section{Maternal arterial supply}

The uterus is bicornuate and each horn is supplied by an arterial arcade fed by the uterine and ovarian arteries. Numerous vessels arise from this arcade and cross the mesometrium to supply the uterine wall. However, only a few of these arteries, usually 3-5, are recruited to supply each placenta. These vessels widen considerably as they approach the placenta and tend to meander across the surface of the uterus. They form a loose plexus beneath the placenta from which there arise a small number of spiral arteries that enter the 

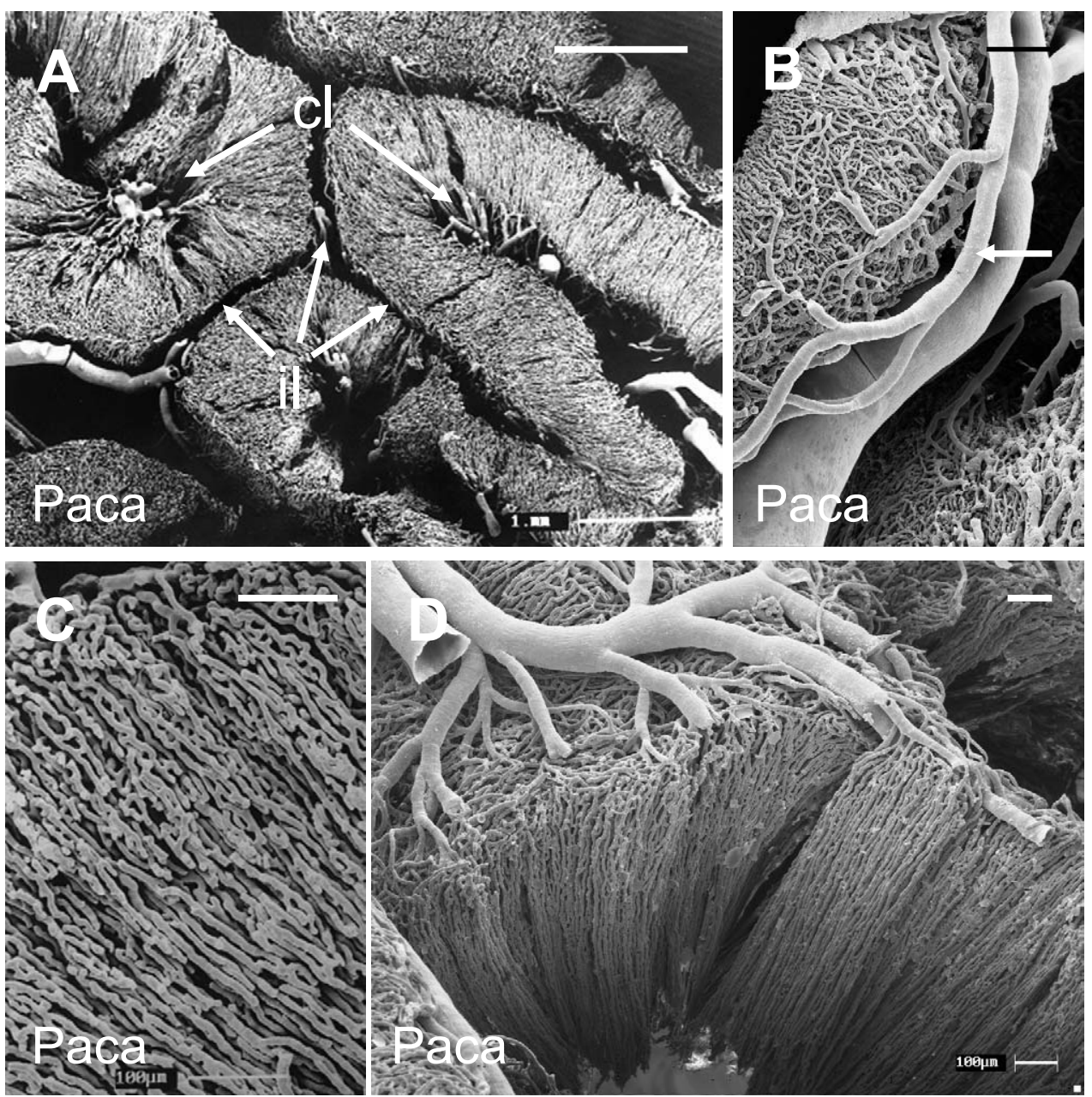

Figure 4. Fine structure of placental vasculature of the paca in late gestation. Vascular cast made by injection of Mercox in a fetal artery and maternal vein. A. Overview showing several placental lobes separated by interlobular areas. Large vessels are confined to the centre of the lobes (cl) and the interlobular regions (il). Vessels within the labyrinth are arranged in radial fashion. Scale bar $1 \mathrm{~mm}$. B. Ramification of a fetal interlobular artery (arrow) over the outer surface of a lobe. Scale bar $300 \mu \mathrm{m}$. C. Fetal capillaries of the placental labyrinth. Note the occurrence of anastomoses between the capillaries. Scale bar $100 \mu \mathrm{m}$. D. Fetal arteries coursing over the outer surface of a lobe then suddenly branching to send capillaries towards its centre. Scale bar $100 \mu \mathrm{m}$.

placental stalk and pass around the perimeter of the subplacenta (Figure 1D).

A small number of arterial channels, now lined by trophoblast, enter the main placenta and ramify in a system of lacunae beneath the fetal surface of the placenta. A single large arterial lacuna enters each lobe and passes down the centre, where it can be seen in vascular casts (Figure 5A, Figure 7C). Small branches arise from this central channel and divide to supply the fine channels of the placental labyrinth (Figure 5B, Figure 7C). These run parallel to the fetal capillaries, from the centre to the periphery of the lobe, creating the anatomical basis for countercurrent exchange. Whilst these fine, trophoblast-lined channels are readily seen in tissue sections, it is difficult to show them in vascular casts (Figure 5B, Figure 7C). However, they were demonstrated in a guinea pig placenta where the injection of Mercox was limited to maternal vessels (Figure $6 \mathrm{D})$ and there revealed a fine network of interlacing channels.

\section{Maternal venous drainage}

The maternal channels of the labyrinth drain into the spaces formed by the latticework of the interlobular trophoblast (Figure 2C). An interlobular region usually receives the venous drainage from two or more lobes (Figure 3B). These small venous channels drain into much larger venous lacunae as can be shown in vascular casts (Figure 3C, Figure 5C-D). The latter show the negative impressions of the nuclei of the syncytiotrophoblast (Figure 3C).

These interlobular venous channels drain into lacunae, some of which run quite superficially over the outside of the placenta (Figure 7F), although within the capsule in agouti (Figure 6C) and paca. Others are situated more centrally within the placenta. Kaufmann and Davidoff [3] refer to these as, respectively, primary marginal lacunae and primary central lacunae. They all drain into a basal venous lacunar ring 

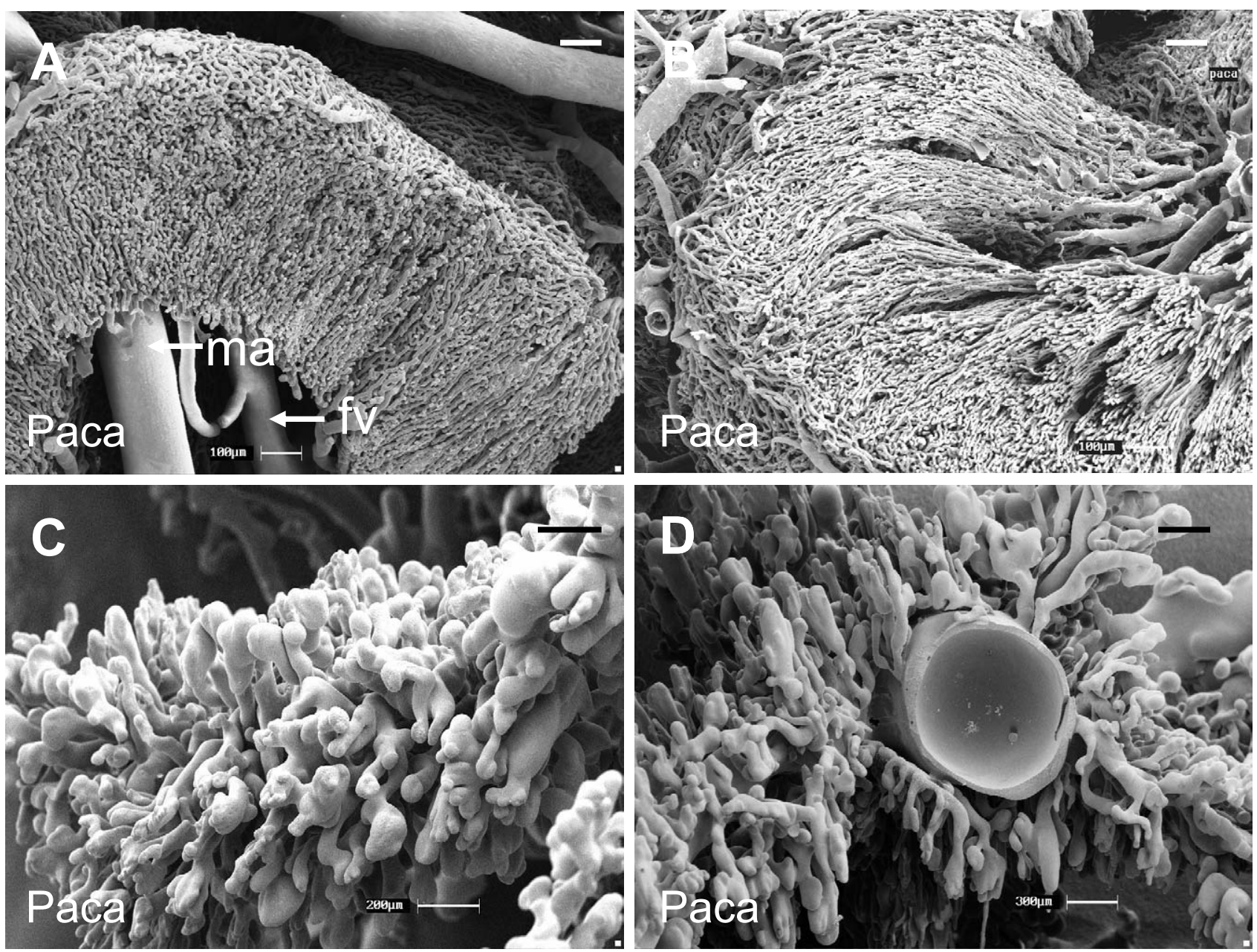

Figure 5. Fine structure of placental vasculature of the paca in late gestation. Vascular casts were made by injection of Mercox in a fetal artery and maternal vein (A-B) or a maternal vein alone (C-D). A. Large vessels at the centre of a lobe include fetal veins ( $\mathrm{fv}$ ) and a large maternal arterial blood channel (ma). Scale bar $100 \mu \mathrm{m}$. B. At left fetal arteries give rise to capillaries that run to the centre of the lobe. At right maternal blood channels supply the fine, trophoblast-lined channels that pass to the periphery; these do not appear in the cast. Scale bar $100 \mu \mathrm{m}$. C. Maternal venous channels in an interlobular region. Scale bar $200 \mu \mathrm{m}$. D. Maternal venous channels draining into a large venous lacuna. Scale bar $300 \mu \mathrm{m}$.

(Figure 8A). A small number of veins leave the ring, pass around the periphery of the subplacenta (Figure 1D), and empty into the mesometrial veins. These join a venous arcade formed by the uterine and ovarian veins. The latter is the most important and is sometimes referred to as the utero-ovarian vein [12].

\section{Subplacenta}

In mid to late gestation, the subplacenta is supplied largely by fetal vessels (Figure 8A). A large branch of the umbilical artery follows the central band of fetal mesenchyme to the base of the main placenta and then branches to supply the subplacenta (Figure 8B). The subplacental vessels pursue a tortuous course with dilatations and constrictions (Figure $8 \mathrm{C}-\mathrm{D}$ ) as in an endocrine gland such as the ovary [13]. A few branches of the maternal artery supply the subplacenta, at least in capybara and paca, where they can be demonstrated by latex injection (data not shown).

\section{Placental stalk and placental capsule}

The placenta rests on a stalk formed by decidua. In agouti and paca (Figure 1C), there is an additional structure, the mesoplacenta, that forms a capsule around the placenta. Capybara has a large placental stalk and an incomplete capsule (Figure 1D). Close inspection of guinea pig and rock cavy placenta shows a structure that may be analogous to the incomplete capsule of the capybara. These structures are supplied only by maternal vessels. In late gestation the capsule is sparsely vascularized. However, the placental stalk receives a rich supply of blood vessels (data not shown). 

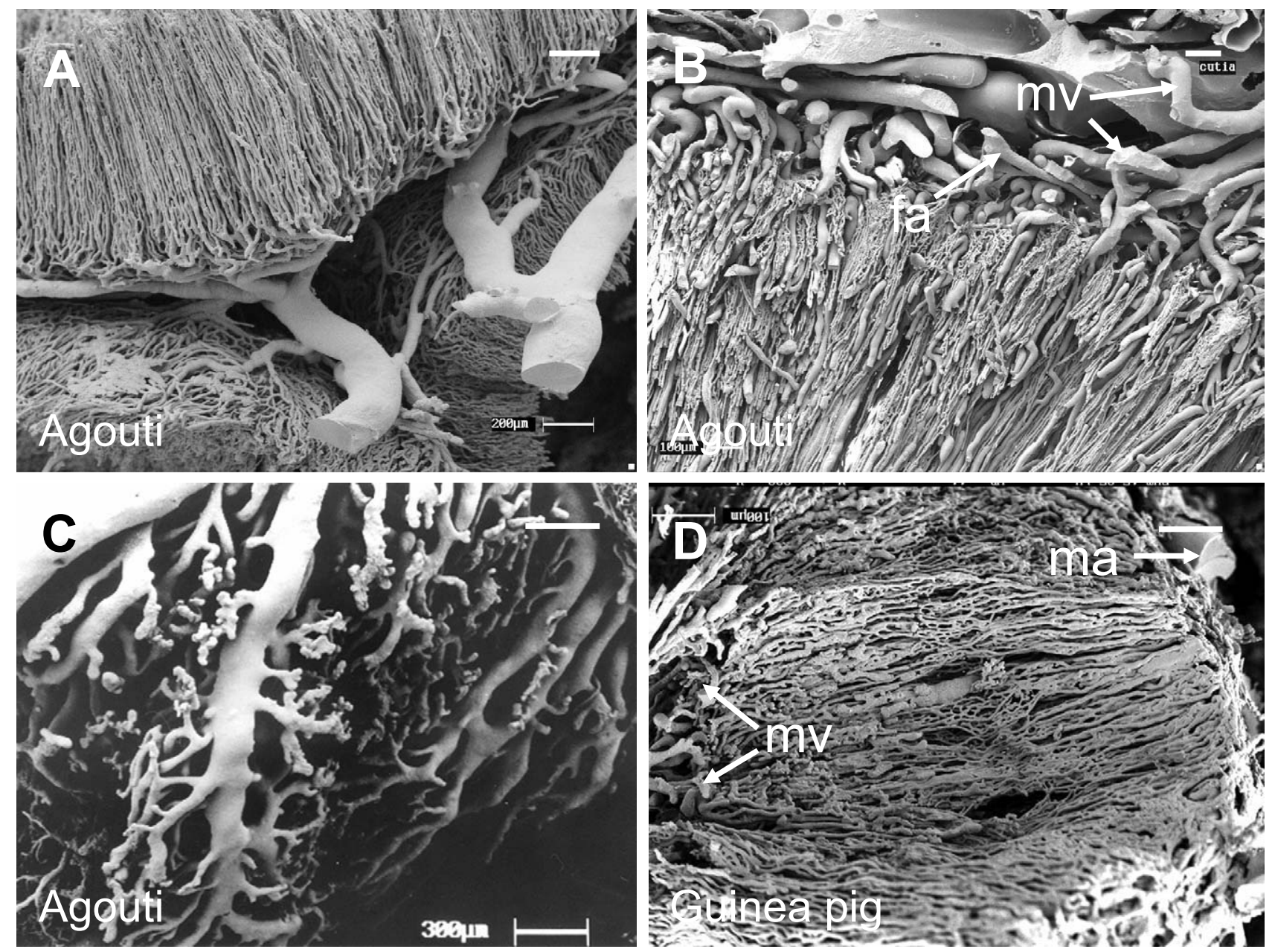

Figure 6. Fine structure of placental vasculature of the agouti (A-C) and guinea pig (D) in late gestation. Vascular casts were made by injection of Mercox in an umbilical artery alone (A) an umbilical artery and a maternal vein (B-C) or a uterine artery (D). A. Fetal interlobular artery branching to give rise to the capillaries of the labyrinth. Scale bar $200 \mu \mathrm{m}$. B. Interlobular region at top includes two sizes of vessel with different patterns of ramification, representing fetal arteries (fa) and maternal venous lacunae (mv). Scale bar $100 \mu \mathrm{m}$. C. Maternal venous lacuna in an interlobular region. Scale bar $300 \mu \mathrm{m}$. D. Maternal channels of the labyrinth. An arterial lacuna (ma) gives rise to an interlacing network of fine channels that drain into the venous channels of the interlobium (mv). Scale bar $100 \mu \mathrm{m}$.

\section{DISCUSSION}

Traditionally, the rodents have been divided into three suborders. The hystricomorph rodents continue to be regarded as a single clade, supported by analysis both of morphological characters and nucleotide sequence data [14]. Indeed, Luckett and Mossman [1] asserted that the hystricomorphs could be regarded as a monophyletic group, based on placental structure alone. The present study of five species from three families of hystricomorphs indicates a remarkable constancy in the arrangement of the placental vasculature. Our data confirm and extend the observations made in the nutria, a member of a fourth family, by Hilleman and Gaynor [2].

We are in agreement with Hilleman and Gaynor [2] that there is a countercurrent arrangement of the blood vessels. Within each lobe, maternal blood flows from the centre to the periphery, whilst fetal blood flows in the opposite direction
(Figure 9). Kaufmann and Davidoff [3] and Dantzer et al. [4] reached a similar conclusion for the guinea pig and chinchilla. In a study of the Canadian porcupine, Perrotta [5] correctly identified the direction of flow in the maternal vessels. However, he suggested that fetal arterioles arose from arteries at the centre of the lobes and then crossed the lobe to supply the capillaries. These then drained into the fetal veins, which he correctly placed at the centre of the lobes. In vessel casts we have been unable to identify vessels corresponding to the fetal arterioles of Perrotta [5]. Instead, we showed that the fetal arteries pass through the interlobular regions to break up into sprays of capillaries on the outer surface of the lobes. Moreover, when coloured latex was injected simultaneously in an umbilical vein and artery, the centre of the lobe was filled exclusively from the venous side.

Countercurrent flow is the common pattern in rodent and lagomorph placentae [15]. It provides for more efficient 

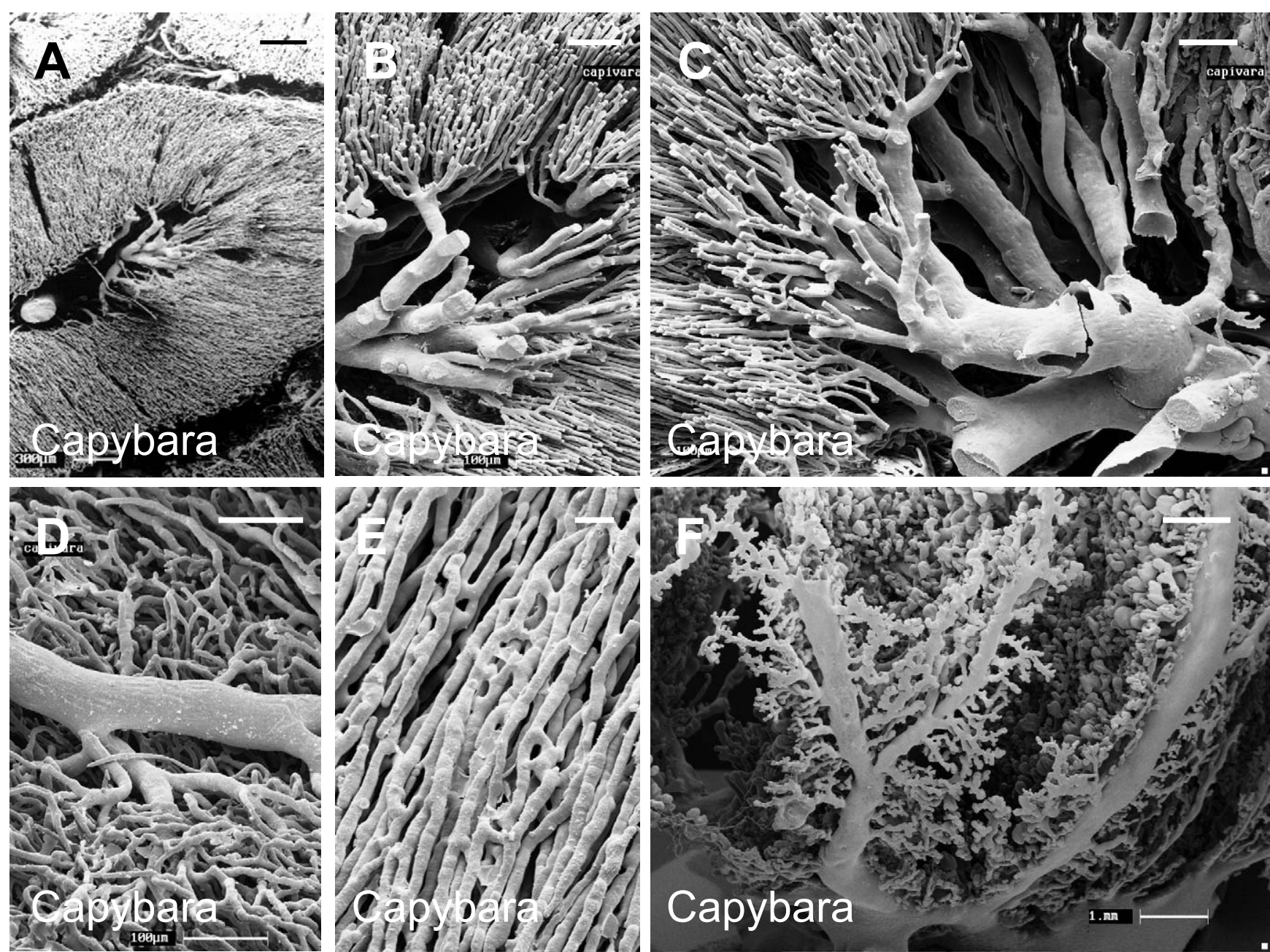

Figure 7. Fine structure of the placental vasculature of the capybara in late gestation. Vascular casts were made by injection of Mercox in an umbilical artery and a maternal vein (A-C), an umbilical artery alone (D-E) or a maternal vein alone (F). A. Parts of several lobes, showing capillaries of the fetal labyrinth. Larger vessels at the centre of the lobe include fetal veins and maternal arterial channels. Scale bar $300 \mu$ m. B. Capillaries draining into fetal veins at the centre of the labyrinth. Scale bar $100 \mu \mathrm{m}$. C. Maternal arterial channels at centre of lobe branching to send fine channels through the trophoblast of the labyrinth; these do not appear at full length in the cast. Scale bar $100 \mu \mathrm{m}$. D. Fetal interlobular artery ramifying across the outer surface of a lobe. Scale bar $100 \mu \mathrm{m}$. E. Fetal capillaries of the labyrinth. Note the occurrence of anastomoses. Scale bar $20 \mu \mathrm{m}$. F. Maternal venous channels of several interlobular regions draining into larger marginal lacunae which, at bottom, join the basal venous lacunar ring. Scale bar $1 \mathrm{~mm}$.

maternal-fetal exchange when, as in the case of oxygen, exchange is flow dependent. What should not be overlooked is that the difference in efficiency between concurrent, crosscurrent and countercurrent flow is dependent on other factors, notably the diffusion capacity of the placenta [16].

Within the labyrinth, the fetal capillaries formed a network of interconnecting vessels. This was paralleled on the maternal side by connections between the trophoblastic tubules carrying maternal blood. This network structure has been described for other hystricomorph species and may be part of the stem pattern of the placenta in rodents [17].

On the maternal side of the placenta, latex injections confirmed the presence of spiral arteries, as previously shown for the guinea pig by angiographic methods [12]. Vascular casts of mouse placenta similarly reveal that maternal blood is supplied through spiral arteries [18] and spiral arteries occur in the rabbit placenta [19]. Thus, a labyrinthine placenta with countercurrent exchange, supplied on the maternal side by spiral arteries, is a common pattern for the Glires (rodents and lagomorphs). There are differences, however, in the nature of the placental barrier. The interhaemal membrane has one layer of trophoblast in hystricomorph rodents compared to two in rabbits and three in the murid rodents [20]. A distinctive feature of the hystricomorph placenta is its division into lobes. However, Hilleman and Gaynor [2] drew an interesting analogy between the arrangement of blood vessels in the entire murid placentae, represented by the hamster, and that of a single lobe of the hystricomorph placenta.

A truly unique feature of the hystricomorph rodents is the presence of a subplacenta [1]. As shown by Kaufmann and 

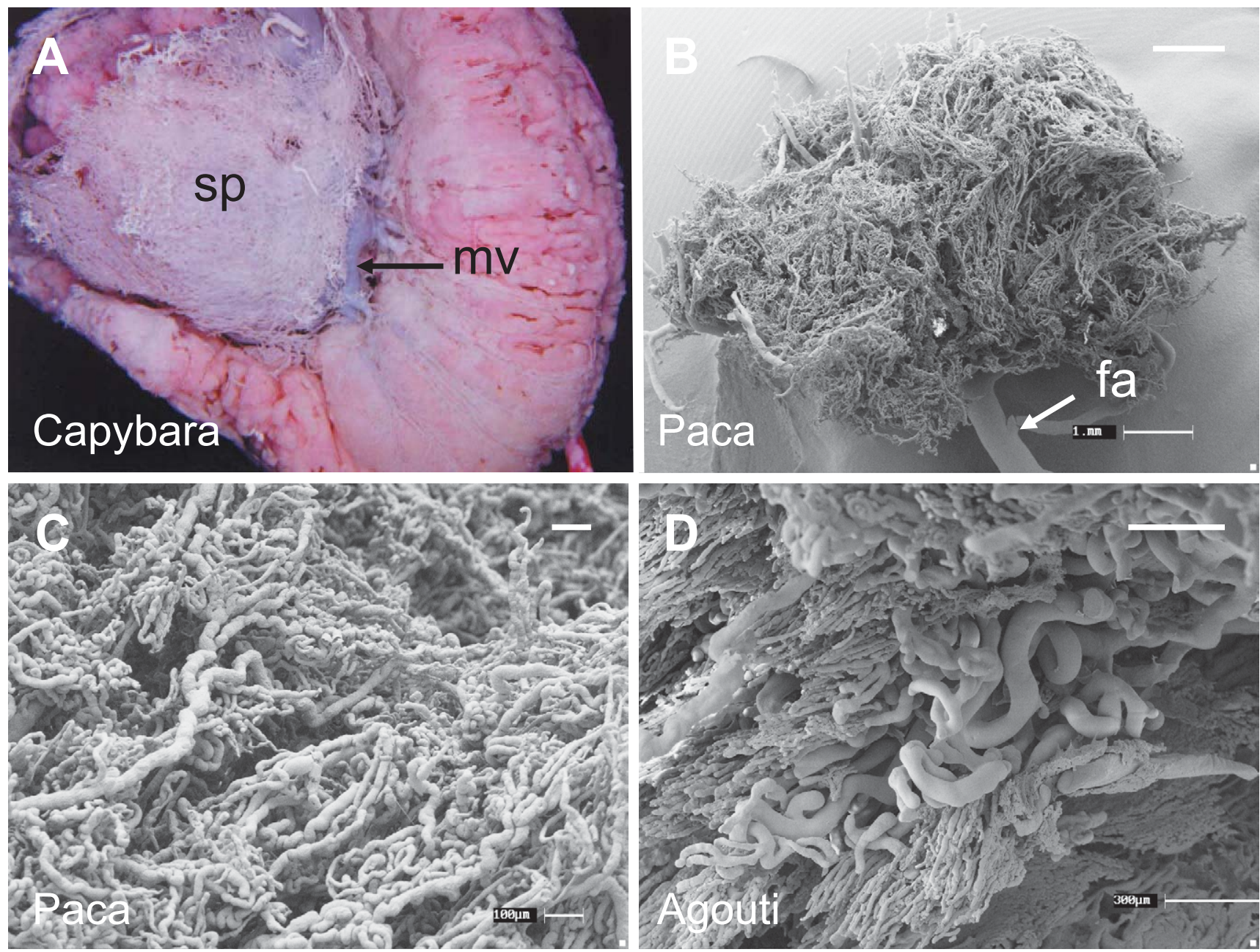

Figure 8. Vessels of the subplacenta. Vascular casts were made by injection of Mercox in an umbilical artery and a maternal vein; only fetal vessels were demonstrated in the subplacenta. A. Maternal-facing surface of a detached capybara placenta showing the vessels of the subplacenta (sp) and the maternal venous ring at the base of the placenta (mv). B. Low power scanning electron micrograph showing a single fetal artery (fa) entering the centre of the subplacenta in paca. Scale bar $1 \mathrm{~mm}$. C. At higher magnification vessels of the paca subplacenta are seen to pursue a tortuous course and are irregular in calibre. Scale bar $100 \mu \mathrm{m}$. D. A similar skein of vessels is seen in the subplacenta of agouti. Scale bar $300 \mu \mathrm{m}$.

Davidoff [3] for the guinea pig, it is supplied by a single fetal artery that follows a central band of mesenchyme to the base of the main placenta, where it branches to supply the subplacenta. Wolfer and Kaufmann [21] showed that from day 15 until at the latest day 28, the subplacenta of the guinea pig contained maternal blood lacunae. A fetal circulation was first established on day 32. Therefore, they concluded that maternal and fetal vessels were never present at the same time. We agree that the subplacenta is unlikely to play a role in maternal-fetal exchange, but did see a few branches of the maternal arteries in the subplacenta of capybara and paca. However, the true function of the subplacenta remains obscure. Based on extensive ultrastructural and histochemical studies, it was proposed that the subplacenta of the guinea pig might secrete gonadotrophic hormones [22,23]. The ultrastructure of chinchilla placenta is also suggestive of secretory activity [24]. Consistent with an endocrine role for this structure, we found that the subplacental vessels pursue a tortuous course with dilatations and constrictions just as in an endocrine gland [13].

In contrast to myomorph rodents, where a number of interesting variations in placental structure occur [25], placentation is remarkably constant in hystricomorph rodents [17]. The placenta is lobate, the interhemal barrier is of the haemomonochorial type and there is a characteristic subplacenta. These features support inclusion of the Old and New World representatives in a monophyletic group [1], an inference sustained by molecular phylogenetics [14]. Our results indicate that this constancy of pattern is reflected in the microvasculature, which is arranged to enable countercurrent transfer in each lobe of the placenta. These features likely evolved in the Eocene period as part of a reproductive strategy with precocial young and long gestation periods [26]. 


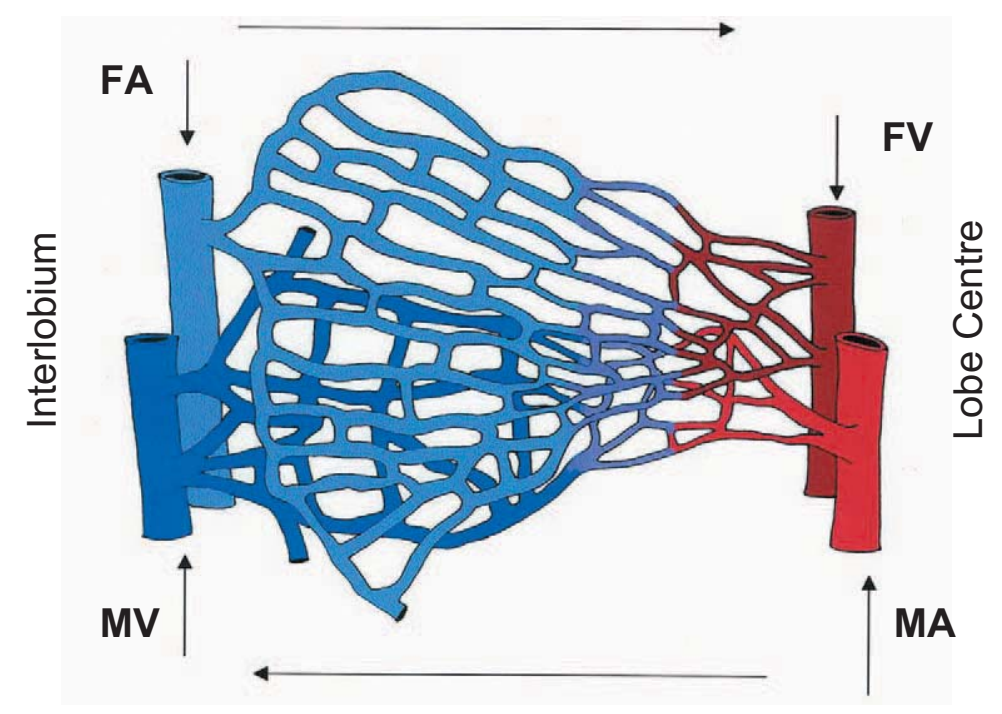

Figure 9. Countercurrent blood flow in the hystricomorph placenta. Fetal blood flows from fetal arteries in the interlobium (FA) to fetal veins at the centre of the lobe (FV), as indicated by the upper arrow. Maternal blood flows from arterial channels at the centre (MA) to venous channels in the interlobium (MV), as indicated by the lower arrow. Vessel diameters and lengths are not drawn to scale.

\section{ACKNOWLEDGEMENTS}

This study was supported by Fundação de Amparo à Pesquisa do Estado de São Paulo (FAPESP) and Conselho Nacional de Desenvolvimento Científico e Tecnológico $(\mathrm{CNPq})$. We gratefully acknowledge the skilful assistance of Karen Nygard.

\section{REFERENCES}

[1] Luckett WP, Mossman HW. Development and phylogenetic significance of the fetal membranes and placenta of the African hystricognathous rodents Bathyergus and Hystrix. Am J Anat 1981;162:265-85.

[2] Hilleman HH, Gaynor AI. The definitive architecture of the placenta of nutria, Myocastor coypus (Molina). Am J Anat 1961;109:299-318.

[3] Kaufmann P, Davidoff M. The guinea-pig placenta. Adv Anat Embryol Cell Biol 1977;53:5-91.

[4] Dantzer V, Leiser R, Kaufmann P, Luckhardt M. Comparative morphological aspects of placental vascularization. Trophoblast Res 1988; 3:235-60.

[5] Perrotta CA. Fetal membranes of the Canadian porcupine, Erithizon dorsatum. Am J Anat 1959;104:35-59.

[6] Miglino MA, Carter AM, dos Santos Ferraz RH, Fernandes Machado MR. Placentation in the capybara (Hydrochaerus hydrochaeris), agouti (Dasyprocta aguti) and paca (Agouti paca). Placenta 2002;23:416-28.

[7] Rood JP, Weir BJ. Reproduction in female wild guinea-pigs. J Reprod Fert 1980;23:393-409.

[8] Carter AM, Tanswell B, Thompson K, Han VK. Immunohistochemical identification of epithelial and mesenchymal cell types in the chorioallantoic and yolk sac placentae of the guinea-pig. Placenta 1998;19:489-500.

[9] Hodde KC, Miodonski A, Bakker C, Veltman W. Scanning electron microscopy of microcorrosion casts with special attention on arteriovenous differences and application to the rat's cochlea. Scan Electron Micros 1977;2:477-84.

[10] Leiser R, Krebs C, Ebert B, Dantzer V. Placental vascular corrosion cast studies: a comparison between ruminants and humans. Microsc Res Tech 1997;38:76-87.

[11] Krebs C, Winther H, Dantzer V, Leiser R. Vascular interrelationships of near-term mink placenta: light microscopy combined with scanning electron microscopy of corrosion casts. Microsc Res Tech 1997; 38:125-36.

[12] Egund N, Carter AM. Uterine and placental circulation in the guineapig: an angiographic study. J Reprod Fert 1974;40:401-10.

[13] Murakami T, Ikebuchi Y, Ohtsuka A, Kikuta A, Taguchi T, Ohtani O. The blood vascular wreath of rat ovarian follicle, with special reference to its changes in ovulation and luteinization: a scanning electron microscopic study of corrosion casts. Arch Histol Cytol 1988;51:299-313.

[14] Huchon D, Madsen O, Sibbald MJ, Ament K, Stanhope MJ, Catzeflis F et al. Rodent phylogeny and a timescale for the evolution of Glires: evidence from an extensive taxon sampling using three nuclear genes. Mol Biol Evol 2002;19:1053-65.

[15] Mossman HW. The rabbit placenta and the problem of placental transmission. Am J Anat 1926;37:433-97.

[16] Metcalfe J, Bartels H, Moll W. Gas exchange in the pregnant uterus. Physiol Rev 1967;47:782-838.

[17] Mess A. Evolutionary transformations of chorioallantoic placental characters in rodentia with special reference to hystricognath species. J Exp Zoolog Part A Comp Exp Biol 2003;299:78-98.

[18] Adamson SL, Lu Y, Whiteley KJ, Holmyard D, Hemberger M, Pfarrer $\mathrm{C}$ et al. Interactions between trophoblast cells and the maternal and fetal circulation in the mouse placenta. Dev Biol 2002;250:358-73.

[19] Carter AM, Göthlin J, Olin T. An angiographic study of the structure and function of the uterine and maternal placental vasculature in the rabbit. J Reprod Fert 1971;25:201-10.

[20] Enders AC. A comparative study of the fine structure of the trophoblast in several hemochorial placentas. Am J Anat 1965;116:29-68.

[21] Wolfer J, Kaufmann P. Die Ultrastruktur der MeerschweinchenSubplazenta. Anat Histol Embryol 1980;9:29-43.

[22] Davies J, Dempsey EW, Amoroso EC. The subplacenta of the guinea pig: An electron microscopic study. J Anat 1961a;95:311-24.

[23] Davies J, Dempsey EW, Amoroso EC. The subplacenta of the guinea pig: Development, histology and histochemistry. J Anat 1961b;95:457-73.

[24] King BF, Tibbitts FD. The fine structure of the chinchilla placenta. Am J Anat 1976;145:33-56.

[25] Enders AC, Blankenship TN, Lantz KC, Enders SS. Morphological variation in the interhemal areas of chorioallantoic placentae. Trophoblast Res 1998;12:1-19.

[26] Mess A, Mohr B, Martin T. Evolutionary transformations of hystricognath Rodentia and the climatic change in the Eocene to Late Oligocene time interval. Mitt Mus Natkd Berlin Zool Reihe 2001;77:193-206. 


\title{
Vascular Organization of the Hystricomorph Placenta: a Comparative Study in the Agouti, Capybara, Guinea Pig, Paca and Rock Cavy
}

\author{
M. A. Miglino ${ }^{a}$, A. M. Carter ${ }^{\text {b, }}$, C. E. Ambrosioc ${ }^{\text {, M. Bonatellid }}{ }^{\text {, M. F. De Oliveira }}{ }^{\text {, R. H. Dos Santos }}$ \\ Ferraz $^{f}$, R. F. Rodrigues ${ }^{a}$ and T. C. Santos ${ }^{a}$ \\ a Department of Surgery, School of Veterinary Medicine, University of São Paulo, São Paulo, Brazil; ${ }^{b}$ Department of \\ Physiology and Pharmacology, University of Southern Denmark, Winsloewparken 21, Third Floor, DK-5000 Odense, \\ Denmark; ' ${ }^{c}$ Otavio Bastos Foundation, São João da Boa Vista, São Paulo, Brazil; ${ }^{d}$ Paulista State University, Jaboticabal, \\ São Paulo, Brazil; ${ }^{e}$ Mossoró Superior School of Agriculture, Rio Grande do Norte, Brazil; ${ }^{\dagger}$ Paulista State University, \\ Araçatuba, São Paulo, Brazil
}

Paper accepted 6 November 2003

\begin{abstract}
The placental vasculature of five hystricomorph rodents was examined by latex injection of the blood vessels, immunohistochemistry and scanning electron microscopy of vessel casts. The pattern of branching of the vessels is described at the level of fine structure. The placenta is divided into lobes separated by interlobular trophoblast. Fetal arteries course through the interlobular areas and give rise to capillaries from which blood drains into veins at the centre of the lobes. Maternal blood reaches the placenta through spiral arteries that pass around the perimeter of the subplacenta. They supply large maternal blood sinuses, lined by trophoblast, which run through the interlobular areas and into the centre of the lobes. Here they supply fine channels that run parallel to the fetal capillaries, so that maternal blood flows from the centre of the lobe to the periphery. This arrangement provides the morphological basis for countercurrent exchange. The maternal channels of the labyrinth drain into spaces formed by the latticework of the interlobular trophoblast and thence through venous lacunae to a basal venous lacunar ring. The subplacenta is supplied by a single fetal artery. The vessels within the subplacenta pursue a tortuous course with dilatations and constrictions as in an endocrine gland.
\end{abstract}

Placenta (2004), 25, 438-448

(C) 2003 Elsevier Ltd. All rights reserved.

\section{INTRODUCTION}

The hystricomorph rodents have a lobulate and haemomonochorial placenta with a characteristic subplacenta [1]. Until now the vascular organization of the placenta has been inferred largely from observations in the light microscope and interpretation of vascular casts at the macroscopical level. The most satisfactory of these descriptions is that given by Hilleman and Gaynor [2] for the nutria. They suggest that, in each lobe, maternal blood and fetal blood flow in opposite directions, allowing for countercurrent exchange. A similar interpretation has been given for the placentae of the guinea pig [3,4] and chinchilla [4]. However, alternative vascular arrangements have been suggested [5] and there are significant gaps in our knowledge of how the vessels reach the lobes and of the vascular supply of other structures, including the subplacenta.

To address these questions, we used three complementary techniques. Firstly, we made latex injections to verify the overall distribution of fetal and maternal vessels within the placenta and its accessory structures, including the uterine

\footnotetext{
* To whom correspondence should be addressed. Tel.: +45-65503716; Fax: +45-6613-3479; E-mail: acarter@health.sdu.dk
}

$0143-4004 / \$-$ see front matter wall. Secondly, we applied histology and immunohistochemistry to distinguish maternal and fetal vessels in tissue sections. Finally, we used scanning electron microscopy of vessel casts to identify the pattern of branching of the vessels at the level of fine structure. Together these enabled us to reconstruct the likely pattern of fetal and maternal blood flow in the hystricomorph placenta.

Our material comprised five South American rodents from three families. Details of reproduction in agouti, capybara and paca are given elsewhere [6]. A female rock cavy weighs $700-800 \mathrm{~g}$ and carries a litter of 1-2 young (usually one). Gestation lasts about 70 days and the newborn weigh around $90 \mathrm{~g}$. At term the placenta is $2.5 \mathrm{~cm}$ in diameter and weighs about $14 \mathrm{~g}$. The guinea pig is a close relative of the rock cavy and in the wild its reproduction is similar [7], but laboratory guinea pigs have been bred for larger litters.

\section{MATERIAL AND METHODS}

\section{Tissue collection}

The observations are based on material collected from 3 agoutis (Dasyprocta aguti), 4 capybaras (Hydrochaeris hydrochaeris), 4 guinea pigs (Cavia porcellus), 3 pacas (Agouti paca) 
and 5 rock cavies (Kerodon rupestris) between midgestation and term of pregnancy. Material was collected from the following breeding centres: Center for Experimental Breeding of Capybara, Paulista State University, Araçatuba, São Paulo; Center for Experimental Breeding of Paca, Paulista State University, Jaboticabal, São Paulo; Center for Experimental Breeding of Agouti, Federal University of Piaui, Teresina, Piaui; and Center for Breeding of Wild Animals, Mossoro. The guinea pig was a laboratory animal (Otavio Bastos Foundation, São João da Boa Vista, São Paulo, Brazil). The research was authorized by the Brazilian Institute of the Environment and Renewable Natural Resources (IBAMA).

Paca were sedated with azaperone (Stresnil; $0.1 \mathrm{mg} / \mathrm{kg}$ I.M.) and given atropine (0.5 mg I.M.). Anaesthesia was induced with xylazine (Coopazine, Coopers Brasil, São Paulo, S.P., Brazil; $1 \mathrm{mg} / \mathrm{kg}$ I.M.) and ketamine (Holliday Scott S.A., Brazil; $20 \mathrm{mg} / \mathrm{kg}$ I.M.). Hemihysterectomy was then performed under aseptic conditions during inhalation anaesthesia with halothane (Hoechst, Frankfurt, Germany). Postoperatively the animals were treated with benzyl penicillin and streptomycin (Pentabiotico ${ }^{\circledR}$, Fort Dodge, Campinas, S.P., Brazil; 8000-24 000 IU/kg I.M.) and an analgetic (metamizol, Dipirona).

Bilateral hysterectomy was performed in capybara and agouti. The animals were premedicated with acepromazine (Univet, São Paulo, S.P., Brazil; 0.1-1.0 mg/kg I.M.). Anaesthesia was induced with xylazine $\left(\right.$ Dorcipec $^{\circledR}$, Vallée S.A., Montes Claros, M.G., Brazil; 0.5-1.0 mg/kg) and ketamine (Cristália, Itapira, S.P., Brazil; 5-10 mg/kg I.M.) and continued with halothane (Hoechst, Frankfurt, Germany; 1 per cent) or enflurane (Etrane ${ }^{\circledR}$, Abbott, São Paulo, S.P., Brazil) in oxygen. Postoperative treatment included antibiotic coverage with benzyl penicillin and streptomycin (Pentabiotico ${ }^{\circledR}$, Fort Dodge, Campinas, S.P., Brazil; 8000-24 000 IU/kg I.M.) and analgesia as required with flunixin meglumine (Banamine ${ }^{\circledR}$, Schering-Plough, Rio de Janeiro, R.J., Brazil).

Rock cavies were premedicated with midazolam (Dormine, Cristália, Itapira, S.P., Brazil; $1 \mathrm{mg} / \mathrm{kg}$ ) and ketamine (Cristália, Itapira, S.P., Brazil; $15 \mathrm{mg} / \mathrm{kg}$ I.M.). Hemihysterectomy was then performed under aseptic conditions during inhalation anaesthesia with isoflurane (Cristália, Itapira, S.P., Brazil) in 100 per cent oxygen. Postoperative treatment included antibiotic coverage with amoxicillin (Bactrosina, Bayer, São Paulo, S.P., Brazil; 22 mg/kg).

Bilateral hysterectomy was performed in guinea pigs anaesthetized with a tiletamine/zolazepam mixture $(90 \mathrm{mg} / \mathrm{kg}$ of each I.M.; Zoletil 50; Virbac, São Paulo, S.P., Brazil).

\section{Histology and immunohistochemistry}

Tissues collected for histology and immunohistochemistry were immersion fixed in 4 per cent paraformaldehyde in $70 \mathrm{~mm}$ phosphate buffer for $48 \mathrm{~h}$, and then washed in cold, phosphate buffered $\mathrm{NaCl}$ solution for $72 \mathrm{~h}$.

For histology, tissues were processed by standard procedures for embedding in paraplast or glycol methacrylate
(Historesin ${ }^{\circledR}$, Leica, Germany). Sections were cut at $2 \mu \mathrm{m}$ (Historesin) or $5 \mu \mathrm{m}$ (paraplast) and transferred to glycerin coated slides. They were stained with haematoxylin and eosin or toluidine blue.

For immunohistochemistry, tissues were processed for embedding in paraffin by standard methods. Five $\mu \mathrm{m}$ thick sections were transferred to Superfrost Plus slides (VWR, Mississauga, Ontario, Canada). Immunohistochemistry for cytokeratin (to identify epithelial cells and trophoblasts) and vimentin (to identify mesenchymal cells and stromal decidua) was performed as previously described [6]. Tissue sections were incubated with either a rabbit polyclonal antibody for wide spectrum screening of cytokeratins (1 : 500; Z622, Dako, Mississauga, Ontario, Canada) or a monoclonal mouse antibody against vimentin ( $1: 50$; clone V9, Dako, Mississauga, Ontario, Canada) at $4^{\circ} \mathrm{C}$ for $24 \mathrm{~h}$. Immunostaining was identified by the avidin-biotin-peroxidase technique, using a Vectastain kit (Vector Laboratories, Burlingame, CA, USA) with diaminobenzidine (DAB) as the chromogen. Sections were counterstained with methyl green. To control for nonspecific binding of the primary antibody, we used normal rabbit IgG for cytokeratins and normal mouse IgG for vimentin, each at a concentration matching the IgG content of the primary antibody.

We have previously described the histology and immunohistochemistry of the placenta in guinea pig [8], capybara, agouti and paca [6]. For the present study we examined histological sections and immunostained sections from two rock cavy placentae.

\section{Vascular casts}

To study the microvasculature, term placentae were injected with Mercox ${ }^{\text {TM }}$ CL-2R (Okenshoji Co., Ltd, Tokyo, Japan) as described by Hodde et al. [9]. The procedures were similar to those applied by others to a wide range of placental types $[10,11]$. A maternal and/or fetal vessel was cannulated and the resin injected under manual control. Tissues were digested by immersion of the preparation in several changes of 20 per cent $\mathrm{NaOH}$ solution at $50-60^{\circ} \mathrm{C}$. The casts were rinsed thoroughly in distilled water and dried in an oven at $37^{\circ} \mathrm{C}$. They were then refrigerated in 20 per cent gelatin. For scanning electron microscopy, pieces of the casts were rinsed in distilled water to remove the gelatin, dried, and mounted on stubs with conductive carbon cement (Neubauer, Münster, Germany). They were then coated with gold using a sputter coater (Model K550, Emitech Products Inc., Houston TX, USA) and examined in a scanning electron microscope (Model $435 \mathrm{VP}$, Leo Electron Microscopy Ltd, Cambridge, UK).

Vascular casts were made of near term placentae in 3 agoutis, 2 capybaras, 4 guinea pigs, 1 paca and 3 rock cavies and of a mid-gestation placenta in 1 capybara and 1 paca.

As a further aid to understanding vessel distribution, some placentae were injected with coloured latex (Neoprene 650, DuPont, Brazil; Latex Stain, Suvinil, Glassurit do Brazil S/A, 

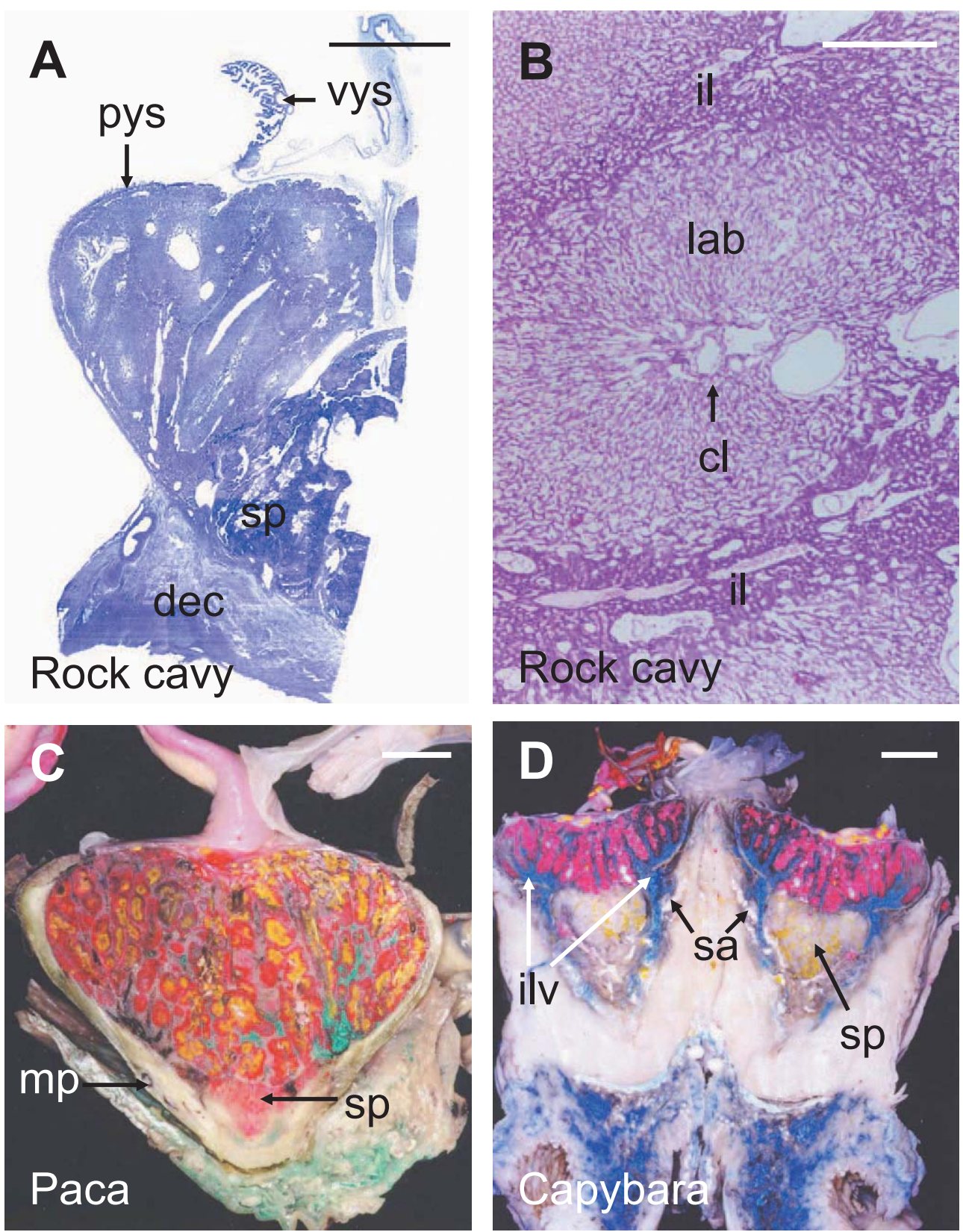

Figure 1. A. Low power view of a rock cavy placenta to show the lobular structure, parietal yolk sac epithelium (pys), visceral yolk sac (vys), subplacenta (sp) and decidua (dec). Hematoxylin and eosin, Scale bar $3 \mathrm{~mm}$. B. Rock cavy placenta to show division of the labyrinth (lab) into lobes by interlobular trophoblast (il). Large vessels are confined to the interlobium and the centre of the lobe (cl). Haematoxylin and eosin, Scale bar $300 \mu \mathrm{m}$. C. Section through paca placenta following latex injection of a uterine artery (white), uterine vein (green), umbilical artery (red) and umbilical vein (yellow). Note that the centre of each lobe is filled by the fetal venous route and the periphery by the fetal arterial route. The subplacenta (sp) is supplied by the fetal arterial route. The mesoplacenta (mp) is poorly vascularized. Scale bar $1 \mathrm{~cm}$. D. Section through capybara placenta following latex injection of a uterine artery (white), uterine vein (blue), umbilical artery (yellow) and umbilical vein (red). The subplacenta ( $\mathrm{sp}$ ) is supplied by the fetal arterial route. The main placenta is supplied by spiral arteries (sa) that skirt around the subplacenta. The interlobular venous channels (ilv) empty into a basal venous lacunar ring, which is drained by branches of the mesometrial veins. Scale bar $1 \mathrm{~cm}$.

São Bernardo do Campo, S.P., Brazil). Different colours were injected in a uterine vein, a uterine artery, an umbilical artery and the umbilical vein. The placentae were then immersion fixed in 10 per cent formalin.

Latex injections were made in one mid-gestation capybara and one paca near term of pregnancy.

\section{RESULTS}

\section{Gross morphology}

As shown for the rock cavy (Figure 1A-B), the main placenta comprises several lobes separated by areas of interlobular syncytium. Large vessels are confined to the centre of the lobes 


\section{IR-CYTOKERATIN}
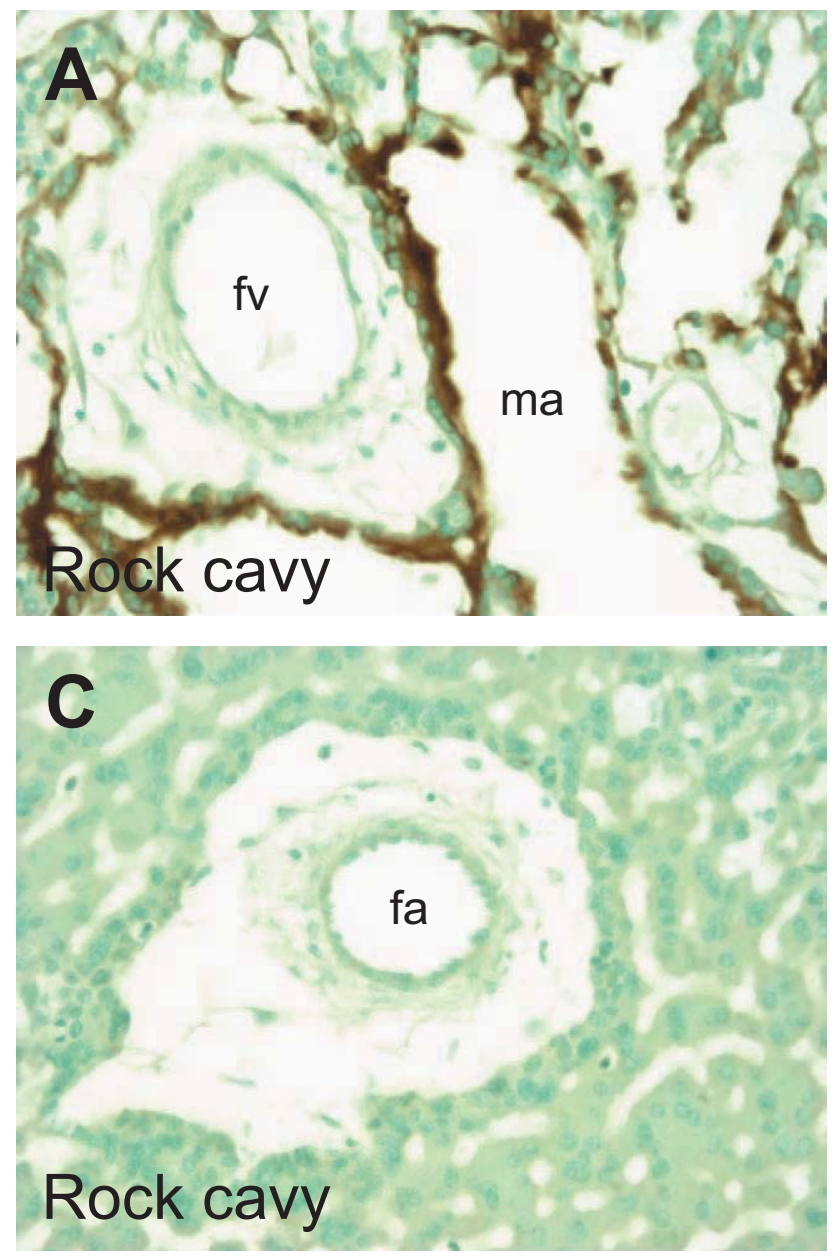

IR-VIMENTIN
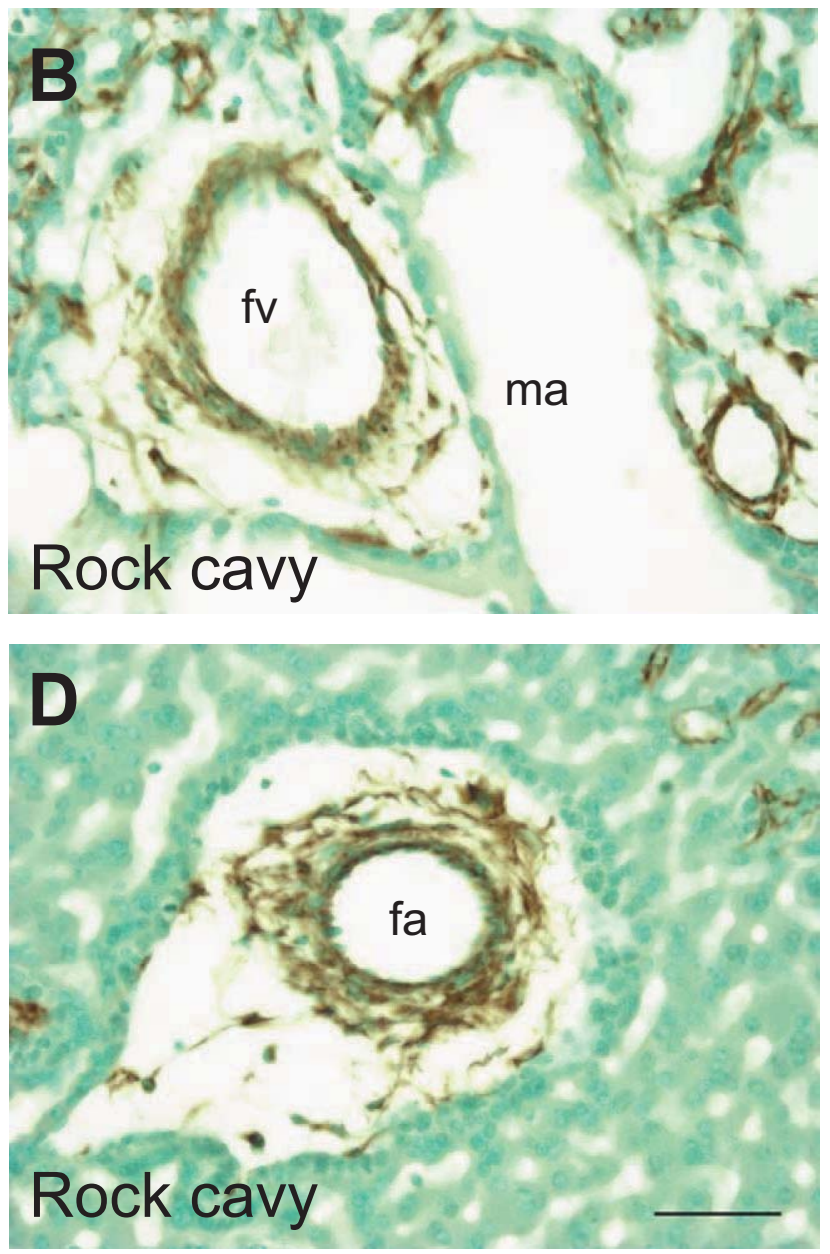

Figure 2. Sections of rock cavy placenta immunostained for cytokeratin (A, C) or vimentin (B, D) and counterstained with methyl green. A-B. Central part of a lobe showing maternal arterial channels lined by cytokeratin-positive trophoblast (ma) and a vimentin-positive fetal vein (fv). C-D. Interlobular region showing connective tissue with a vimentin-positive fetal artery (fa). Scale bar $50 \mu \mathrm{m}$.

and the interlobular areas (Figure 1B). The biggest vessels at the centre of the lobes are often irregular in shape and are lined by trophoblast that is strongly cytokeratin-positive (Figure 2A). Clearly they are maternal blood channels. The smaller vessels at the centre of the lobes are rounder in shape and their walls are vimentin-positive (Figure 2B). Vimentin-positive vessels also occur in the interlobular areas (Figure 2D). As previously seen in agouti and paca [6], the interlobular trophoblast of the rock cavy failed to immunostain for cytokeratin (Figure 2C). When latex of different hues is injected simultaneously in an umbilical artery and vein, the centre of the lobes is filled by the venous route and the periphery from the arterial route (Figure 1C). Thus the vimentin-positive vessels in the interlobular areas are fetal arteries, whilst those at the centre of the lobes are fetal veins. On the maternal side, venous drainage is through interlobular vessels that are filled by latex injected through a branch of the uterine vein (Figure 1D). They drain a latticework of venous channels in the interlobular areas, but these are not strongly cytokeratin-positive (not shown). A few large, round vessels lined by trophoblast are found in the interlobular areas (not shown). We surmise that these are the maternal arterial channels that supply the trophoblast-lined vessels at the centre of the lobes.

Below the main placenta, and separated from it by a layer of fetal mesenchyme, is the subplacenta (Figure 1A, C-D), a structure unique to the hystricomorph rodents. The uterine decidua forms a placental stalk or pedicle and, in agouti and paca (Figure 1C), a placental capsule or mesoplacenta. The following sections deal first with the fetal and maternal vessels of the main placenta and then with the vascular supply of the subplacenta and the decidual components of the placenta.

\section{Fetal arterial supply}

The cord carries five blood vessels: the two umbilical arteries, an umbilical vein and a vitelline artery and vein that supply the yolk sac placenta. The umbilical arteries attach at the centre of 

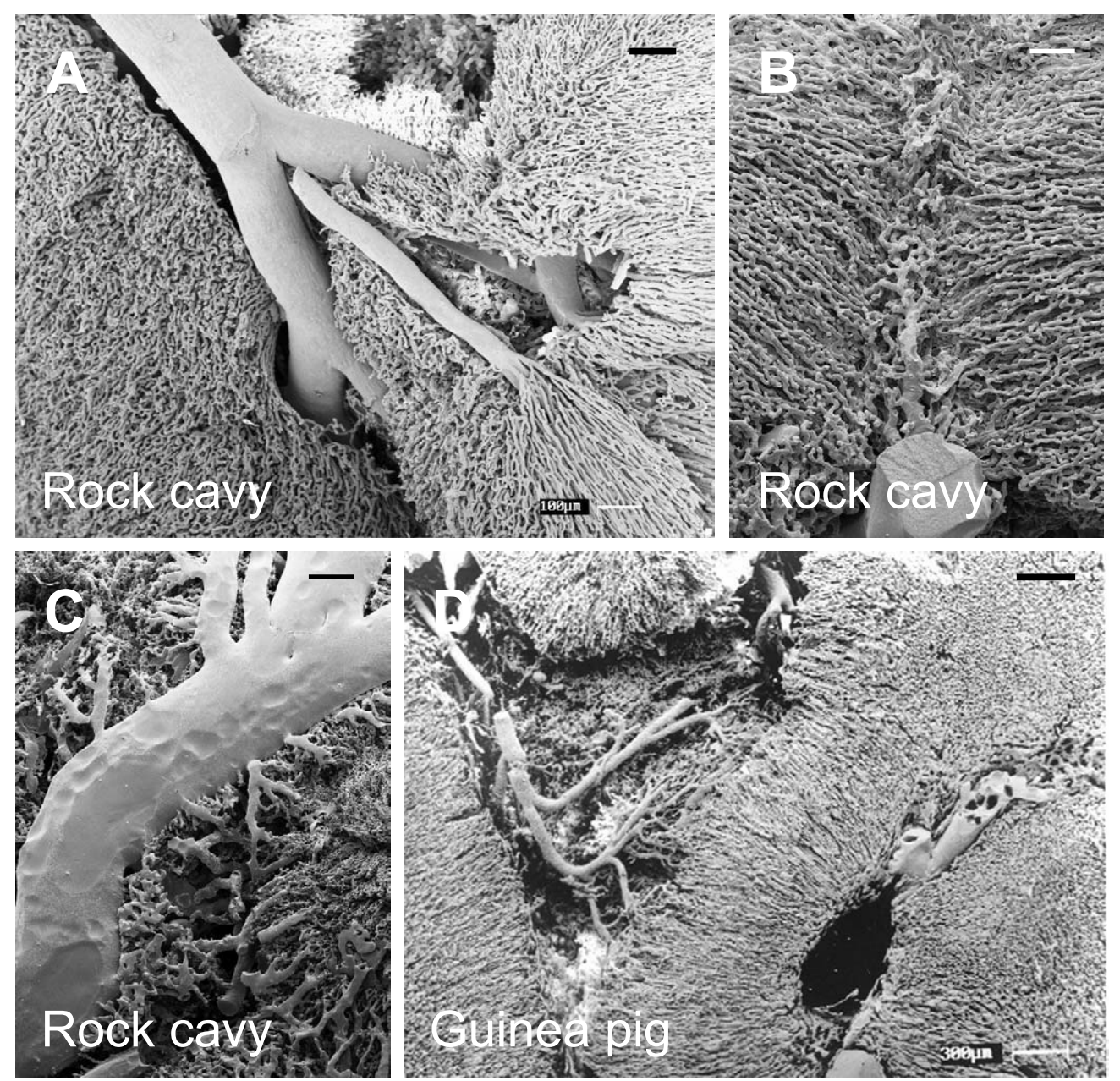

Figure 3. Fine structure of placental vasculature of the rock cavy $(A-C)$ and guinea pig $(D)$ in late gestation. Vascular casts were made by injection of Mercox in an umbilical artery and a maternal vein. A. Fetal arteries supplying several lobes. One vessel passes into the interlobium to supply a deeper lying lobe. Scale bar $100 \mu \mathrm{m}$. B. Interlobium with maternal venous channel receiving the drainage from two lobes. Scale bar $100 \mu \mathrm{m}$. C. Maternal channels draining the labyrinth empty into a large maternal lacuna in the interlobular region. This shows the negative impressions of the nuclei of the syncytiotrophoblast. Scale bar $200 \mu \mathrm{m}$. D. Overview showing an interlobular region and parts of three lobes. Fetal interlobular arteries are seen supplying the capillaries of the labyrinth. At right, the large vessel at the centre of the lobe is likely a maternal arterial sinus. Scale bar $300 \mu \mathrm{m}$.

the placenta, where there is a layer of fetal mesenchyme. They then branch across the fetal surface of the placenta. From here arteries descend perpendicular to the surface either to supply the more superficial lobes or to pass through the interlobular areas to reach deeper lying lobes, as shown for the rock cavy (Figure 3A). The interlobular arteries ramify across the outer surface of the lobes, as shown for paca (Figure 4B), before suddenly dividing to send bursts of capillaries towards the centre of the lobe, shown for guinea pig (Figure 3D), paca (Figure 4D, Figure 5B) and agouti (Figure 6A, B). Within the lobes, the capillaries are arranged in radial fashion with anastomoses between them (Figure 4C, Figure 7E).

\section{Fetal venous drainage}

At the centre of the lobe, the fetal capillaries drain into small veins, as can be seen in tissue sections (Figure 2B) and vascular casts (Figure 7A-B). These form one or more larger veins that leave through the base of the lobe to drain into a network of veins below the surface of the placenta. This network feeds into branches of the umbilical vein that run across the fetal surface of the placenta.

\section{Maternal arterial supply}

The uterus is bicornuate and each horn is supplied by an arterial arcade fed by the uterine and ovarian arteries. Numerous vessels arise from this arcade and cross the mesometrium to supply the uterine wall. However, only a few of these arteries, usually 3-5, are recruited to supply each placenta. These vessels widen considerably as they approach the placenta and tend to meander across the surface of the uterus. They form a loose plexus beneath the placenta from which there arise a small number of spiral arteries that enter the 

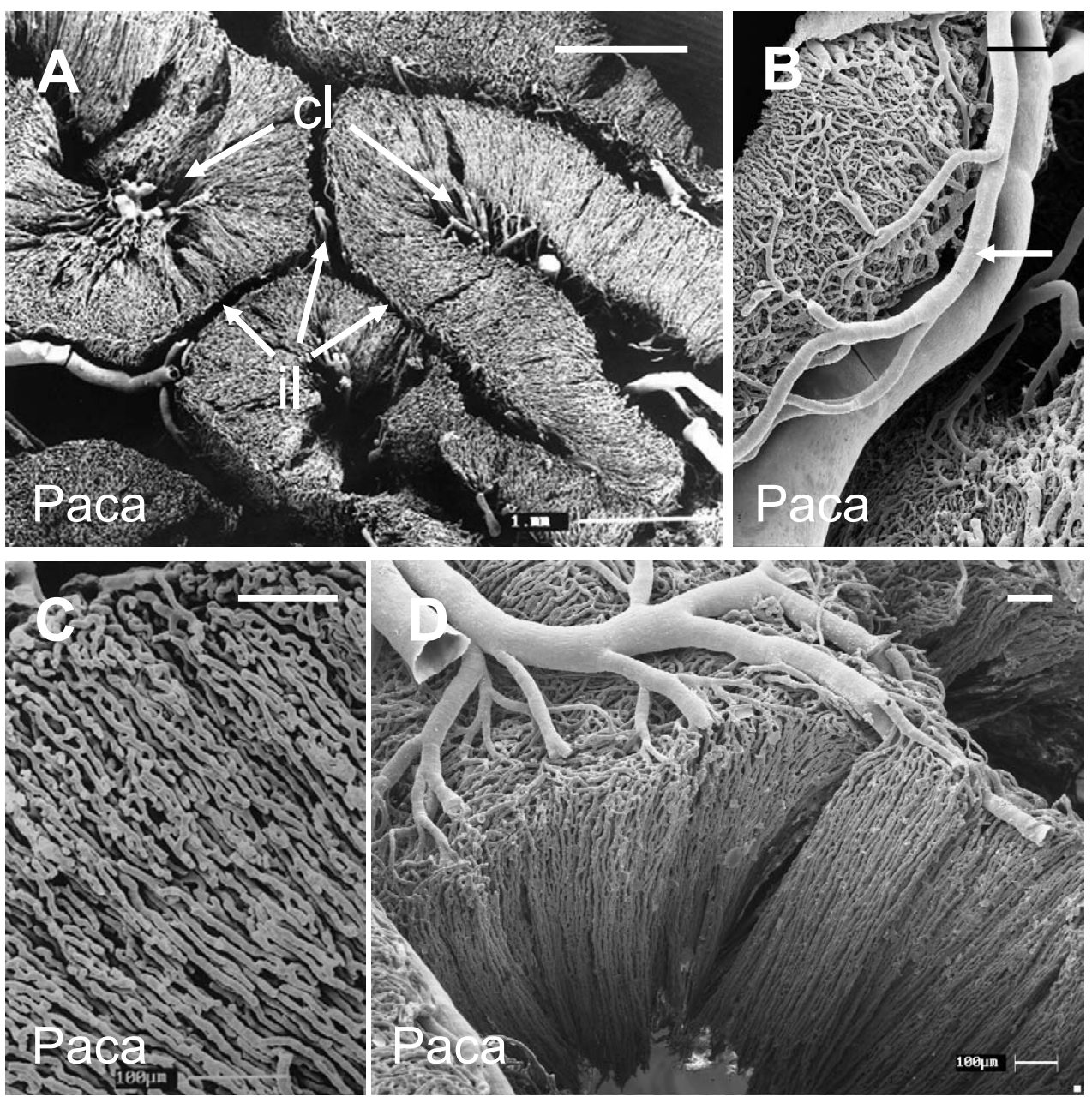

Figure 4. Fine structure of placental vasculature of the paca in late gestation. Vascular cast made by injection of Mercox in a fetal artery and maternal vein. A. Overview showing several placental lobes separated by interlobular areas. Large vessels are confined to the centre of the lobes (cl) and the interlobular regions (il). Vessels within the labyrinth are arranged in radial fashion. Scale bar $1 \mathrm{~mm}$. B. Ramification of a fetal interlobular artery (arrow) over the outer surface of a lobe. Scale bar $300 \mu \mathrm{m}$. C. Fetal capillaries of the placental labyrinth. Note the occurrence of anastomoses between the capillaries. Scale bar $100 \mu \mathrm{m}$. D. Fetal arteries coursing over the outer surface of a lobe then suddenly branching to send capillaries towards its centre. Scale bar $100 \mu \mathrm{m}$.

placental stalk and pass around the perimeter of the subplacenta (Figure 1D).

A small number of arterial channels, now lined by trophoblast, enter the main placenta and ramify in a system of lacunae beneath the fetal surface of the placenta. A single large arterial lacuna enters each lobe and passes down the centre, where it can be seen in vascular casts (Figure 5A, Figure 7C). Small branches arise from this central channel and divide to supply the fine channels of the placental labyrinth (Figure 5B, Figure 7C). These run parallel to the fetal capillaries, from the centre to the periphery of the lobe, creating the anatomical basis for countercurrent exchange. Whilst these fine, trophoblast-lined channels are readily seen in tissue sections, it is difficult to show them in vascular casts (Figure 5B, Figure 7C). However, they were demonstrated in a guinea pig placenta where the injection of Mercox was limited to maternal vessels (Figure $6 \mathrm{D})$ and there revealed a fine network of interlacing channels.

\section{Maternal venous drainage}

The maternal channels of the labyrinth drain into the spaces formed by the latticework of the interlobular trophoblast (Figure 2C). An interlobular region usually receives the venous drainage from two or more lobes (Figure 3B). These small venous channels drain into much larger venous lacunae as can be shown in vascular casts (Figure 3C, Figure 5C-D). The latter show the negative impressions of the nuclei of the syncytiotrophoblast (Figure 3C).

These interlobular venous channels drain into lacunae, some of which run quite superficially over the outside of the placenta (Figure 7F), although within the capsule in agouti (Figure 6C) and paca. Others are situated more centrally within the placenta. Kaufmann and Davidoff [3] refer to these as, respectively, primary marginal lacunae and primary central lacunae. They all drain into a basal venous lacunar ring 

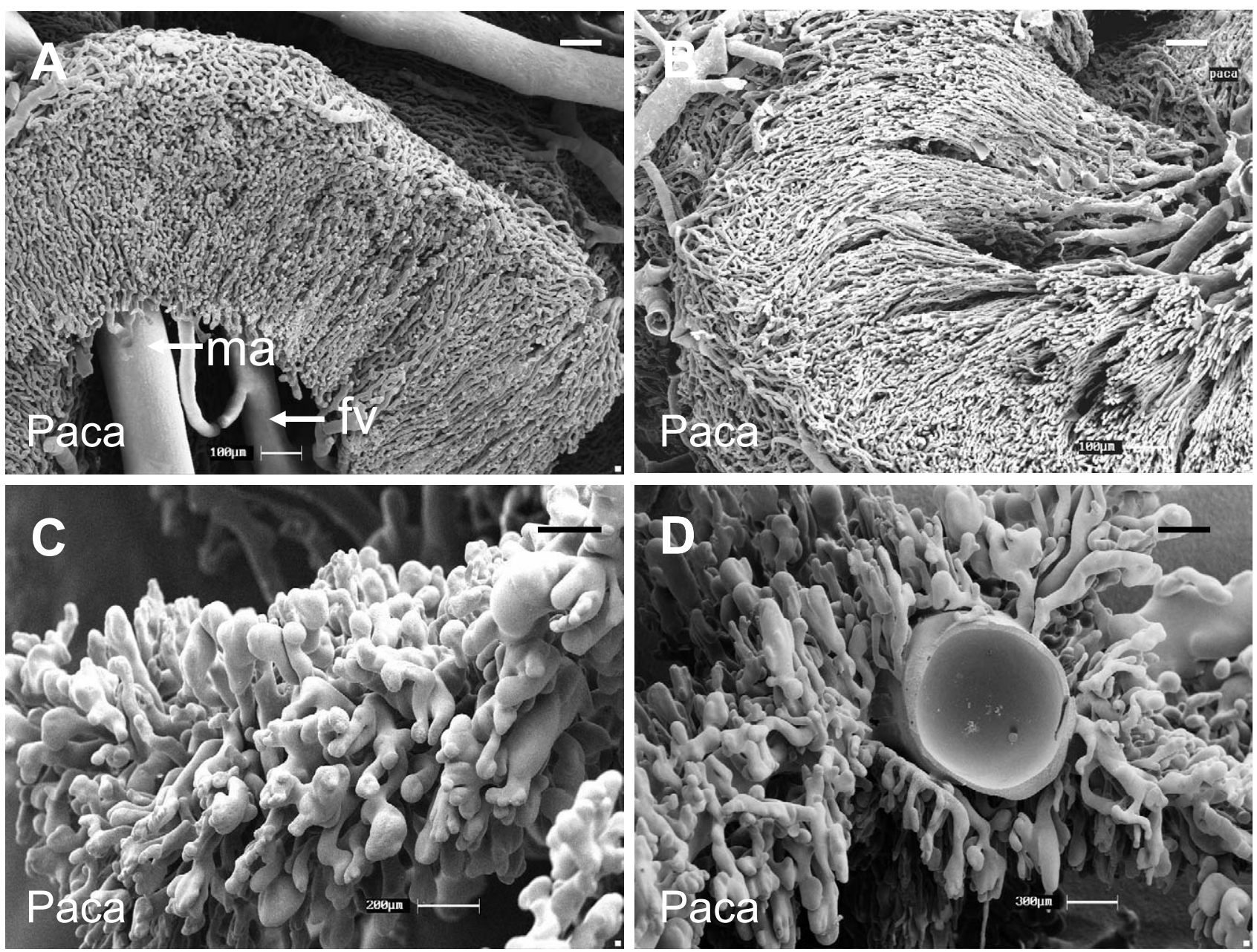

Figure 5. Fine structure of placental vasculature of the paca in late gestation. Vascular casts were made by injection of Mercox in a fetal artery and maternal vein (A-B) or a maternal vein alone (C-D). A. Large vessels at the centre of a lobe include fetal veins ( $\mathrm{fv}$ ) and a large maternal arterial blood channel (ma). Scale bar $100 \mu \mathrm{m}$. B. At left fetal arteries give rise to capillaries that run to the centre of the lobe. At right maternal blood channels supply the fine, trophoblast-lined channels that pass to the periphery; these do not appear in the cast. Scale bar $100 \mu \mathrm{m}$. C. Maternal venous channels in an interlobular region. Scale bar $200 \mu \mathrm{m}$. D. Maternal venous channels draining into a large venous lacuna. Scale bar $300 \mu \mathrm{m}$.

(Figure 8A). A small number of veins leave the ring, pass around the periphery of the subplacenta (Figure 1D), and empty into the mesometrial veins. These join a venous arcade formed by the uterine and ovarian veins. The latter is the most important and is sometimes referred to as the utero-ovarian vein [12].

\section{Subplacenta}

In mid to late gestation, the subplacenta is supplied largely by fetal vessels (Figure 8A). A large branch of the umbilical artery follows the central band of fetal mesenchyme to the base of the main placenta and then branches to supply the subplacenta (Figure 8B). The subplacental vessels pursue a tortuous course with dilatations and constrictions (Figure $8 \mathrm{C}-\mathrm{D}$ ) as in an endocrine gland such as the ovary [13]. A few branches of the maternal artery supply the subplacenta, at least in capybara and paca, where they can be demonstrated by latex injection (data not shown).

\section{Placental stalk and placental capsule}

The placenta rests on a stalk formed by decidua. In agouti and paca (Figure 1C), there is an additional structure, the mesoplacenta, that forms a capsule around the placenta. Capybara has a large placental stalk and an incomplete capsule (Figure 1D). Close inspection of guinea pig and rock cavy placenta shows a structure that may be analogous to the incomplete capsule of the capybara. These structures are supplied only by maternal vessels. In late gestation the capsule is sparsely vascularized. However, the placental stalk receives a rich supply of blood vessels (data not shown). 

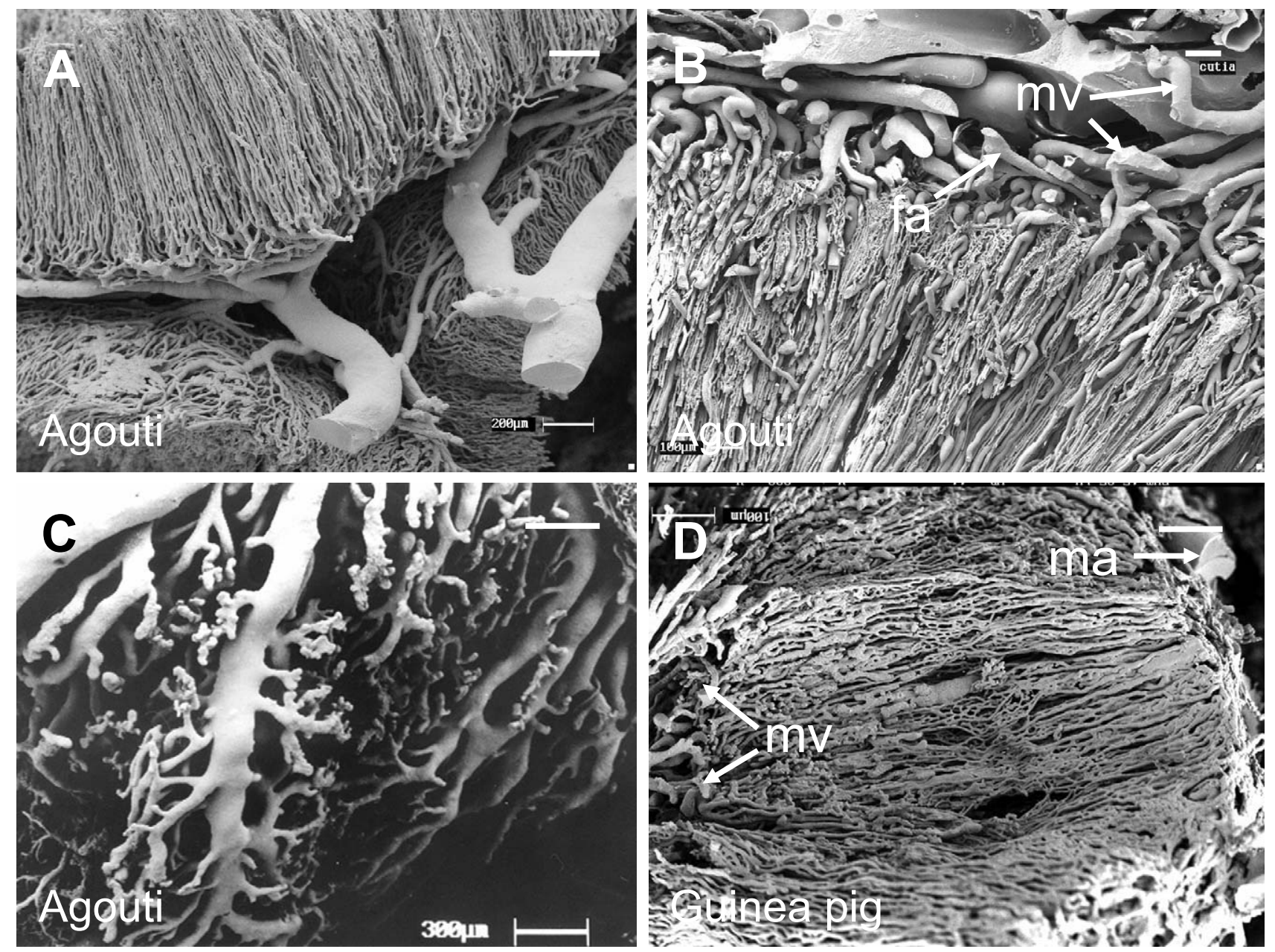

Figure 6. Fine structure of placental vasculature of the agouti (A-C) and guinea pig (D) in late gestation. Vascular casts were made by injection of Mercox in an umbilical artery alone (A) an umbilical artery and a maternal vein (B-C) or a uterine artery (D). A. Fetal interlobular artery branching to give rise to the capillaries of the labyrinth. Scale bar $200 \mu \mathrm{m}$. B. Interlobular region at top includes two sizes of vessel with different patterns of ramification, representing fetal arteries (fa) and maternal venous lacunae (mv). Scale bar $100 \mu \mathrm{m}$. C. Maternal venous lacuna in an interlobular region. Scale bar $300 \mu \mathrm{m}$. D. Maternal channels of the labyrinth. An arterial lacuna (ma) gives rise to an interlacing network of fine channels that drain into the venous channels of the interlobium (mv). Scale bar $100 \mu \mathrm{m}$.

\section{DISCUSSION}

Traditionally, the rodents have been divided into three suborders. The hystricomorph rodents continue to be regarded as a single clade, supported by analysis both of morphological characters and nucleotide sequence data [14]. Indeed, Luckett and Mossman [1] asserted that the hystricomorphs could be regarded as a monophyletic group, based on placental structure alone. The present study of five species from three families of hystricomorphs indicates a remarkable constancy in the arrangement of the placental vasculature. Our data confirm and extend the observations made in the nutria, a member of a fourth family, by Hilleman and Gaynor [2].

We are in agreement with Hilleman and Gaynor [2] that there is a countercurrent arrangement of the blood vessels. Within each lobe, maternal blood flows from the centre to the periphery, whilst fetal blood flows in the opposite direction
(Figure 9). Kaufmann and Davidoff [3] and Dantzer et al. [4] reached a similar conclusion for the guinea pig and chinchilla. In a study of the Canadian porcupine, Perrotta [5] correctly identified the direction of flow in the maternal vessels. However, he suggested that fetal arterioles arose from arteries at the centre of the lobes and then crossed the lobe to supply the capillaries. These then drained into the fetal veins, which he correctly placed at the centre of the lobes. In vessel casts we have been unable to identify vessels corresponding to the fetal arterioles of Perrotta [5]. Instead, we showed that the fetal arteries pass through the interlobular regions to break up into sprays of capillaries on the outer surface of the lobes. Moreover, when coloured latex was injected simultaneously in an umbilical vein and artery, the centre of the lobe was filled exclusively from the venous side.

Countercurrent flow is the common pattern in rodent and lagomorph placentae [15]. It provides for more efficient 

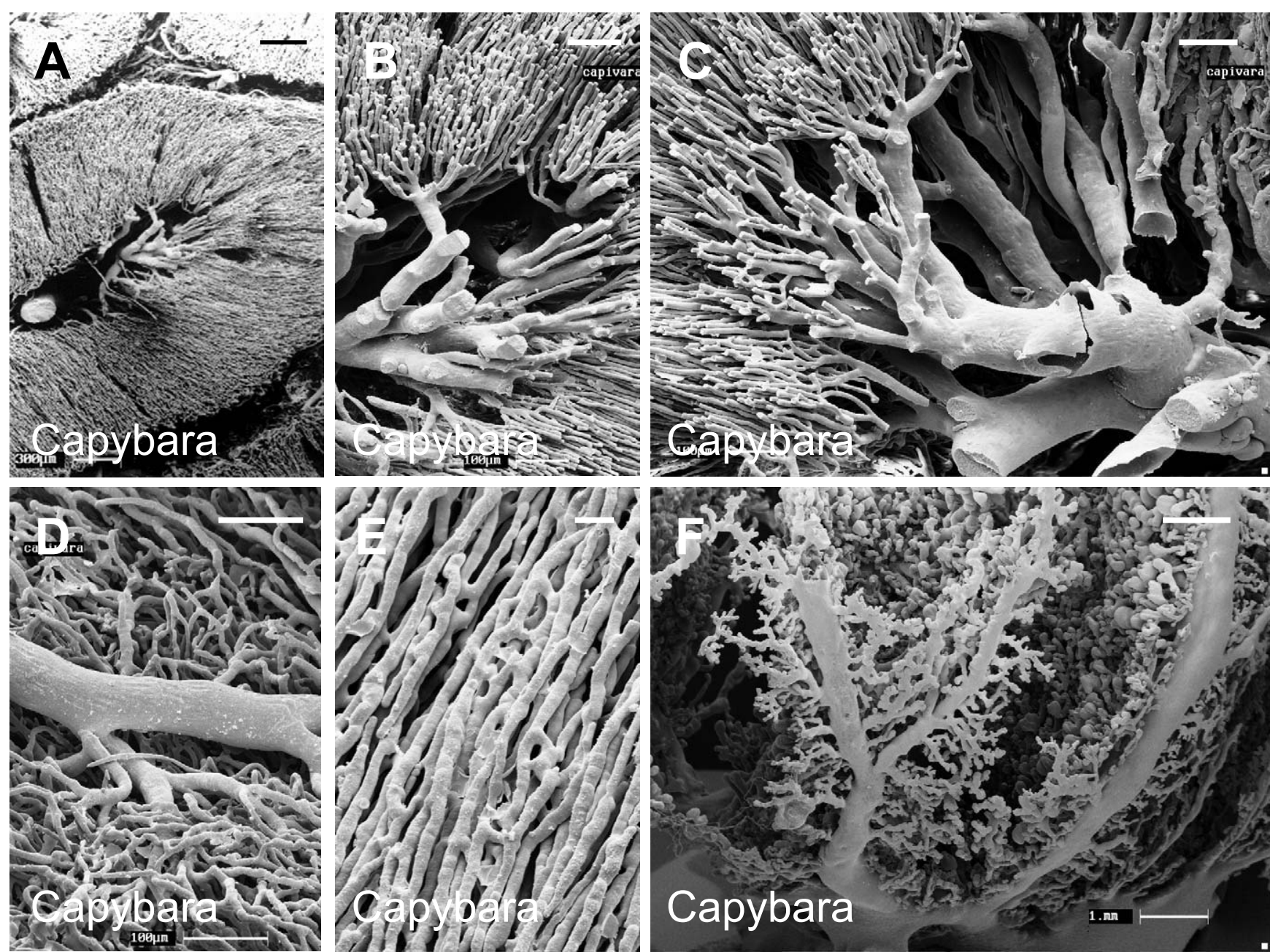

Figure 7. Fine structure of the placental vasculature of the capybara in late gestation. Vascular casts were made by injection of Mercox in an umbilical artery and a maternal vein (A-C), an umbilical artery alone (D-E) or a maternal vein alone (F). A. Parts of several lobes, showing capillaries of the fetal labyrinth. Larger vessels at the centre of the lobe include fetal veins and maternal arterial channels. Scale bar $300 \mu$ m. B. Capillaries draining into fetal veins at the centre of the labyrinth. Scale bar $100 \mu \mathrm{m}$. C. Maternal arterial channels at centre of lobe branching to send fine channels through the trophoblast of the labyrinth; these do not appear at full length in the cast. Scale bar $100 \mu \mathrm{m}$. D. Fetal interlobular artery ramifying across the outer surface of a lobe. Scale bar $100 \mu \mathrm{m}$. E. Fetal capillaries of the labyrinth. Note the occurrence of anastomoses. Scale bar $20 \mu \mathrm{m}$. F. Maternal venous channels of several interlobular regions draining into larger marginal lacunae which, at bottom, join the basal venous lacunar ring. Scale bar $1 \mathrm{~mm}$.

maternal-fetal exchange when, as in the case of oxygen, exchange is flow dependent. What should not be overlooked is that the difference in efficiency between concurrent, crosscurrent and countercurrent flow is dependent on other factors, notably the diffusion capacity of the placenta [16].

Within the labyrinth, the fetal capillaries formed a network of interconnecting vessels. This was paralleled on the maternal side by connections between the trophoblastic tubules carrying maternal blood. This network structure has been described for other hystricomorph species and may be part of the stem pattern of the placenta in rodents [17].

On the maternal side of the placenta, latex injections confirmed the presence of spiral arteries, as previously shown for the guinea pig by angiographic methods [12]. Vascular casts of mouse placenta similarly reveal that maternal blood is supplied through spiral arteries [18] and spiral arteries occur in the rabbit placenta [19]. Thus, a labyrinthine placenta with countercurrent exchange, supplied on the maternal side by spiral arteries, is a common pattern for the Glires (rodents and lagomorphs). There are differences, however, in the nature of the placental barrier. The interhaemal membrane has one layer of trophoblast in hystricomorph rodents compared to two in rabbits and three in the murid rodents [20]. A distinctive feature of the hystricomorph placenta is its division into lobes. However, Hilleman and Gaynor [2] drew an interesting analogy between the arrangement of blood vessels in the entire murid placentae, represented by the hamster, and that of a single lobe of the hystricomorph placenta.

A truly unique feature of the hystricomorph rodents is the presence of a subplacenta [1]. As shown by Kaufmann and 

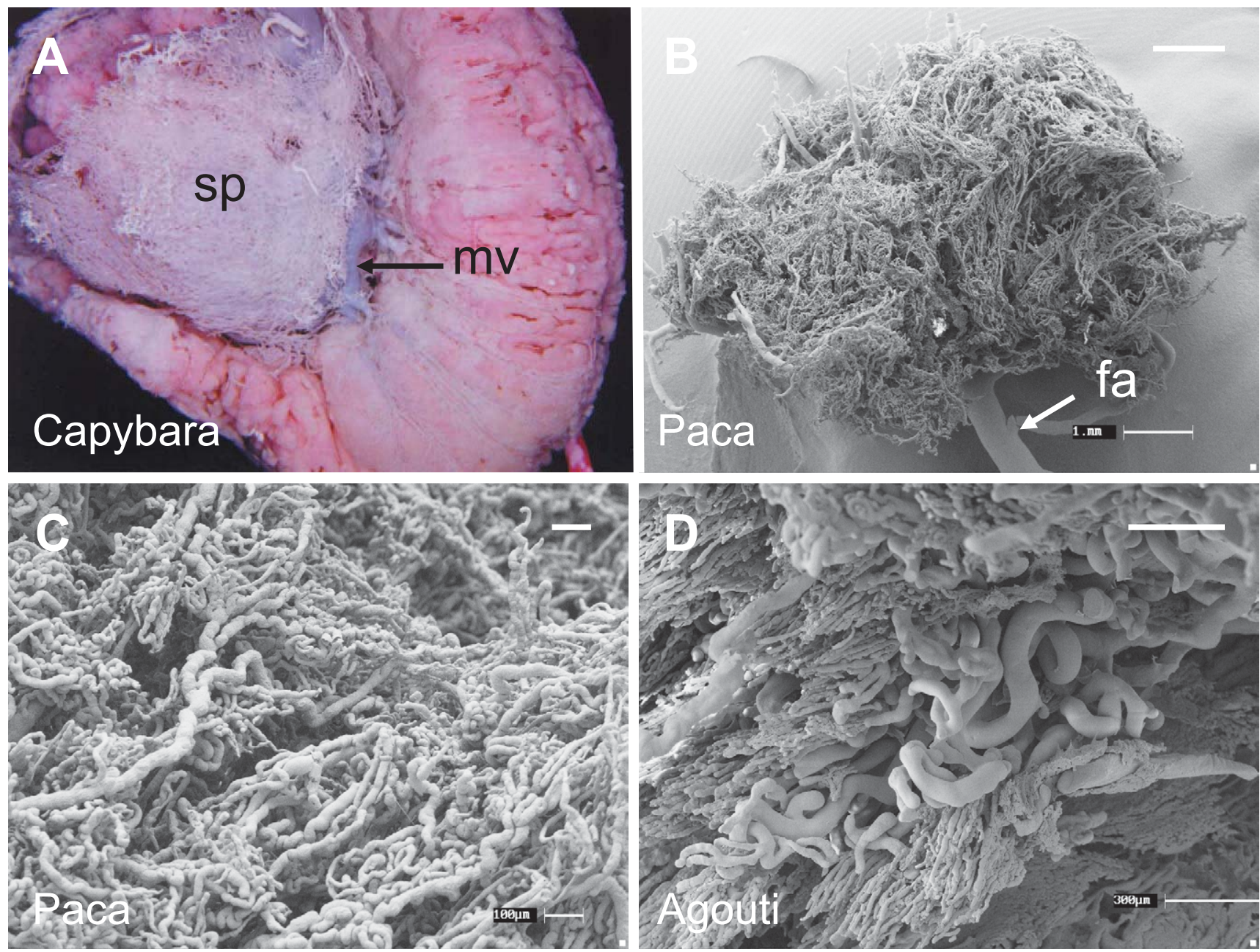

Figure 8. Vessels of the subplacenta. Vascular casts were made by injection of Mercox in an umbilical artery and a maternal vein; only fetal vessels were demonstrated in the subplacenta. A. Maternal-facing surface of a detached capybara placenta showing the vessels of the subplacenta (sp) and the maternal venous ring at the base of the placenta (mv). B. Low power scanning electron micrograph showing a single fetal artery (fa) entering the centre of the subplacenta in paca. Scale bar $1 \mathrm{~mm}$. C. At higher magnification vessels of the paca subplacenta are seen to pursue a tortuous course and are irregular in calibre. Scale bar $100 \mu \mathrm{m}$. D. A similar skein of vessels is seen in the subplacenta of agouti. Scale bar $300 \mu \mathrm{m}$.

Davidoff [3] for the guinea pig, it is supplied by a single fetal artery that follows a central band of mesenchyme to the base of the main placenta, where it branches to supply the subplacenta. Wolfer and Kaufmann [21] showed that from day 15 until at the latest day 28, the subplacenta of the guinea pig contained maternal blood lacunae. A fetal circulation was first established on day 32. Therefore, they concluded that maternal and fetal vessels were never present at the same time. We agree that the subplacenta is unlikely to play a role in maternal-fetal exchange, but did see a few branches of the maternal arteries in the subplacenta of capybara and paca. However, the true function of the subplacenta remains obscure. Based on extensive ultrastructural and histochemical studies, it was proposed that the subplacenta of the guinea pig might secrete gonadotrophic hormones [22,23]. The ultrastructure of chinchilla placenta is also suggestive of secretory activity [24]. Consistent with an endocrine role for this structure, we found that the subplacental vessels pursue a tortuous course with dilatations and constrictions just as in an endocrine gland [13].

In contrast to myomorph rodents, where a number of interesting variations in placental structure occur [25], placentation is remarkably constant in hystricomorph rodents [17]. The placenta is lobate, the interhemal barrier is of the haemomonochorial type and there is a characteristic subplacenta. These features support inclusion of the Old and New World representatives in a monophyletic group [1], an inference sustained by molecular phylogenetics [14]. Our results indicate that this constancy of pattern is reflected in the microvasculature, which is arranged to enable countercurrent transfer in each lobe of the placenta. These features likely evolved in the Eocene period as part of a reproductive strategy with precocial young and long gestation periods [26]. 


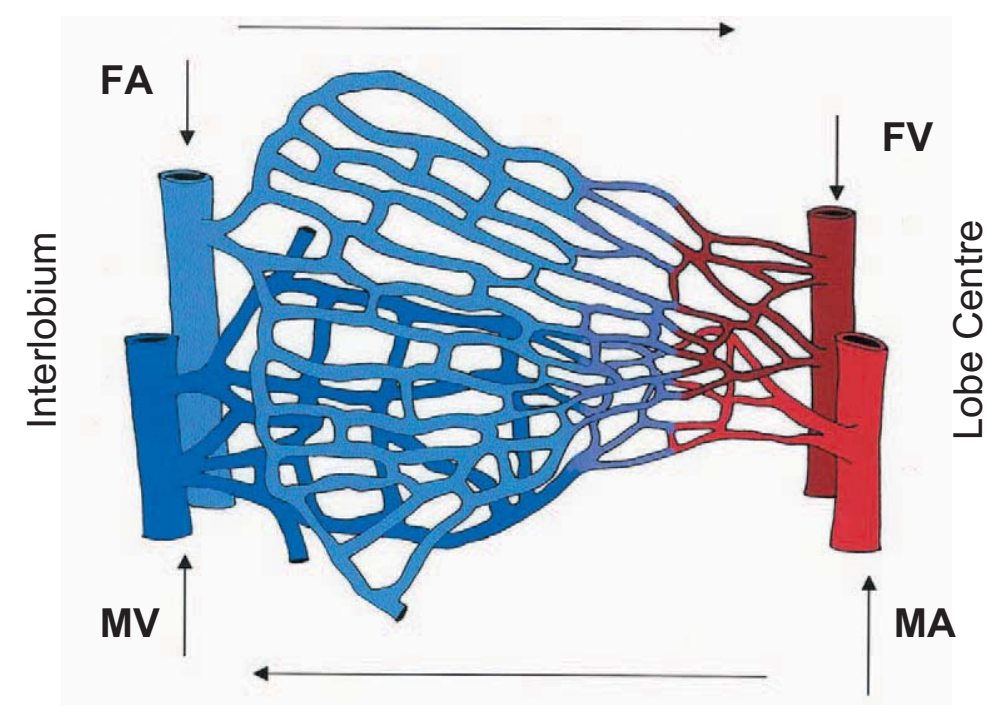

Figure 9. Countercurrent blood flow in the hystricomorph placenta. Fetal blood flows from fetal arteries in the interlobium (FA) to fetal veins at the centre of the lobe (FV), as indicated by the upper arrow. Maternal blood flows from arterial channels at the centre (MA) to venous channels in the interlobium (MV), as indicated by the lower arrow. Vessel diameters and lengths are not drawn to scale.

\section{ACKNOWLEDGEMENTS}

This study was supported by Fundação de Amparo à Pesquisa do Estado de São Paulo (FAPESP) and Conselho Nacional de Desenvolvimento Científico e Tecnológico $(\mathrm{CNPq})$. We gratefully acknowledge the skilful assistance of Karen Nygard.

\section{REFERENCES}

[1] Luckett WP, Mossman HW. Development and phylogenetic significance of the fetal membranes and placenta of the African hystricognathous rodents Bathyergus and Hystrix. Am J Anat 1981;162:265-85.

[2] Hilleman HH, Gaynor AI. The definitive architecture of the placenta of nutria, Myocastor coypus (Molina). Am J Anat 1961;109:299-318.

[3] Kaufmann P, Davidoff M. The guinea-pig placenta. Adv Anat Embryol Cell Biol 1977;53:5-91.

[4] Dantzer V, Leiser R, Kaufmann P, Luckhardt M. Comparative morphological aspects of placental vascularization. Trophoblast Res 1988; 3:235-60.

[5] Perrotta CA. Fetal membranes of the Canadian porcupine, Erithizon dorsatum. Am J Anat 1959;104:35-59.

[6] Miglino MA, Carter AM, dos Santos Ferraz RH, Fernandes Machado MR. Placentation in the capybara (Hydrochaerus hydrochaeris), agouti (Dasyprocta aguti) and paca (Agouti paca). Placenta 2002;23:416-28.

[7] Rood JP, Weir BJ. Reproduction in female wild guinea-pigs. J Reprod Fert 1980;23:393-409.

[8] Carter AM, Tanswell B, Thompson K, Han VK. Immunohistochemical identification of epithelial and mesenchymal cell types in the chorioallantoic and yolk sac placentae of the guinea-pig. Placenta 1998;19:489-500.

[9] Hodde KC, Miodonski A, Bakker C, Veltman W. Scanning electron microscopy of microcorrosion casts with special attention on arteriovenous differences and application to the rat's cochlea. Scan Electron Micros 1977;2:477-84.

[10] Leiser R, Krebs C, Ebert B, Dantzer V. Placental vascular corrosion cast studies: a comparison between ruminants and humans. Microsc Res Tech 1997;38:76-87.

[11] Krebs C, Winther H, Dantzer V, Leiser R. Vascular interrelationships of near-term mink placenta: light microscopy combined with scanning electron microscopy of corrosion casts. Microsc Res Tech 1997; 38:125-36.

[12] Egund N, Carter AM. Uterine and placental circulation in the guineapig: an angiographic study. J Reprod Fert 1974;40:401-10.

[13] Murakami T, Ikebuchi Y, Ohtsuka A, Kikuta A, Taguchi T, Ohtani O. The blood vascular wreath of rat ovarian follicle, with special reference to its changes in ovulation and luteinization: a scanning electron microscopic study of corrosion casts. Arch Histol Cytol 1988;51:299-313.

[14] Huchon D, Madsen O, Sibbald MJ, Ament K, Stanhope MJ, Catzeflis F et al. Rodent phylogeny and a timescale for the evolution of Glires: evidence from an extensive taxon sampling using three nuclear genes. Mol Biol Evol 2002;19:1053-65.

[15] Mossman HW. The rabbit placenta and the problem of placental transmission. Am J Anat 1926;37:433-97.

[16] Metcalfe J, Bartels H, Moll W. Gas exchange in the pregnant uterus. Physiol Rev 1967;47:782-838.

[17] Mess A. Evolutionary transformations of chorioallantoic placental characters in rodentia with special reference to hystricognath species. J Exp Zoolog Part A Comp Exp Biol 2003;299:78-98.

[18] Adamson SL, Lu Y, Whiteley KJ, Holmyard D, Hemberger M, Pfarrer $\mathrm{C}$ et al. Interactions between trophoblast cells and the maternal and fetal circulation in the mouse placenta. Dev Biol 2002;250:358-73.

[19] Carter AM, Göthlin J, Olin T. An angiographic study of the structure and function of the uterine and maternal placental vasculature in the rabbit. J Reprod Fert 1971;25:201-10.

[20] Enders AC. A comparative study of the fine structure of the trophoblast in several hemochorial placentas. Am J Anat 1965;116:29-68.

[21] Wolfer J, Kaufmann P. Die Ultrastruktur der MeerschweinchenSubplazenta. Anat Histol Embryol 1980;9:29-43.

[22] Davies J, Dempsey EW, Amoroso EC. The subplacenta of the guinea pig: An electron microscopic study. J Anat 1961a;95:311-24.

[23] Davies J, Dempsey EW, Amoroso EC. The subplacenta of the guinea pig: Development, histology and histochemistry. J Anat 1961b;95:457-73.

[24] King BF, Tibbitts FD. The fine structure of the chinchilla placenta. Am J Anat 1976;145:33-56.

[25] Enders AC, Blankenship TN, Lantz KC, Enders SS. Morphological variation in the interhemal areas of chorioallantoic placentae. Trophoblast Res 1998;12:1-19.

[26] Mess A, Mohr B, Martin T. Evolutionary transformations of hystricognath Rodentia and the climatic change in the Eocene to Late Oligocene time interval. Mitt Mus Natkd Berlin Zool Reihe 2001;77:193-206. 